Mariana Tavares Guimarães

\title{
Avaliação de desfechos relacionados à gestação em áreas contaminadas na região do estuário de Santos e São Vicente
}

Tese apresentada à Faculdade de Medicina da Universidade de São Paulo para obtenção do título de Doutor em Ciências

Programa de Patologia

Orientador: Prof. Dr. Luiz Alberto Amador Pereira

São Paulo

2012 
Mariana Tavares Guimarães

\section{Avaliação de desfechos relacionados à gestação em áreas contaminadas na região do estuário de Santos e São Vicente}

Tese apresentada à Faculdade de Medicina da Universidade de São Paulo para obtenção do título de Doutor em Ciências

Programa de Patologia

Orientador: Prof. Dr. Luiz Alberto Amador Pereira

São Paulo

2012 
Dados Internacionais de Catalogação na Publicação (CIP)

Preparada pela Biblioteca da

Faculdade de Medicina da Universidade de São Paulo

Creprodução autorizada pelo autor

Guimarães, Mariana Tavares

Avaliação de desfechos relacionados à gestação em áreas contaminadas na região do estuário de Santos e São Vicente / Mariana Tavares Guimarães. -São Paulo, 2012.

Tese(doutorado)--Faculdade de Medicina da Universidade de São Paulo. Programa de Patologia.

Orientador: Luiz Alberto Amador Pereira.

Descritores: 1.Gravidez 2.Aborto 3.Baixo peso ao nascer 4.Prematuro 5.Anormalidades congênitas 6.Contaminação ambiental

USP/FM/DBD-191/12 
Aos meus pais, Marluce e Jorge, pelo apoio e incentivo que sempre me deram, especialmente durante 0 doutorado, dedico este trabalho. 


\section{AGRADECIMENTOS}

Ao Prof. Dr. Luiz Alberto Amador Pereira, meu orientador, não só pela dedicação e pelos muitos ensinamentos que passou, mas principalmente pela amizade e confiança;

Ao Prof. Dr. Alfésio Luís Ferreira Braga pelos ensinamentos, disponibilidade e atenção;

À Prof $^{\mathrm{a}} \mathrm{Dr}^{\mathrm{a}}$ Ligia Vizeu Barrozo pelos imprescindíveis ensinamentos e ajuda no georreferenciamento dos dados;

À $\mathrm{Dr}^{\mathrm{a}}$ Lourdes Conceição Martins pela gentileza em me ajudar na parte estatística;

A todos os integrantes do Núcleo de Estudos em Epidemiologia Ambiental - NEEA/FMUSP, em especial à Samya de Lara Pinheiro e Camila Villegas pela amizade e descontração no ambiente da Universidade;

A todos os colegas, professores e funcionários do Laboratório de Poluição Atmosférica Experimental do Departamento de Patologia da FMUSP pelo suporte;

A todos que participaram nas etapas da pesquisa de campo, em especial à Michele Granato Cunha, Daniele Fernandes Pena Carvalho e Tatyana Sampaio Ribeiro pela parceria; 
Aos integrantes da banca de qualificação, $\operatorname{Prof}^{\mathrm{a}} \operatorname{Dr}^{\mathrm{a}}$ Elnara Márcia Negri, Prof. Dr. Ubiratan de Paula Santos, e novamente Prof. Dr. Alfésio Luís Ferreira Braga pelas enriquecedoras contribuições dadas durante o exame; Aos amigos e familiares pelo incentivo, apoio e compreensão;

A Fundação de Amparo à Pesquisa do Estado de São Paulo FAPESP pela bolsa de estudo;

Ao Conselho Nacional de Pesquisa - CNPq pelo suporte financeiro ao projeto. 


\section{NORMALIZAÇÃO ADOTADA}

Esta tese está de acordo com as seguintes normas, em vigor no momento desta publicação: Referências: adaptado de International Committee of Medical Journals Editors (Vancouver). Universidade de São Paulo. Faculdade de Medicina. Divisão de Biblioteca e Documentação. Guia de apresentação de dissertações, teses e monografias. Elaborado por Anneliese Carneiro da Cunha, Maria Julia de A. L. Freddi, Maria F. Crestana, Marinalva de Souza Aragão, Suely Campos Cardoso, Valéria Vilhena. 3a ed. São Paulo: Divisão de Biblioteca e Documentação; 2011.

Abreviaturas dos títulos dos periódicos de acordo com List of Journals Indexed in Index Medicus. 


\title{
SUMÁRIO
}

\author{
LISTA DE FIGURAS \\ LISTA DE ABREVIATURAS, SÍMBOLOS E SIGLAS \\ LISTA DE TABELAS \\ RESUMO \\ ABSTRACT
}

1. INTRODUÇÃO. .1

2. ESTUÁRIO DE SANTOS E DE SÃO VICENTE.......................................

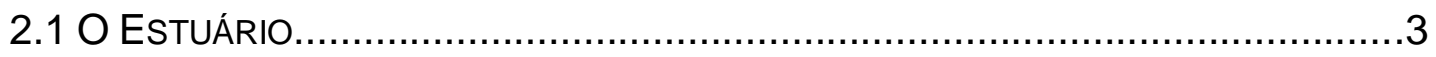

2.2 HISTÓRICO DA INDUSTRIALIZAÇÃO E CONTAMINAÇÃO DA REGIÃO DO

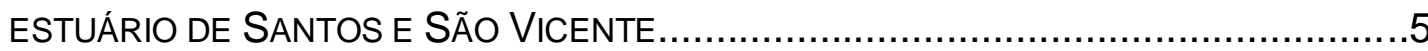

2.3 FONTES DE POLUIÇÃO E CONTAMINANTES ENCONTRADOS NA REGIÃO

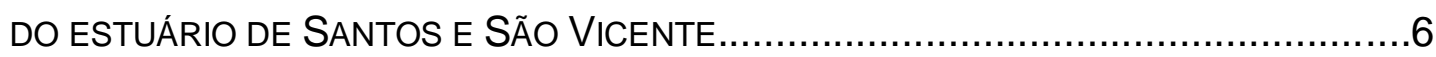

3. CONTAMINAÇÃO AMBIENTAL E EFEITOS NA GESTAÇÃO...................

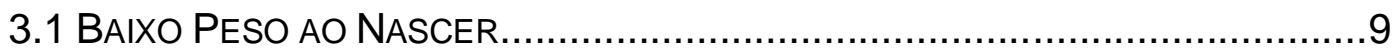

3.2 PREMATURIDADE

3.3 ABORTO ESPONTÂNEO E NATIMORTALIDADE...........................................11

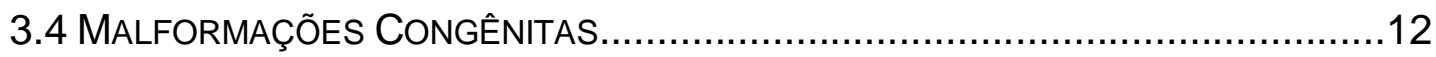

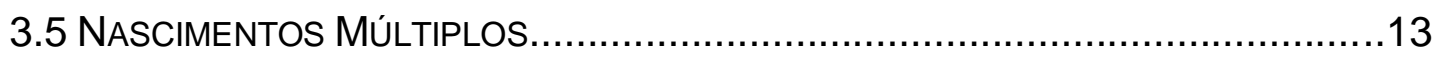




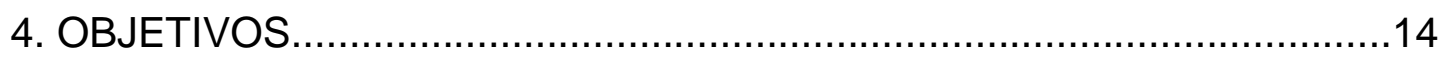

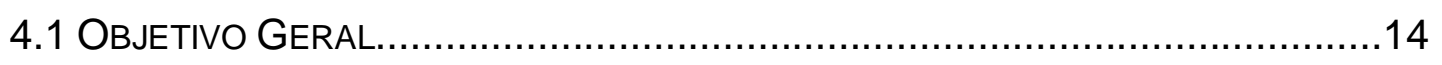

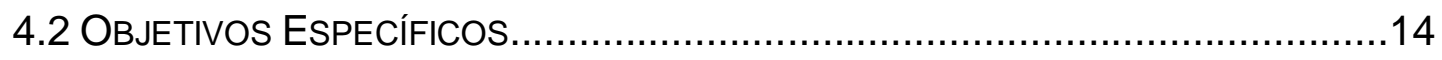

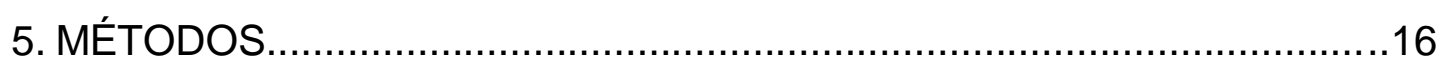

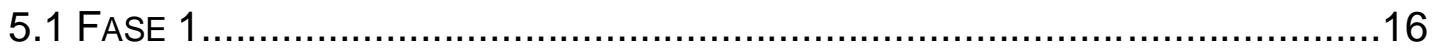

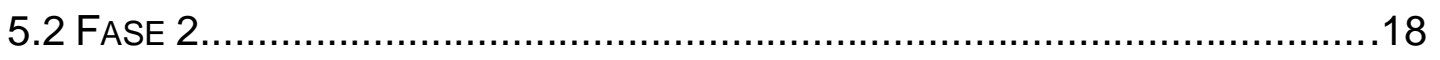

5.2.1 DEFINIÇÃO DAS ÁREAS E DA POPULAÇÃO DE ESTUDO...........................19

5.2.2 CÁlCULO E SELEÇÃO DA AMOSTRA...............................................21

5.2.3 COLETA DE INFORMAÇÕES NO DOMICÍLIO.......................................22

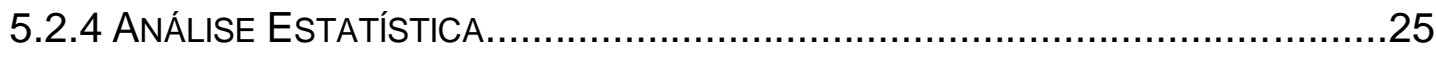

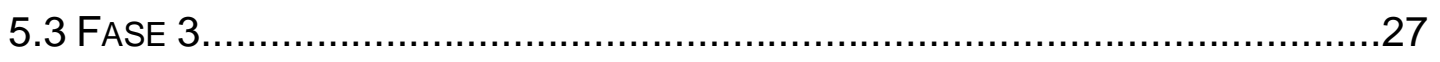

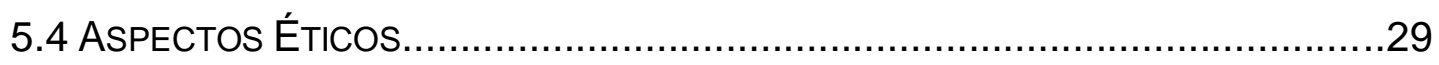

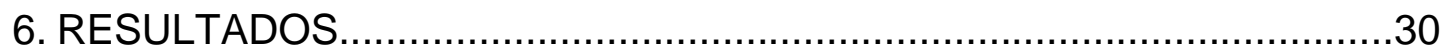

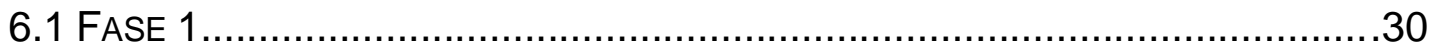

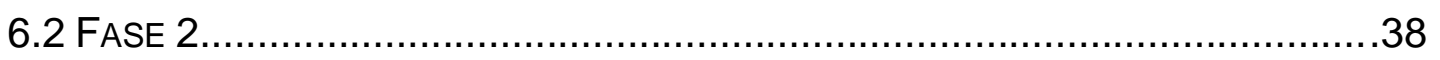

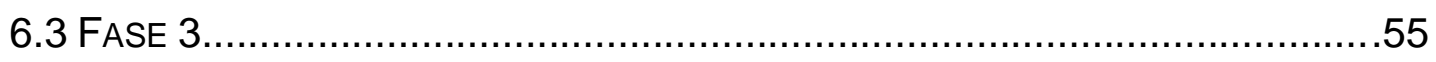

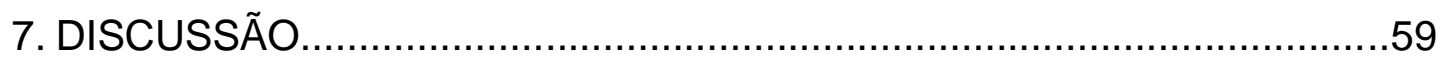

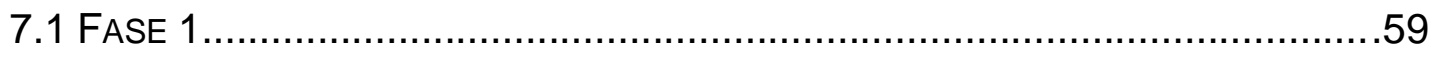

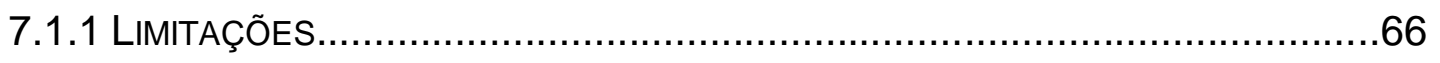

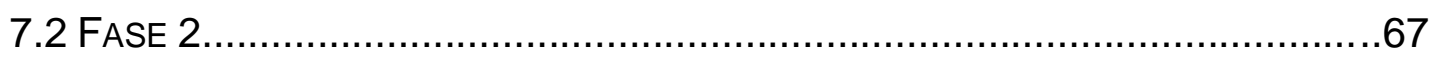

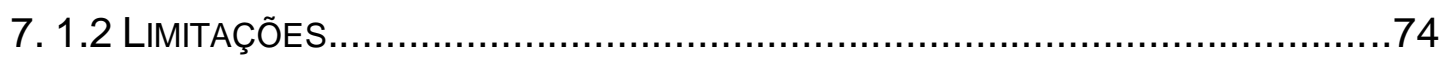




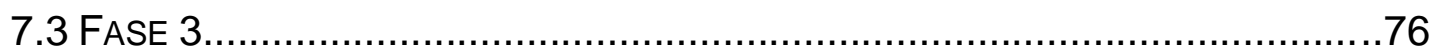

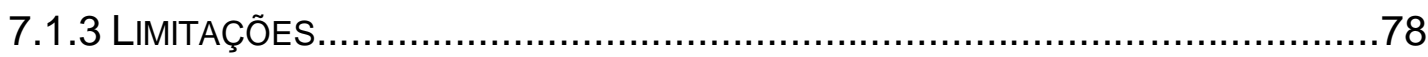

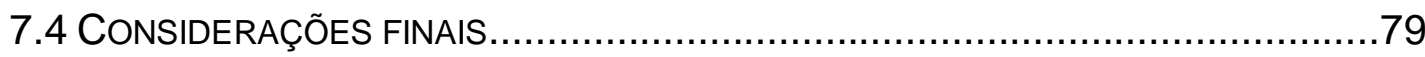

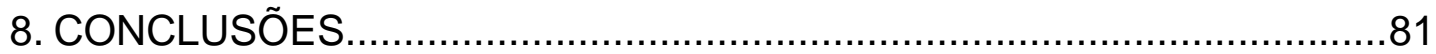

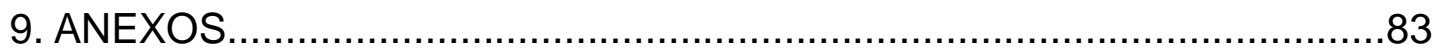

9.1 ANEXo A - CARTA de ConsEntiMENTO LiVRE E ESCLARECIDO....................83

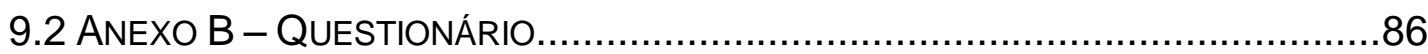

9.3 ANEXO C - APROVAÇÃO NO COMITÊ DE ÉTICA DA CAPPESQ......................132

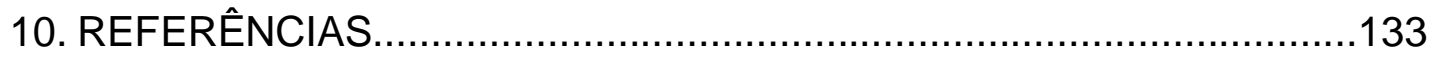




\section{LISTA DE FIGURAS}

Figura 1 - Região do Estuário de Santos e São Vicente.................................

Figura 2 - Localização das áreas contaminadas na Baixada Santista............7

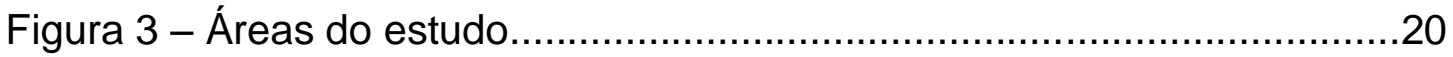

Figura 4 - Localização das cavas de áreas contaminadas no município

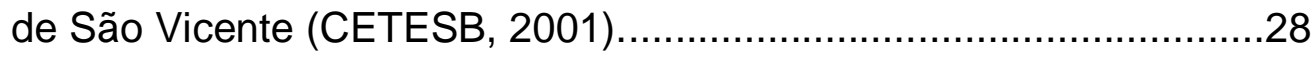

Figura 5 - Bairros de São Vicente (área continental)...................................29

Figura 6 - Percentual de nascidos vivos no período entre 2003 e 2007 segundo o município de residência

Figura 7 - Taxa bruta de natalidade no período entre 2003 e 2007 segundo o município de residência materna

Figura 8 - Taxa de fecundidade total no período entre 2003 e 2007 segundo o município de residência materna

Figura 9 - Distribuição percentual das mulheres em idade fértil segundo a área 39

Figura 10 - Percentual de mulheres em idade fértil segundo o tempo de moradia na região. 40

Figura 11 - Odds ratio ajustado de não engravidar segundo a área analisada. .53

Figura 12 - Odds ratio ajustado de abortos segundo a área analisada. .54

Figura 13 - Mapa de distribuição dos casos de aborto e não-aborto na área 3 (São Vicente continental) nos últimos cinco anos. 
Figura 14 - Mapa de distribuição dos casos de gestantes na área 3

(São Vicente continental) nos últimos cinco anos.............................57

Figura 15 - Mapa de distribuição dos casos de não gestantes na área 3

(São Vicente continental) nos últimos cinco anos.............................58 


\section{LISTA DE TABELAS}

Tabela 1 - Nascidos vivos por ano segundo o município de nascimento.......30

Tabela 2 - Dados demográficos das mães de nascidos vivos no período

de 2003 a 2007 segundo os municípios de residência.

Tabela 3 - Tipo de parto e número de consultas pré-natal das mães

de nascidos vivos no período de 2003 a 2007 segundo os

municípios de residência

Tabela 4 - Distribuição dos eventos gestacionais no período entre 2003

e 2007 segundo o município de residência. .36

Tabela 5 - Odds ratio ajustado dos eventos gestacionais segundo o

município de residência da mãe no período de 2003 a 2007

Tabela 6 - Características dos domicílios das mulheres em idade fértil segundo a área

Tabela 7 - Características socio-demográficas das mulheres em idade fértil segundo a área estudada

Tabela 8 - Hábitos das mulheres em idade fértil segundo a área analisada..47

Tabela 9 - Mulheres grávidas e atendimento pré-natal nos últimos cinco

anos segundo a área analisada.

Tabela 10 - Desfechos gestacionais nos últimos cinco anos segundo a área analisada.

Tabela 11 - Odds ratio bruto dos desfechos gestacionais segundo as áreas analisadas. 


\section{RESUMO}

Guimarães MT. Avaliação de desfechos relacionados à gestação em áreas contaminadas na região do estuário de Santos e São Vicente [tese]. São Paulo: Faculdade de Medicina, Universidade de São Paulo, 2012.

Introdução: O Estuário de Santos e São Vicente está contaminado com metais pesados, compostos organoclorados, dioxinas e furanos. Estudos epidemiológicos evidenciam que fetos são mais susceptíveis às substâncias tóxicas que adultos. Este trabalho avaliou a ocorrência de eventos relacionados à gestação em áreas contaminadas e não contaminada na região estuarina. Métodos: Estudo transversal onde foram analisados dados do SINASC entre 2003 e 2007 nos municípios de São Vicente, Guarujá, Cubatão e Bertioga. Foram calculadas as taxas bruta de natalidade e de fecundidade total por ano e os riscos de nascimento prematuro, baixo peso de nascimento, nascimento múltiplo e presença de anormalidade congênita no período, por município. Um questionário estruturado e pré-testado foi aplicado em uma amostra de base populacional (820 famílias) em cinco áreas da região, quatro dessas em áreas contaminadas e uma (controle) sem contaminação conhecida. Foram calculados os riscos de ocorrência de mulheres em idade fértil que engravidaram, aborto, parto prematuro, baixo peso ao nascer, natimorto, malformação congênita e nascimento múltiplo. Os dados de aborto e ocorrência de gestação foram georreferenciados na área 3, São Vicente continental. Utilizou-se o teste do qui-quadrado de Pearson ou teste exato de Fisher investigando associações entre as áreas e as variáveis qualitativas. $\mathrm{O}$ "odds ratio" $(\mathrm{OR})$ e os intervalos de confiança de $95 \%$ foram calculados por regressão logística de acordo com as áreas, ajustados para fatores de confusão (socioeconômicos, demográficos e de hábitos das mulheres). Nível de significância foi de $5 \%$. Resultados: As taxas de natalidade e fecundidade diminuíram no período em todos os municípios, predominantemente em Bertioga. Existe risco significativamente maior $(p=0,00)$ de ocorrência de baixo peso de nascimento em São Vicente (OR=2,25; $1,93-2,62)$, no Guarujá ( $\mathrm{OR}=2,14 ; 1,80$ - 2,56) e em Cubatão $(\mathrm{OR}=2,06 ; 1,75-2,43)$, que em Bertioga, controlado pela idade, estado civil e escolaridade da mãe, consulta pré-natal, e malformações congênitas. $O$ risco de parto prematuro também foi significativamente maior $(p=0,00)$ em São Vicente $(O R=2,24 ; 1,89-2,65)$, no Guarujá $(O R=2,31 ; 1,91-2,80)$ e em Cubatão ( $\mathrm{OR}=2,51 ; 2,09-3,00)$ que em Bertioga, controlado por idade, estado civil e escolaridade da mãe, consulta pré-natal, e malformações congênitas. $O$ risco de malformações congênitas também significativamente maior no Guarujá ( $O R=2,24 ; 1,43-3,50 ; p=0,00)$ e em Cubatão $(O R=1,62$; $1,04-2,52 ; p=0,03)$ que em Bertioga, controlado por idade e estado civil da mãe, consulta pré-natal, e nascimento múltiplo. A prevalência dos desfechos gestacionais foi maior nas quatro áreas contaminadas que na área controle. Comparado com a área 5 (controle), um risco significativamente maior de 
não ocorrência de gestantes, controlando para idade materna, escolaridade materna e renda familiar, foi encontrado na área $2(\mathrm{OR}=1,47 ; 1,16-1,85)$, na área $3(\mathrm{OR}=1,31 ; 1,03-1,66)$ e na área $4(\mathrm{OR}=1,40 ; 1,10-1,77)$. Também houve um risco significativamente maior de abortos na área 3 $(\mathrm{OR}=1,83 ; 1,07-3,12)$ controlando para anos morando na região, idade e escolaridade materna, renda familiar e uso de tabaco materno passado. Conclusões: O estudo evidencia um aumento de risco de desfechos gestacionais em áreas contaminadas na região dos Estuários de Santos e São Vicente.

Descritores: gravidez, aborto, baixo peso ao nascer, prematuro, anormalidades congênitas, contaminação ambiental. 


\section{ABSTRACT}

Guimarães MT. Evaluation of pregnancy outcomes in contaminated areas of Santos and São Vicente estuary region [thesis] São Paulo: "Faculdade de Medicina, Universidade de São Paulo", 2012.

Background: Santos and São Vicente Estuary is contaminated with heavy metals, organochlorines compounds, dioxins and furans. Epidemiological studies show that fetuses are more susceptible to toxic chemicals than adults. This study evaluated occurrence of pregnancy events in contaminated and non-contaminated areas in estuarine region. Methods: This crosssectional study analyzed SINASC data from 2003 to 2007 in São Vicente, Guarujá, Cubatão and Bertioga cities. Crude birth and total fertility rates per year, and risks of preterm birth, low birth weight, multiple birth and congenital abnormality in the period were calculated by city. A pre-tested and structured questionnaire was applied in a population-based sample (820 families each) in five areas. Four of these areas are in contaminated regions and one (control) has no known environmental contamination. Risks of childbearing age women who became pregnant, abortion, premature birth, low birth weight, stillbirth, congenital malformation and multiple birth were calculated. Data of abortion and pregnancy occurrence were georeferenced in area 3, continental part of São Vicente city. Pearson's chi-square test or Fisher's exact test were used to investigate associations between areas and qualitative variables. Odds ratio and 95\% confidence intervals were calculated by logistic regression according to the area, adjusted for confounding factors (socioeconomic, demographic and women habits). The statistical significance level was set at $5 \%$. Results: Birth and fertility rates declined over the years in all cities, predominantly in Bertioga. There were significant higher risks $(p<0.01)$ of low birth weight in São Vicente $(O R=2.25$, 1.93 - 2.62), Guarujá $(\mathrm{OR}=2,14,1.80$ - 2.56) and Cubatão $(\mathrm{OR}=2.06,1.75-$ 2.43), compared to Bertioga, controlling for maternal age, marital status, maternal education, prenatal, and congenital abnormalities. Risk of preterm birth was also significantly higher $(p<0.01)$ in São Vicente $(O R=2.24,1.89-$ 2.65), Guarujá ( $\mathrm{OR}=2.31,1.91-2.80)$, and Cubatão $(\mathrm{OR}=2.51,2.09-3.00)$ than Bertioga, controlling for maternal age, marital status, maternal education, prenatal, and congenital abnormalities. Risk of congenital abnormalities was significantly higher in Guarujá $(\mathrm{OR}=2.24,1.43-3.50$, $\mathrm{p}=0.00)$ and Cubatão $(\mathrm{OR}=1.62,1.04-2.52, \mathrm{p}=0.03)$ than Bertioga, controlling for maternal age, marital status, prenatal and multiple birth. Prevalences of pregnancy outcomes were higher in the four contaminated areas than in control area. Compared to area 5 (control), significantly higher risks $(p<0.05)$ of non-pregnant women was found in areas $2(\mathrm{OR}=1.47,1.16$ - 1.85), $3(\mathrm{OR}=1.31,1.03-1.66)$, and $4(\mathrm{OR}=1.40,1.10-1.77)$ controlling for maternal age, maternal education, and family income. There was also a significantly higher risk of abortion in area $3(\mathrm{OR}=1.83,1.07-3.12)$ controlling for years living in the region, maternal age and education, family 
income and maternal past smoking. Conclusions: The study shows an increased risk of pregnancy outcomes in contaminated areas of Santos and São Vicente Estuary region.

Descriptors: pregnancy, abortion, low birth weigh, premature, congenital abnormalities, environmental pollution. 


\section{INTRODUÇÃO}

A industrialização no Brasil foi mais impactante para o meio ambiente nos centros urbanos. Vários episódios de contaminações ambientais por atividade industrial ocorreram ao longo das últimas décadas em cidades como Volta Redonda/RJ, e nas Regiões Metropolitanas de São Paulo, Campinas, e das Baixadas Santista e Fluminense, entre outras ${ }^{1}$.

Especificamente a Região Metropolitana da Baixada Santista sofreu um forte processo de degradação ambiental e perda de qualidade de vida com a poluição industrial, portuária e doméstica, segregando a população mais pobre em áreas mais deterioradas e insalubres ${ }^{2}$. A relação entre pobreza e proximidade de poluentes cria uma situação de risco para o aparecimento de diversas doenças na região ${ }^{3}$.

A identificação de áreas contaminadas, bem como a investigação da exposição destes poluentes em populações expostas é de suma importância para o delineamento de políticas públicas que possam remediar os riscos e melhorar a qualidade de vida destas populações, principalmente as parcelas mais susceptíveis ${ }^{4}$. Nesse contexto, uma parcela que deve ser melhor investigada são as mulheres em idade fértil.

Assim, o objetivo deste estudo foi avaliar os riscos reprodutivos à que as mulheres em idade fértil estão expostas na região reconhecidamente 
contaminada da Baixada Santista.

Para isso, foram concebidas três fases de estudo avaliando a ocorrência de eventos relacionados à gestação com o local de moradia. A primeira, mais ampla, abrangendo os municípios de Cubatão, Guarujá, São Vicente e Bertioga, onde dados secundários de nascimentos foram analisados. A segunda, a partir de dados primários, onde populações de mulheres em idade fértil que moravam próximas a áreas reconhecidamente contaminadas nos municípios de Cubatão, Guarujá e São Vicente e uma área sem contaminação conhecida nem suspeita no município de Bertioga foram investigadas. Por último, foram georreferenciados os dados coletados na segunda fase em uma das áreas contaminadas. 


\section{ESTUÁRIO DE SANTOS E DE SÃO VICENTE}

\subsection{O ESTUÁRIO}

Estuários são ecossistemas de grande complexidade por serem zonas de transição entre a rede hidrográfica continental e o ambiente marinho. A presença de contaminantes apresenta impacto significativo nestes frágeis ecossistemas ${ }^{5}$.

A região do estuário de Santos e de São Vicente está localizada no litoral sudeste do Estado de São Paulo, ao longo da Baixada Santista (Figura 1) envolvendo os municípios de Santos, Guarujá, Cubatão, São Vicente, Praia Grande e Bertioga. As atividades industriais estão concentradas em Cubatão, mas os municípios de Santos e São Vicente abrigam um grande número de indústrias. Estas cidades concentram também os setores de comércio e serviços. Guarujá e Bertioga apresentam atividades principalmente ligadas ao turismo ${ }^{6}$. 


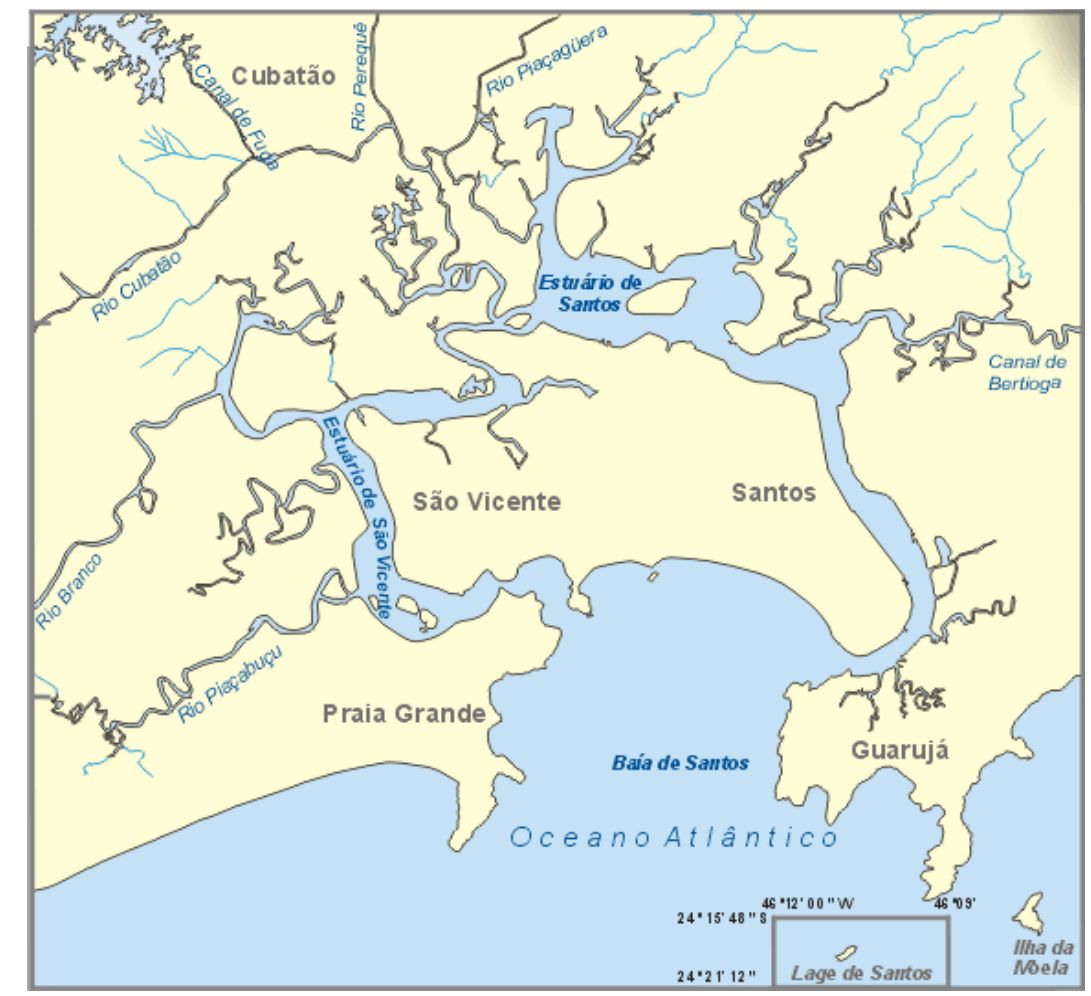

FONTE: CETESB, 2001.

Figura 1: Região do Estuário de Santos e São Vicente.

Segundo a Fundação Sistema Estadual de Análise de Dados $\mathrm{SEADE}^{7}$, a Região Metropolitana da Baixada Santista (RMBS) ocupa uma área total de $2.422,78 \mathrm{~km}^{2}$ com uma população estimada de 1.683 .725 habitantes para o ano de 2011. Apresenta discreto predomínio da população feminina (cerca de 92 homens para cada 100 mulheres); densidade demográfica de 694,96 habitantes/ km²; renda "per capita" de 2,89 salários mínimos em 2000. A abrangência do abastecimento de água e da coleta de lixo para a população, com nível de atendimento acima de $90 \%$ dos domicílios, contrasta com uma distribuição insuficiente (67\%) na rede de esgoto sanitário. Do ponto de vista das estatísticas vitais e de saúde, em 
2010 apresentou uma taxa de natalidade de 14,65 por 1.000 habitantes e uma taxa de fecundidade geral de 53,06 por 1.000 mulheres em idade fértil. A distribuição de crianças consideradas de risco para morbimortalidade infantil revelou um percentual de baixo peso ao nascer de $8,53 \%$, e $7,82 \%$ dos partos ocorreram prematuramente, e taxa de mortalidade infantil de 15,15 por 1.000 nascidos vivos, sendo que $76,72 \%$ das mães realizaram sete ou mais consultas pré-natais.

\subsection{HISTÓRICO DA INDUSTRIALIZAÇÃO E CONTAMINAÇÃO DA REGIÃO DO ESTUÁRIO DE SANTOS E SÃo VicENTE}

O cenário de poluição do meio ambiente no Brasil começa a partir da década de 1950, diante da política desenvolvimentista adotada pelo governo. A Baixada Santista foi uma das áreas que atraiu várias indústrias multinacionais, principalmente aquelas voltadas para o setor de base (petroquímicas, siderúrgicas, de fertilizantes, entre outras) ${ }^{8}$.

Somado à inserção de indústrias, o adensamento populacional nas áreas urbanas trouxe outros problemas relacionados com 0 esgoto doméstico, destinação do lixo, poluição do ar e, mais recentemente, a poluição pelos deslocamentos dessa população ou transporte de produtos para abastecimento, causados pelos veículos automotores ${ }^{9}$. 
Entre as décadas de 60 e 70, inúmeros países economicamente periféricos, ávidos por novas fontes de recursos e desenvolvimento, receberam indústrias multinacionais de produtos de base, principalmente na área petroquímica. Muitas dessas indústrias tinham como sede países onde a legislação ambiental determinava que altos investimentos em tecnologia fossem efetivados, principalmente para a prevenção de possíveis acidentes ambientais. À medida que os países desenvolvidos foram aperfeiçoando formas de controle ambiental, várias indústrias passaram a migrar para países onde a legislação e o seu controle fosse mais ameno ou até mesmo inexistente ${ }^{10}$.

\subsection{FonTES DE POLUIÇÃO E CONTAMINANTES ENCONTRADOS NA REGIÃo DO ESTUÁRIO de SANTOS E SÃo Vicente}

A região dos estuários de Santos e São Vicente é uma região muito exposta à poluição, por ter um grande parque industrial, ser portuária, populosa e, ainda, ter atividades de agricultura e pecuária. A poluição de origem industrial constitui a principal fonte de contaminantes químicos na região. As áreas com solos contaminados constituem fontes de alto risco, que foram depositados de forma irregular em diversos pontos da região, contaminando o meio ambiente por poeiras, metais pesados, organoclorados, bifenilas policloradas (PCBs), hidrocarbonetos policíclicos 
aromáticos (HPAs), dioxinas e furanos ${ }^{6}$.

A figura 2 mostra as áreas contaminadas na Baixada Santista em 1999 de acordo com a CETESB ${ }^{6}$ : áreas com deposição irregular de resíduos industriais; áreas industriais com solos contaminados; locais de disposição de resíduos sólidos domésticos; locais de disposição de gesso resultante da fabricação de fertilizantes fosforados; e locais de disposição de sedimentos contaminados.

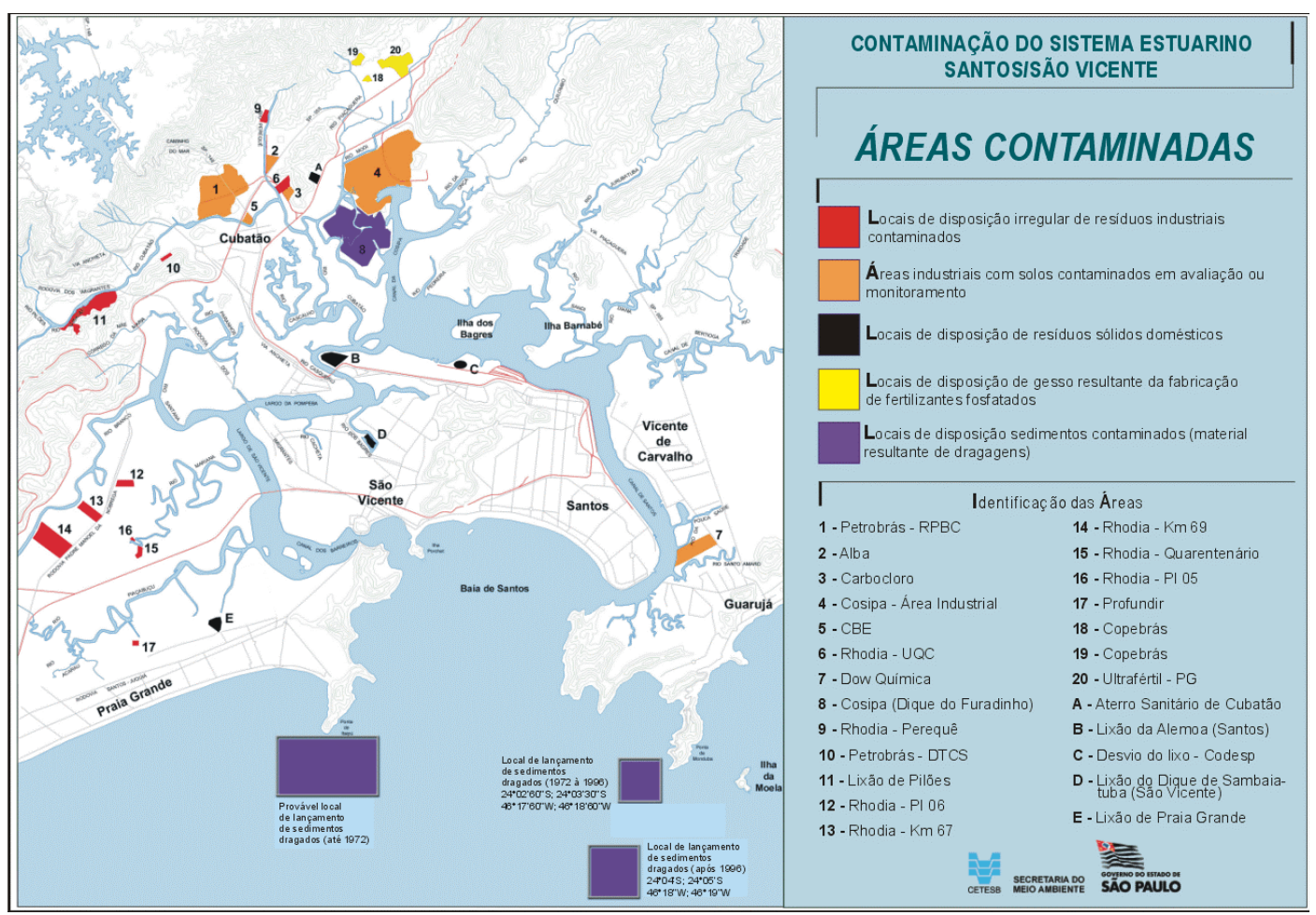

FONTE: CETESB, 2001.

Figura 2: Localização das áreas contaminadas na Baixada Santista. 


\section{CONTAMINAÇÃO AMBIENTAL E EFEITOS NA GESTAÇÃO}

A gestação é um episódio fisiológico na vida da mulher e se dá, na maioria das vezes, sem intercorrências ${ }^{11}$. A partir da segunda metade do século 20 , instalou-se uma preocupação crescente quanto ao possível efeito sobre o embrião ou feto em desenvolvimento, de substâncias ou organismos a que uma gestante estivesse exposta. Segundo Schüller-Faccini e colaboradores $^{12}$, os danos reprodutivos podem ser agrupados em quatro classes: (1) morte do concepto, (2) malformações, (3) retardo de crescimento intrauterino, e (4) deficiências funcionais.

A identificação da síndrome da rubéola congênita, no início da década de 40 , derrubou a ideia de que a placenta era uma barreira eficaz de proteção contra organismos exógenos ${ }^{13}$. No início da década de 1960, com a publicação do livro de Rachel Carson, "Primavera Silenciosa", chamou atenção para o perigo do uso extensivo e generalizado de pesticidas para o ambiente e também para a saúde humana ${ }^{14}$.

Embriões, fetos e bebês são altamente susceptíveis a inúmeras substâncias tóxicas ambientais, e a exposição materna pode levar a ocorrência de efeitos reprodutivos adversos ${ }^{15,16}$. Estudos humanos e experimentais indicam que este grupo etário é mais sensível do que os adultos às substâncias tóxicas ambientais, incluindo fumaça de cigarro, HPAs e pesticidas ${ }^{17,18}$. 
Os desfechos adversos da gestação, como baixo peso ao nascer, prematuridade, malformações congênitas entre outros, podem ser parâmetros úteis para avaliar possíveis contaminações ambientais ${ }^{15}$, principalmente entre a associação entre a poluição do ar e os desfechos na gestação ${ }^{19}$.

Tolf e colaboradores ${ }^{20}$, numa revisão sobre os efeitos de compostos organoclorados na reprodução humana sugerem ocorrência de anormalidades reprodutivas incluindo redução na qualidade do sêmen e câncer de testículo em homens; alterações do ciclo menstrual, aborto espontâneo e aumento do tempo para ocorrer a gravidez em mulheres, redução do peso de nascimento, distorção da razão de sexo e alteração da idade de desenvolvimento sexual.

\subsection{Baixo Peso ao Nascer}

Baixo peso ao nascer é o peso de nascimento inferior a $2.500 \mathrm{~g}^{21}$. Este desfecho adverso da gravidez é determinado pela duração da gestação e/ou pela taxa de crescimento fetal ${ }^{22}$.

A Organização Mundial da Saúde (OMS) considera o baixo peso ao nascer como fator isolado mais importante na sobrevivência infantil ${ }^{23}$, sendo também um fator importante na determinação da morbimortalidade neonatal e pós-neonatal ${ }^{24}$. É um indicador mais sensível dos efeitos ambientais que 
outros desfechos gestacionais, pois pequenos efeitos podem ser detectados em uma grande população ${ }^{25}$.

Segundo a $\operatorname{SEADE}^{7}$ no ano de 2010 o município de Bertioga teve prevalência de $4,65 \%$, São Vicente de $9,22 \%$, Cubatão de $9,50 \%$ e o Guarujá de $8,46 \%$.

Um estudo na Inglaterra avaliou o risco de desfechos adversos ao nascimento em populações residentes próximas a aterros e encontraram um pequeno aumento no risco de baixo peso ao nascer ${ }^{26}$. No Brasil, Oliveira e colaboradores ${ }^{27}$ encontraram correlação positiva entre baixo peso ao nascer e proximidade geográfica da residência materna a um polo petroquímico no Rio Grande do Sul. Em São Paulo, Medeiros e Gouveia ${ }^{23}$ encontraram associação entre poluição do ar e diminuição no peso de nascimento.

\subsection{Prematuridade}

A OMS definiu, em 1972, como prematura toda criança nascida viva no período de gestação inferior a 37 semanas completas (contadas a partir da data da última menstruação), não importando 0 seu peso $^{28}$. $O$ parto prematuro ainda é a principal causa de morbidade e mortalidade perinatal ${ }^{29}$.

Em 2010 o percentual de gestações pré-termo foi de 4,65\% no município de Bertioga, 8,82\% em São Vicente, 7,45\% em Cubatão e 8,84\% no Guarujá 7 . 
Existe evidência que a exposição materna a poluição do ar durante a gestação está associada ao aumento do risco de partos prematuros ${ }^{30}$. Maroziene e Gravuleviciene ${ }^{31}$ encontraram uma relação dose-dependente entre ocorrência de parto prematuro e concentrações de dióxido de nitrogênio $\left(\mathrm{NO}_{2}\right)$ na Lituânia. Ritz e colaboradores ${ }^{32}$ encontraram uma relação dose-dependente entre prematuridade e concentração de material particulado (PM10).

\subsection{ABORTO ESPONTÂNEO E NATIMORTALIDADE}

Aborto espontâneo é a perda fetal na idade gestacional de até 22 semanas ou peso de nascimento inferior a 500g; natimorto é a perda fetal na idade gestacional de 22 semanas ou mais, segundo a $\mathrm{OMS}^{33}$. A probabilidade de ocorrência de aborto espontâneo é maior quanto mais próximo o início da gestação ${ }^{34}$. Existem poucos trabalhos conclusivos investigando a associação entre a poluição e estes desfechos adversos da gravidez.

Korrick e colaboradores ${ }^{35}$ em estudo caso-controle encontrou risco aumentado de abortos espontâneos associado com níveis séricos materno de DDE. Um estudo ecológico mostrou que viver em áreas com maior nível de poluição industrial está associado com maiores taxas de aborto espontâneo ${ }^{36}$. 
No Brasil, Pereira ${ }^{37}$ encontrou associação dose-dependente entre a poluição atmosférica e perdas fetais tardias no município de São Paulo.

\subsection{MALFORMAÇÕES CONGÊNITAS}

Malformações congênitas são todas aquelas presentes ao nascer, mesmo com manifestação tardia na vida pós-neonatal. Cerca de $30 \%$ das malformações congênitas são de etiologia genética, 5\% de etiologia ambiental e $65 \%$ não têm causa conhecida ou são multifatoriais ${ }^{38}$. As malformações congênitas fazem parte de um espectro de desfechos adversos da gestação que podem estar associadas com a exposição materna aos poluentes ambientais ${ }^{39}$.

Elliott e colaboradores ${ }^{26}$ avaliaram o risco de desfechos adversos ao nascimento em populações residentes próximos a aterros na Inglaterra, e encontraram um pequeno aumento no risco para algumas malformações congênitas.

Dois trabalhos realizados nos Estados Unidos da América sugeriram associação entre exposição à poluição do ar durante a gestação e ocorrência de defeitos cardíacos ${ }^{40,41}$.

No Brasil, alguns estudos levantaram a hipótese de danos à saúde fetal durante a gestação em Cubatão. Um amplo projeto de estudo foi elaborado não chegando a resultados conclusivos ${ }^{42}$. 


\subsection{NASCIMENTOS MúLTIPLOS}

Nascimentos múltiplos são associados com riscos mais altos para a mãe e criança, como gestação mais curta, parto prematuro, baixo peso de nascimento e morte perinatal ${ }^{43}$ e raramente são investigados em estudos de saúde ambiental ${ }^{44}$.

Obis-Osius e colaboradores ${ }^{45}$ encontraram um risco maior de ocorrência de nascimentos múltiplos em uma população residente próximo a um incinerador de lixo tóxico na Alemanha. 


\section{OBJETIVOS}

\subsection{ObJetivo Geral}

Avaliar a ocorrência de eventos relacionados à gestação nas áreas contaminadas e não contaminada a partir de dados primários e secundários.

\subsection{OBJetivos EsPeCíficos}

Calcular a taxa bruta de natalidade e a taxa de fecundidade total nos municípios de Bertioga, Cubatão, Guarujá e São Vicente entre os anos de 2003 e 2007.

Investigar a associação entre baixo peso ao nascer, prematuridade, malformação congênita e nascimento múltiplo nos municípios de Cubatão, Guarujá e São Vicente comparando com o município de Bertioga, entre os anos de 2003 a 2007;

Investigar a associação entre proporção de mulheres em idade fértil que engravidaram e residir em áreas contaminadas, comparando com a área não contaminada; 
Investigar a associação entre desfechos da gestação (baixo peso ao nascer, prematuridade, natimorto, aborto espontâneo, malformação congênita e nascimento múltiplo) e residir em áreas contaminadas, comparando com a área não contaminada;

Georeferenciar os eventos relacionados à gestação determinados na área estudada em São Vicente continental. 


\section{MÉTODOS}

\subsection{FASE 1}

Esta fase compreendeu um estudo transversal, onde os dados de nascidos vivos nos municípios de São Vicente, Cubatão, Guarujá e Bertioga foram obtidos através da SEADE, da Secretaria de Planejamento e Desenvolvimento Regional do Governo do Estado de São Paulo, referentes ao Sistema de Informações sobre Nascidos Vivos (SINASC) no período de 2003 a 2007.

Os eventos foram separados por município de residência. Para cada um dos municípios estudados foram obtidas as informações sobre as estimativas populacionais disponíveis pelo IBGE.

Dentre as variáveis constantes no banco de dados do SINASC, as variáveis dependentes estudadas foram: nascimento prematuro, baixo peso de nascimento, nascimento múltiplo e presença de anormalidade congênita. A variável independente foi o município de residência da mãe. As variáveis de confusão foram aquelas relacionadas às características do recémnascido (presença de anomalia congênita - sim ou não), da mãe (idade 
materna - menor ou igual a 19 anos, 20 a 34 anos, maior ou igual a 25 anos; estado civil da mãe - casada, solteira ou outros; escolaridade materna - até três anos de estudo, de quatro a sete anos de estudo ou oito ou mais anos de estudo), da gestação e do parto (tipo de gravidez - única ou múltipla; tipo de parto - vaginal ou cesáreo; consulta pré-natal - adequada, sete ou mais consultas ou inadequada, menos que sete consultas pré-natal).

Para as variáveis parto prematuro e baixo peso de nascimento foram excluídos da análise casos com variáveis fortemente correlacionadas. Para baixo peso de nascimento foram excluídos da análise os nascimentos prematuros e/ou múltiplos, enquanto que para partos prematuros foram excluídos os nascimentos múltiplos.

Séries históricas dos coeficientes padronizados dos eventos relacionados à gestação foram calculadas ao longo dos períodos de tempo definidos, estratificando-se por ano e por cidade.

A taxa bruta de natalidade se refere ao número de nascidos vivos e a população total expressa por 1.000 habitantes. A taxa de fecundidade total se refere ao número médio de filhos nascidos vivos tidos por uma mulher ao final do seu período reprodutivo, calculada pela soma das taxas específicas de fecundidade para as mulheres residentes de 15 a 49 anos, multiplicandose por cinco, que corresponde ao intervalo entre os grupos etários trabalhados (15-19, 20-24, 25-29, 30-34, 35-39, 40-44, e 45-49 anos $)^{46}$.

Para avaliar associação entre as variáveis qualitativas foi utilizado o teste de qui-quadrado de Pearson ${ }^{47}$. 
As razões de chance (odds ratio - OR) entre os desfechos relacionados à gestação e ao local de residência da mãe foram estimadas por modelos de regressão logística múltipla ${ }^{48}$. Antes de serem inseridas no modelo final, as associações com possíveis variáveis de confusão foram analisadas previamente por regressão logística bivariada, determinando sua entrada ou não.

Foram calculadas: medida de associação, estimador de risco com seus respectivos intervalos de confiança de 95\% (IC 95\%) e adotado nível de significância menor ou igual que 0,05 em todas as análises estatísticas, utilizando o pacote estatístico "Statistical Package for Social Sciences" (SPSS), versão 17.0.

\subsection{FASE 2}

Esta fase tratou-se de um estudo transversal e fez parte de um projeto mais amplo e extenso intitulado "Estudo Epidemiológico na População Residente na Baixada Santista - Estuário de Santos: Avaliação de Indicadores de Efeito e de Exposição a Contaminantes Ambientais" que teve como objetivo estimar os efeitos na saúde associados à exposição aos contaminantes ambientais entre os moradores da Baixada Santista - 
Estuário de Santos e São Vicente. O estudo foi submetido e aprovado pelo Comitê de Ética Médica em Pesquisa da Universidade de Santo Amaro, e teve financiamento do $\mathrm{CNPq}^{49}$.

\subsubsection{DefinIÇÃo das ÁREAS E dA POPULAÇÃo dE ESTUdo}

A identificação das áreas contaminadas utilizadas neste estudo foi feita a partir do relatório da CETESB denominado "Sistema Estuarino de Santos e São Vicente" ${ }^{\text {, }}$ que teve como objetivo avaliar a contaminação da água, dos sedimentos e dos organismos aquáticos do sistema estuarino de Santos e São Vicente e a Baía de Santos, relacionando-a com as fontes potenciais de poluentes na região.

Assim, foram definidas cinco áreas para a realização do estudo, sendo quatro em regiões comprovadamente contaminadas e uma em região onde não existe contaminação conhecida e nem suspeita (área controle) (Figura 3). 


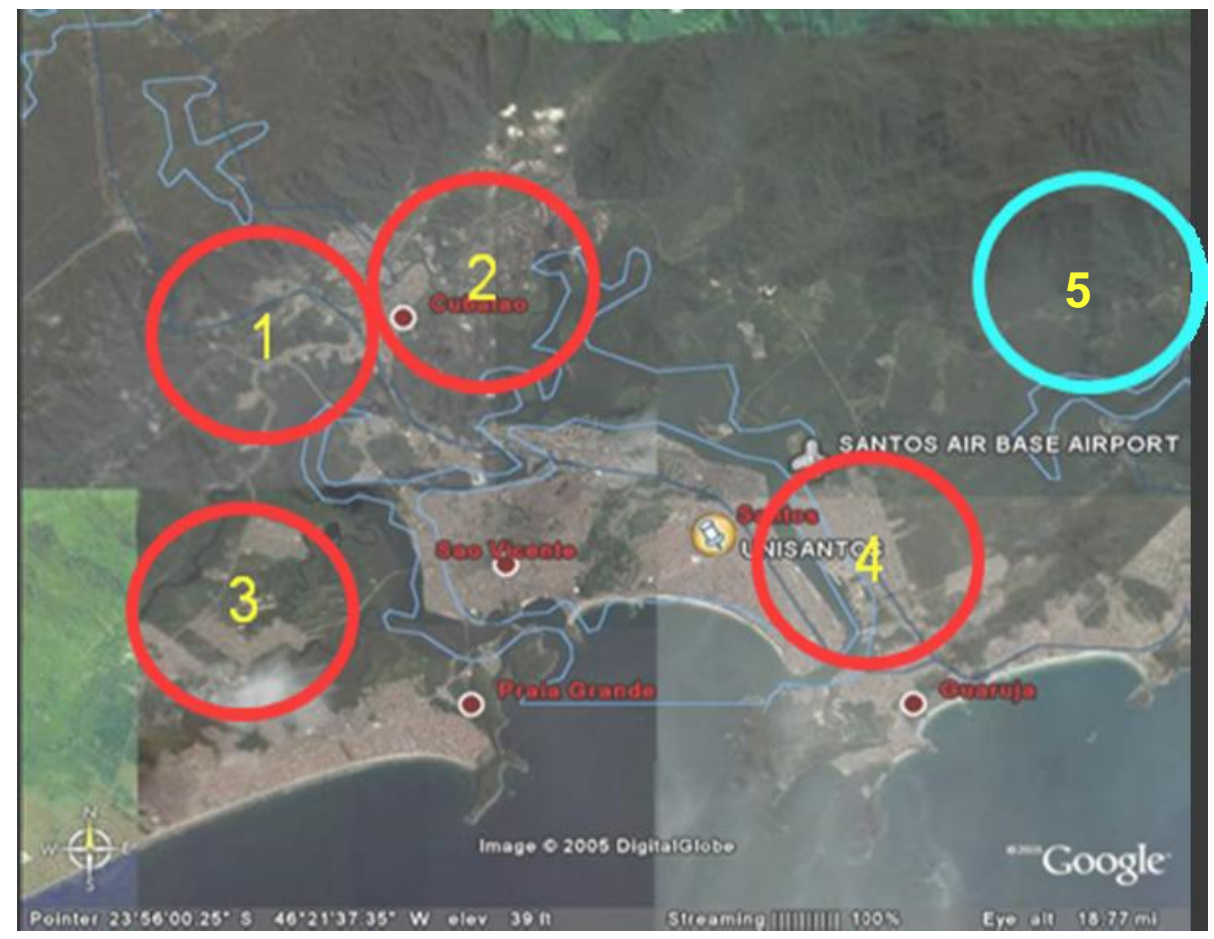

FONTE: Braga et al., 2009

Figura 3: Áreas do estudo

Área 1: Região de pilões e, mais especificamente, a comunidade situada às margens do rio Cubatão, entre as rodovias Imigrantes e Anchieta, na encosta do Morro Marzagão, ao longo das vias estrada para Itutinga e rua Elias Zarzur e nos Bairros Fabril e Pinheiro Miranda;

Área 2: no entorno da região que compreende o centro de Cubatão (oeste), a Cosipa (leste) e o Vale do Rio Perequê (norte);

Área 3: em São Vicente continental, compreendendo as áreas do Conjunto Residencial Humaitá, Vila Nova Mariana, Parque Continental, 
Gleba II, Parque das Bandeiras, Samaritá, Vila Iolanda, Vila Ema e Vila Matias, Jardim Rio Branco e Vila Ponte Nova;

Área 4: no entorno da Dow Química, em Vicente de Carvalho, Guarujá, compreendendo as áreas do Sítio Conceiçãozinha, Conjunto Habitacional Jardim Conceição, Jardim Conceiçãozinha e Jardim Boa Esperança.

A área 5, ou área controle, onde não existe contaminação conhecida e nem suspeita, incluiu as seguintes comunidades de Bertioga: Jardim Vicente de Carvalho II, Jardim Albatroz II, Vista Linda, Projeto Condomínio Social e a área de assentamento do Jardim Indaiá $2^{\underline{a}}$ Gleba.

\subsubsection{Cálculo e Seleção da Amostra}

O plano de amostragem foi delineado considerando o objetivo de estimar parâmetros (prevalência) de desfechos da gestação nos últimos cinco anos, doenças respiratórias e doenças cardiovasculares em populações moradoras em áreas reconhecidamente contaminadas. Inicialmente, foram identificados os setores censitários mais próximos às fontes de exposição. O número de moradores nos domicílios existentes nestes setores foram apurados através dos dados do Censo Demográfico de 
2000 do Instituto Brasileiro de Geografia e Estatística ${ }^{50}$.

O desfecho de interesse menos frequente, malformação congênita, foi utilizado como base para calcular a amostra. Para uma prevalência de malformações congênitas em torno de $2 \%$ no Brasil ${ }^{38}$, estimando que em áreas contaminadas a prevalência seja de 4\%, adotado nível de significância de $5 \%$, poder do teste de $80 \%$ para um teste bicaudal e assumindo uma perda de $20 \%$. Através desses critérios, foi estimada uma amostra de 820 domicílios por área estudada, sendo esta dividida de modo proporcional em cada bairro, levando em consideração o número de domicílios existentes por setor censitário.

\subsubsection{COLETA DE INFORMAÇÕES NO DOMICÍLIO}

Em cada domicílio foi aplicado um questionário estruturado tendo como referência o questionário de morbidade referida desenvolvido por pesquisadores do Instituto Nacional do Câncer - INCA ${ }^{51}$. Esse questionário foi adaptado para as necessidades do projeto de pesquisa e pré-testado com o objetivo de garantir sua consistência e aplicabilidade.

O grupo de entrevistadores foi formado por alunos do ensino médio, 
da iniciação científica e da pós-graduação (Universidade Católica de Santos - UNISANTOS, Faculdade de Medicina da Universidade de São Paulo FMUSP, Faculdade de Medicina da Universidade de Santo Amaro FMUNISA e Centro de Estudos de Cultura Contemporânea - CEDEC), previamente treinados.

A aplicação dos questionários foi supervisionada por uma gerente de campo, com experiência em trabalhos similares e responsável pela avaliação periódica dos entrevistadores. A qualidade do preenchimento dos questionários foi sistematicamente verificada por sorteios aleatórios.

A estratégia de abordagem nos domicílios sorteados foi convidar a participar do estudo todos os moradores, incluindo crianças e adultos. $\mathrm{O}$ informante, normalmente o responsável pelo domicílio, tinha 18 anos ou mais e era capaz de dar as informações precisas e detalhadas de cada um dos moradores, e quando necessário os demais membros do domicílio complementavam com suas informações pessoais. As entrevistas foram realizadas durante os finais de semana, e os objetivos do estudo e os procedimentos a serem realizados foram explicados detalhadamente através do texto contido no termo de consentimento livre e esclarecido, sendo em seguida assinado pelo informante (Anexo A).

O questionário aplicado era composto pelos seguintes módulos (Anexo B):

- Características do domicílio e infraestrutura: com informações sobre a construção, tempo de moradia, água consumida, esgoto, lixo, iluminação e 
fogão;

- Dados biodemográficos dos moradores do domicílio;

- Ingestão alimentar: tipos de alimentos consumidos, origem e frequência, com ênfase em produtos pescados ou produzidos no local de residência ou nas proximidades;

- Exposição ocupacional atual e pregressa: tipos de atividades exercidas, condições de trabalho e tempo de atividade;

- Tabagismo;

- Alcoolismo;

- Percepção de saúde e morbidade referida: neste item investigou-se a presença de doenças, sinais ou sintomas associados à exposição aos poluentes encontrados na região. Foram investigadas: doenças cardíacas; hipertensão arterial; acidente vascular cerebral; doenças respiratórias; doenças renais; alterações hepáticas; cânceres; doenças hematológicas; doenças de pele; distúrbios neurológicos; distúrbios de aprendizagem; SIDA; hanseníase.

- Desfechos da gestação: prematuridade; baixo peso ao nascer; natimortalidade; aborto espontâneo; malformações congênitas; nascimentos múltiplos. 


\subsubsection{ANÁLISE Estatística}

Primeiramente foi feita uma análise descritiva das características das mulheres em idade fértil, entre 15 e $49 \operatorname{anos}^{50}$. Para avaliar os desfechos da gravidez foram utilizados os dados das mulheres que engravidaram nos últimos cinco anos.

As variáveis qualitativas apresentadas em seus valores absolutos e relativos. As variáveis quantitativas apresentadas em seus valores absolutos e relativos, ou em seus valores de tendência central e de dispersão.

Para avaliar associação entre as variáveis qualitativas foi utilizado o teste de qui-quadrado de Pearson ${ }^{47}$.

Foram excluídos das análises os questionários que contiverem erros de marcação, em branco e quando o entrevistado não soube informar.

As razões de chance (OR) entre os desfechos relacionados à gestação (número de gestações, baixo peso ao nascer, parto prematuro, aborto espontâneo, natimorto, nascimento múltiplo e malformação congênita) e a área foram feitas por modelos de regressão logística bivariada e/ou múltipla ${ }^{48}$. Antes de serem inseridas no modelo final, as associações com possíveis variáveis de confusão foram analisadas previamente por regressão logística bivariada, determinando sua entrada ou não no modelo múltiplo.

As variáveis de confusão foram determinadas da seguinte maneira: 
- Anos morando na região - menos que cinco anos ou cinco ou mais anos;

- Idade materna - 15 a 20 anos, 21 a 30 anos, 31 a 40 anos, 41 a 49 anos;

- Escolaridade materna - analfabeta funcional (analfabetas e que cursaram até $\circ 2^{\circ}$ ano do ensino fundamental), ensino fundamental, ensino médio, ensino superior;

- Estado civil da mãe - casada ou morando com companheiro, solteira/ separada/ divorciada, viúva;

- Renda familiar - menor ou igual a três salários mínimos ou mais que três salários mínimos;

- Exposição ocupacional atual ou pregressa - sim ou não;

- Tabagismo atual ou pregresso - sim ou não;

- Consumo de álcool atual ou pregresso - sim ou não;

- Consulta pré-natal - adequada, sete ou mais consultas ou inadequada, menos que sete consultas pré-natais.

Foram calculadas: medida de associação, estimador de risco com seus respectivos IC 95\%, e adotado nível de significância menor ou igual que 0,05 em todas as análises estatísticas, utilizando o pacote estatístico SPSS, versão 17.0. 


\subsection{FASE 3}

A fase 3 consistiu na análise espacial dos dados de gravidez e aborto na área 3, por ser a única área do estudo com sua fonte de contaminação bem delimitada e com população fixa em seu entorno.

A análise geográfica foi definida durante o delineamento do estudo. A análise espacial do levantamento epidemiológico foi feita por meio de geoprocessamento, utilizando-se coleta de coordenadas geográficas por meio de receptor GPS e criação de banco de dados em ambiente de Sistema de Informações Geográficas (SIG). A análise espacial compreendeu as seguintes fases:

- Coleta de coordenadas geográficas dos endereços das mulheres em idade fértil que responderam ao questionário;

- Localização das cavas mapeadas pela CETESB (figura 4) em imagem de satélite disponíveis no programa Google Earth;

- Digitalização das estradas principais e limites dos bairros da área de estudo a partir de imagem de satélite no programa Google Earth (figura 5);

- Importação dos endereços, centróides das cavas, estradas e bairros no programa ArcGIS 10;

- Definição de "buffers" de 1000 m em torno dos centróides das cavas; 
- Seleção e contagem dos endereços por desfecho de interesse (mulheres que tiveram aborto; mulheres que não tiveram aborto; mulheres que engravidaram e mulheres que não engravidaram) dentro e fora dos "buffers";

- Elaboração de mapas dos desfechos de interesse.

A análise estatística foi feita por medida de associação (teste exato de Fisher) ${ }^{47}$, adotado nível de significância de $5 \%$ e utilizado o pacote estatístico SPSS, versão 17.0.

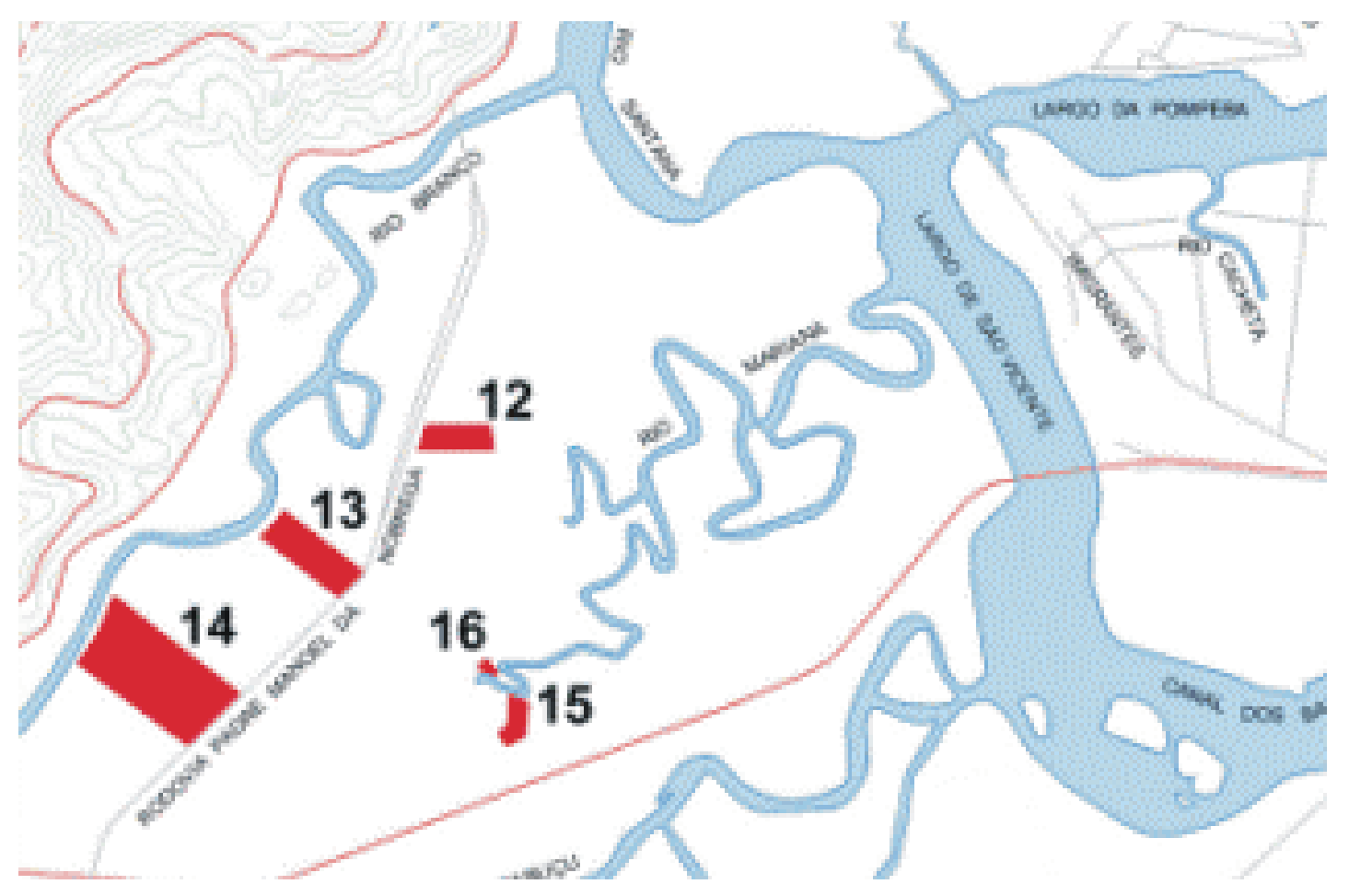

Figura 4: Localização das cavas de áreas contaminadas no município de São Vicente (CETESB, 2001). 


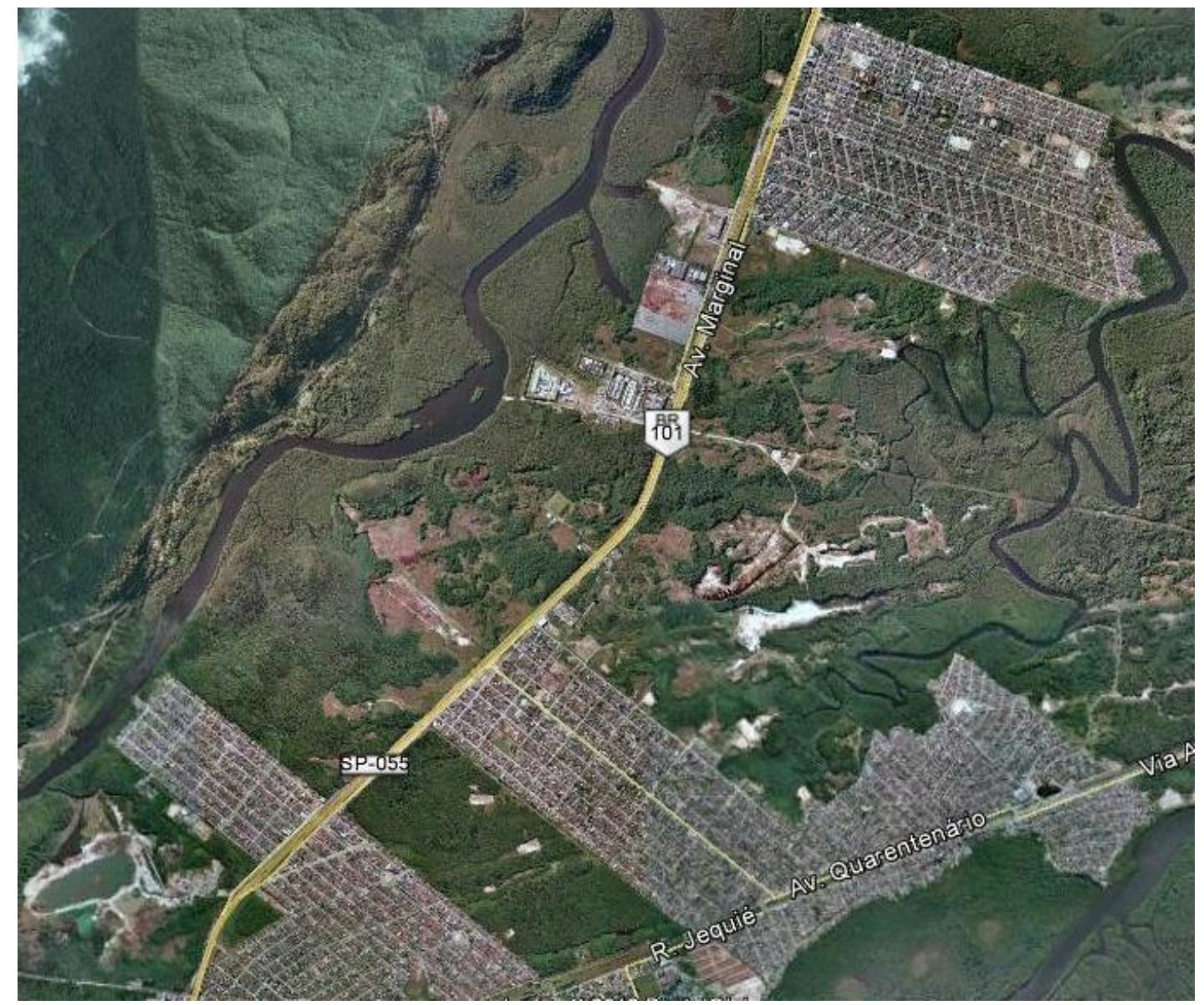

Fonte: Google Earth.Ink

Figura 5: Bairros de São Vicente (área continental).

\subsection{Aspectos Éticos}

O projeto de pesquisa foi aprovado pela Comissão de Ética para Análise de Projetos de Pesquisa (CAPPesq), da Faculdade de Medicina da Universidade de São Paulo, conforme protocolo $n^{0}$ 0262/09 (Anexo C). 


\section{Resultados}

\subsection{FASE 1}

Entre os anos de 2003 e 2007 ocorreram 64.616 nascidos vivos nos quatro municípios estudados, sendo 25.731 (39,8\%) em São Vicente, 24.522 (38,0\%) no Guarujá, 10.093 (15,6\%) em Cubatão e 4.270 (6,6\%) em Bertioga (Tabela 1). A distribuição percentual dos nascidos vivos se manteve constante entre os municípios no período estudado (Figura 6), sem associação entre o município de residência e o ano de ocorrência $(p=0,22)$.

Tabela 1: Nascidos vivos por ano segundo o município de nascimento.

\begin{tabular}{lccccc}
\hline & \multicolumn{5}{c}{ Municípios } \\
\cline { 2 - 5 } & $\begin{array}{c}\text { São } \\
\text { Vicente }\end{array}$ & Guarujá & Cubatão & Bertioga & Total \\
\hline 2003 & 5068 & 4805 & 2051 & 799 & 12723 \\
2004 & 5130 & 4810 & 2021 & 864 & 12825 \\
2005 & 5156 & 4972 & 2088 & 895 & 13111 \\
2006 & 5126 & 4996 & 1997 & 854 & 12973 \\
2007 & 5251 & 4939 & 1936 & 858 & 12984 \\
Total & 25731 & 24522 & 10093 & 4270 & 64616 \\
\hline
\end{tabular}




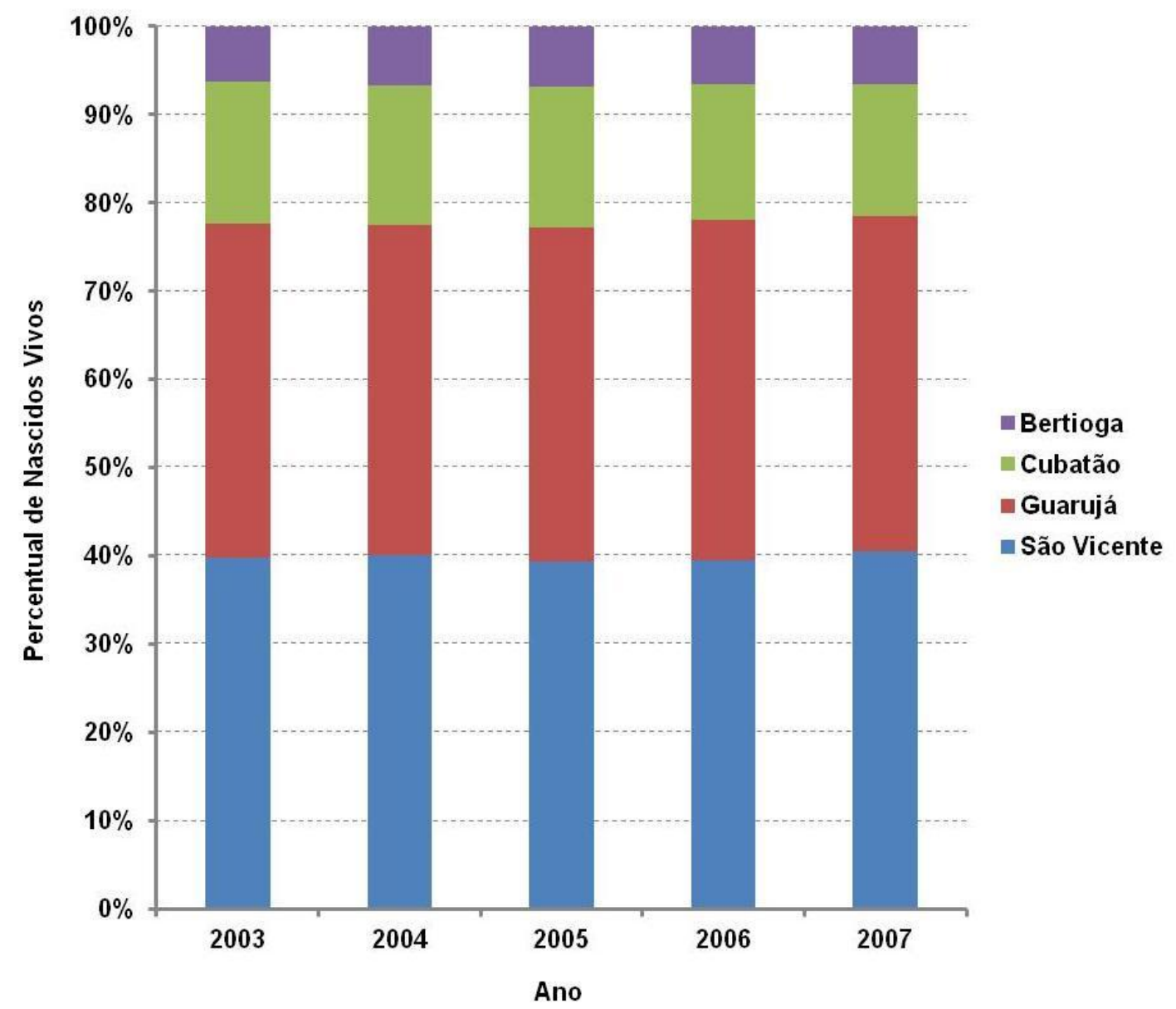

Figura 6: Percentual de nascidos vivos no período entre 2003 e 2007 segundo o município de residência.

A idade mediana das mães foi de 25 anos, exceto em Bertioga (24 anos). Cerca de $70 \%$ das mães tinham idade entre 20 e 34 anos $(71,4 \%$ em São Vicente, 69,4\% em Guarujá, 70,7\% em Cubatão, e 70,2\% em Bertioga), a maioria sendo solteira ou separada $(65,2 \%$ em São Vicente, $63,3 \%$ em Guarujá, 59,9\% em Cubatão, e 72,2\% em Bertioga) e com escolaridade média de 8 a 11 anos de estudo (55,5\% em São Vicente, 43,1\% em Guarujá, 52,0\% em Cubatão, e 46,7\% em Bertioga) (Tabela 2). Houve associação entre a mãe residir em São Vicente e ter entre 20 e 34 anos $(p=0,00)$, ser solteira ou separada $(p=0,00)$ e entre 8 e 11 anos de estudo $(p=0,00)$. 
Tabela 2: Dados demográficos das mães de nascidos vivos no período de 2003 a 2007 segundo os municípios de residência.

\begin{tabular}{|c|c|c|c|c|c|}
\hline & \multicolumn{4}{|c|}{ Municípios } & \multirow[b]{2}{*}{ Total } \\
\hline & $\begin{array}{c}\text { São } \\
\text { Vicente }\end{array}$ & Guarujá & Cubatão & Bertioga & \\
\hline & \multicolumn{5}{|c|}{$\mathrm{N}(\%)$} \\
\hline \multicolumn{6}{|l|}{ Faixa Etária } \\
\hline Até 19 anos & $\begin{array}{l}4554 \\
(17,7)\end{array}$ & $\begin{array}{l}4910 \\
(20,0)\end{array}$ & $\begin{array}{l}1912 \\
(18,9)\end{array}$ & $\begin{array}{c}921 \\
(21,6)\end{array}$ & $\begin{array}{l}12297 \\
(19,0)\end{array}$ \\
\hline $\begin{array}{l}\text { Entre } 20 \text { e } 34 \\
\text { anos }\end{array}$ & $\begin{array}{c}18365 \\
(71,4)\end{array}$ & $\begin{array}{l}17027 \\
(69,4)\end{array}$ & $\begin{array}{l}7131 \\
(70,7)\end{array}$ & $\begin{array}{l}2996 \\
(70,2)\end{array}$ & $\begin{array}{c}45519 \\
(70,4)\end{array}$ \\
\hline $\begin{array}{l}\text { Acima de } 35 \\
\text { anos }\end{array}$ & $\begin{array}{l}2812 \\
(10,9)\end{array}$ & $\begin{array}{l}2585 \\
(10,5)\end{array}$ & $\begin{array}{l}1049 \\
(10,4)\end{array}$ & $\begin{array}{l}352 \\
(8,2)\end{array}$ & $\begin{array}{l}6798 \\
(10,5)\end{array}$ \\
\hline Total & $\begin{array}{l}25731 \\
(100,0)\end{array}$ & $\begin{array}{l}24522 \\
(100,0)\end{array}$ & $\begin{array}{l}10092 \\
(100,0)\end{array}$ & $\begin{array}{c}4269 \\
(100,0)\end{array}$ & $\begin{array}{c}64614 \\
(100,00)\end{array}$ \\
\hline \multicolumn{6}{|l|}{ Estado Civil } \\
\hline $\begin{array}{l}\text { Solteira ou } \\
\text { separada }\end{array}$ & $\begin{array}{c}15796 \\
(65,2)\end{array}$ & $\begin{array}{c}13959 \\
(63,3)\end{array}$ & $\begin{array}{l}5852 \\
(59,9)\end{array}$ & $\begin{array}{l}2860 \\
(72,2)\end{array}$ & $\begin{array}{c}38467 \\
(64,1)\end{array}$ \\
\hline $\begin{array}{l}\text { Casada ou } \\
\text { morando com } \\
\text { companheiro }\end{array}$ & $\begin{array}{l}8341 \\
(34,5)\end{array}$ & $\begin{array}{l}7999 \\
(36,3)\end{array}$ & $\begin{array}{l}3883 \\
(39,8)\end{array}$ & $\begin{array}{l}1089 \\
(27,5)\end{array}$ & $\begin{array}{c}21312 \\
(35,6)\end{array}$ \\
\hline Viúva & $\begin{array}{c}80 \\
(0,3)\end{array}$ & $\begin{array}{c}79 \\
(0,4)\end{array}$ & $\begin{array}{c}28 \\
(0,3)\end{array}$ & $\begin{array}{c}13 \\
(0,3)\end{array}$ & $\begin{array}{l}200 \\
(0,3)\end{array}$ \\
\hline Total & $\begin{array}{l}24.217 \\
(100,0) \\
\end{array}$ & $\begin{array}{l}22037 \\
(100,0) \\
\end{array}$ & $\begin{array}{r}9763 \\
(100,0) \\
\end{array}$ & $\begin{array}{r}3962 \\
(100,0) \\
\end{array}$ & $\begin{array}{l}59979 \\
(100,0) \\
\end{array}$ \\
\hline \multicolumn{6}{|l|}{$\begin{array}{l}\text { Escolaridade } \\
\text { (anos de } \\
\text { estudo) }\end{array}$} \\
\hline Até 3 & $\begin{array}{l}1164 \\
(4,9)\end{array}$ & $\begin{array}{r}2081 \\
(9,0)\end{array}$ & $\begin{array}{l}665 \\
(6,8)\end{array}$ & $\begin{array}{l}321 \\
(8,1)\end{array}$ & $\begin{array}{c}4231 \\
(7,0)\end{array}$ \\
\hline 4 a 7 & $\begin{array}{l}7153 \\
(29,7)\end{array}$ & $\begin{array}{l}7207 \\
(31,1)\end{array}$ & $\begin{array}{l}3223 \\
(33,0)\end{array}$ & $\begin{array}{l}1444 \\
(36,4)\end{array}$ & $\begin{array}{c}19027 \\
(31,2)\end{array}$ \\
\hline 8 a 11 & $\begin{array}{c}13391 \\
(55,5)\end{array}$ & $\begin{array}{l}9982 \\
(43,1)\end{array}$ & $\begin{array}{l}5060 \\
(52,0)\end{array}$ & $\begin{array}{l}1847 \\
(46,7)\end{array}$ & $\begin{array}{c}30280 \\
(49,6)\end{array}$ \\
\hline 12 e mais & $\begin{array}{r}2391 \\
(9,9)\end{array}$ & $\begin{array}{l}3895 \\
(16,8)\end{array}$ & $\begin{array}{l}804 \\
(8,2)\end{array}$ & $\begin{array}{l}350 \\
(8,8)\end{array}$ & $\begin{array}{l}7440 \\
(12,2)\end{array}$ \\
\hline Total & $\begin{array}{l}24099 \\
(100,0)\end{array}$ & $\begin{array}{l}23165 \\
(100,0)\end{array}$ & $\begin{array}{c}9752 \\
(100,0)\end{array}$ & $\begin{array}{c}3962 \\
(100,0)\end{array}$ & $\begin{array}{l}60978 \\
(100,0)\end{array}$ \\
\hline
\end{tabular}


Houve associação entre a mãe residir em São Vicente e o tipo de parto cesáreo $(p=0,00)$. Nos municípios de São Vicente, Guarujá e Cubatão ocorreu um maior percentual de partos cesáreos $(51,2 \%, 50,8 \%$ e $55,0 \%$, respectivamente), em relação a Bertioga (40,9\%). Um elevado número de mães tiveram quatro ou mais consultas pré-natal $(94,0 \%$ em São Vicente, 90,2\% em Guarujá, 94,2\% em Cubatão, e 81,6\% em Bertioga) no período estudado (Tabela 3) e esteve associado com a mãe residir em São Vicente $(p=0,00)$.

Tabela 3: Tipo de parto e número de consultas pré-natal das mães de nascidos vivos no período de 2003 a 2007 segundo os municípios de residência.

\begin{tabular}{lccccc}
\hline & \multicolumn{4}{c}{ Municípios } & \\
\cline { 2 - 4 } & $\begin{array}{c}\text { São } \\
\text { Vicente }\end{array}$ & Guarujá & Cubatão & Bertioga & Total \\
\hline Tipo de Parto & \multicolumn{5}{c}{$\mathrm{N}(\%)$} \\
Vaginal & 12513 & 12047 & 4543 & 2521 & 31624 \\
& $(48,8)$ & $(49,2)$ & $(45,0)$ & $(59,1)$ & $(49,1)$ \\
Cesáreo & 13133 & 12415 & 5543 & 1748 & 32839 \\
& $(51,2)$ & $(50,8)$ & $(55,0)$ & $(40,9)$ & $(50,9)$ \\
Total & 25646 & 24462 & 10086 & 4269 & 64463 \\
& $(100,0)$ & $(100,0)$ & $(100,0)$ & $(100,0)$ & $(100,00)$ \\
\hline Número de & & & & & \\
consultas pré- & & & & & \\
natal & 1523 & 92367 & 580 & 759 & 5229 \\
Até 3 & $(6,0)$ & $(9,8)$ & $(5,8)$ & $(18,4)$ & $(8,2)$ \\
& 23968 & 21933 & 9393 & 3365 & 58659 \\
4 ou mais & $(94,0)$ & $(90,2)$ & $(94,2)$ & $(81,6)$ & $(91,8)$ \\
& 25491 & 24300 & 9973 & 4124 & 63888 \\
Total & $(100,0)$ & $(100,0)$ & $(100,0)$ & $(100,0)$ & $(100,0)$ \\
\hline
\end{tabular}


A taxa bruta de natalidade diminuiu em todos os municípios ao longo do período estudado (de 16,12 para 15,75 em São Vicente; de 17,06 para 15,86 em Guarujá, de 18,05 para 15,75 em Cubatão, e de 22,34 para 18,71 em Bertioga; por 1000 habitantes, em 2003 e em 2007, respectivamente) (Figura 7).

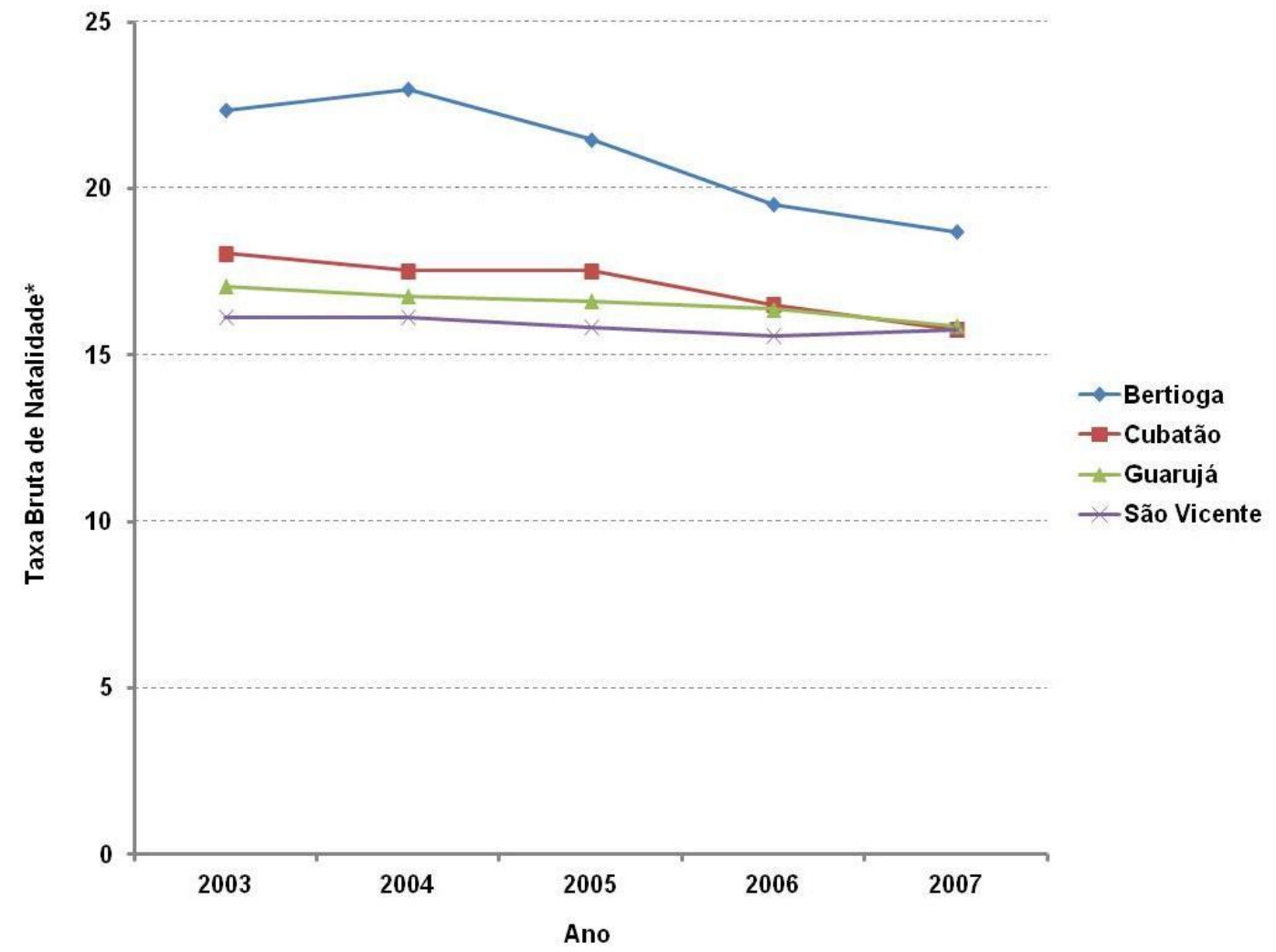

* por 1000 habitantes

Figura 7: Taxa bruta de natalidade no período entre 2003 e 2007 segundo o município de residência materna.

A figura 8 mostra que a taxa de fecundidade total nos municípios entre 2003 e 2007. Houve um declínio mais acentuado em Bertioga, de 2,35 em 2003 para 1,94 em 2007. Em São Vicente, Cubatão e Guarujá as taxas 
se mantiveram semelhantes ao longo dos anos, variando entre 1,73 (2006) a 1,80 (2004 e 2007) em São Vicente, entre 1,74 (2007) e 1,91 (2003) em Cubatão, e 1,75 (2007) a 1,81 (2003) no Guarujá.

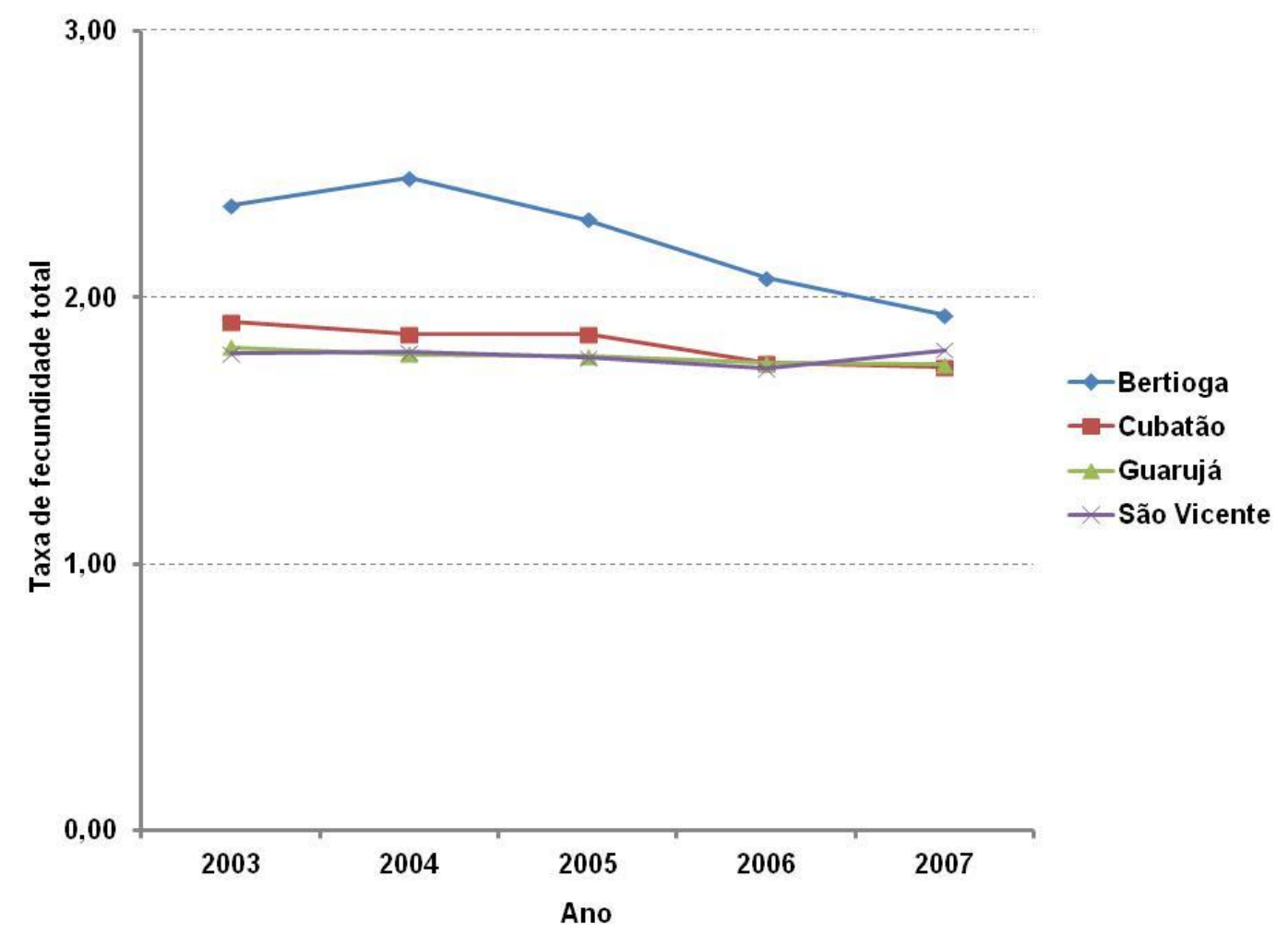

Figura 8: Taxa de fecundidade total no período entre 2003 e 2007 segundo o município de residência materna.

A Tabela 4 mostra a distribuição dos eventos gestacionais no período estudado segundo o município de residência da mãe. O percentual de partos prematuros variou entre 6 e $7 \%$, já nascimentos com peso abaixo de $2.500 \mathrm{~g}$ entre 7 e $9 \%$ e a variação de ocorrência de partos múltiplos foi de 1,5 a 2,3\%, segundo o município de residência. O Guarujá apresentou o maior percentual de malformações congênitas (1,3\%). 
Tabela 4: Distribuição dos eventos gestacionais no período entre 2003 e 2007 segundo o município de residência.

\begin{tabular}{|c|c|c|c|c|c|}
\hline & \multicolumn{4}{|c|}{ Municípios } & \multirow[b]{2}{*}{ Total } \\
\hline & $\begin{array}{c}\text { São } \\
\text { Vicente }\end{array}$ & Guarujá & Cubatão & Bertioga & \\
\hline & \multicolumn{5}{|c|}{$\overline{\mathrm{N}(\%)}$} \\
\hline \multicolumn{6}{|l|}{$\begin{array}{l}\text { Nascimento } \\
\text { prematuro* }\end{array}$} \\
\hline Prematuro & $\begin{array}{c}1752 \\
(7,2)\end{array}$ & $\begin{array}{l}1543 \\
(6,7)\end{array}$ & $\begin{array}{l}741 \\
(7,6)\end{array}$ & $\begin{array}{l}249 \\
(6,2)\end{array}$ & $\begin{array}{c}4285 \\
(7,0)\end{array}$ \\
\hline Termo & $\begin{array}{c}22467 \\
(92,8)\end{array}$ & $\begin{array}{c}21642 \\
(93,3)\end{array}$ & $\begin{array}{l}9022 \\
(92,4)\end{array}$ & $\begin{array}{l}3767 \\
(93,8)\end{array}$ & $\begin{array}{c}56898 \\
(93,0)\end{array}$ \\
\hline Total & $\begin{array}{l}24219 \\
(100,0)\end{array}$ & $\begin{array}{l}23185 \\
(100,0)\end{array}$ & $\begin{array}{c}9763 \\
(100,0)\end{array}$ & $\begin{array}{c}4016 \\
(100,0)\end{array}$ & $\begin{array}{c}61183 \\
(100,00)\end{array}$ \\
\hline \multicolumn{6}{|l|}{$\begin{array}{l}\text { Peso de } \\
\text { nascimento }\end{array}$} \\
\hline Baixo peso** & $\begin{array}{c}2183 \\
(9,1)\end{array}$ & $\begin{array}{c}2135 \\
(9,2)\end{array}$ & $\begin{array}{l}825 \\
(8,3)\end{array}$ & $\begin{array}{l}301 \\
(7,1)\end{array}$ & $\begin{array}{c}5444 \\
(8,9)\end{array}$ \\
\hline Peso normal & $\begin{array}{c}21867 \\
(90,9)\end{array}$ & $\begin{array}{c}21043 \\
(90,8)\end{array}$ & $\begin{array}{l}9078 \\
(91,7)\end{array}$ & $\begin{array}{l}3931 \\
(92,9)\end{array}$ & $\begin{array}{c}55919 \\
(91,1)\end{array}$ \\
\hline Total & $\begin{array}{l}24050 \\
(100,0)\end{array}$ & $\begin{array}{l}23178 \\
(100,0)\end{array}$ & $\begin{array}{c}9903 \\
(100,0)\end{array}$ & $\begin{array}{c}4232 \\
(100,0)\end{array}$ & $\begin{array}{l}61363 \\
(100,0)\end{array}$ \\
\hline \multicolumn{6}{|l|}{$\begin{array}{l}\text { Tipo de } \\
\text { gravidez }\end{array}$} \\
\hline Única & $\begin{array}{c}25118 \\
(97,7)\end{array}$ & $\begin{array}{c}23988 \\
(98,0)\end{array}$ & $\begin{array}{l}9929 \\
(98.5)\end{array}$ & $\begin{array}{l}4180 \\
(98,4)\end{array}$ & $\begin{array}{c}63215 \\
(98,0)\end{array}$ \\
\hline Múltipla & $\begin{array}{l}589 \\
(2,3)\end{array}$ & $\begin{array}{l}489 \\
(2,0)\end{array}$ & $\begin{array}{c}152 \\
(1,5)\end{array}$ & $\begin{array}{c}70 \\
(1,6)\end{array}$ & $\begin{array}{c}1300 \\
(2,0)\end{array}$ \\
\hline Total & $\begin{array}{l}25707 \\
(100,0)\end{array}$ & $\begin{array}{l}24477 \\
(100,0)\end{array}$ & $\begin{array}{l}10081 \\
(100,0)\end{array}$ & $\begin{array}{c}4250 \\
(100,0)\end{array}$ & $\begin{array}{l}64515 \\
(100,0)\end{array}$ \\
\hline \multicolumn{6}{|l|}{$\begin{array}{l}\text { Malformação } \\
\text { congênita }\end{array}$} \\
\hline Sim & $\begin{array}{c}191 \\
(0,8)\end{array}$ & $\begin{array}{c}90 \\
(1,3)\end{array}$ & $\begin{array}{c}98 \\
(1,0)\end{array}$ & $\begin{array}{c}29 \\
(0,8)\end{array}$ & $\begin{array}{l}408 \\
(0,9)\end{array}$ \\
\hline Não & $\begin{array}{c}24610 \\
(99,2)\end{array}$ & $\begin{array}{l}6828 \\
(98,7)\end{array}$ & $\begin{array}{l}9716 \\
(99,0)\end{array}$ & $\begin{array}{l}3831 \\
(99,2)\end{array}$ & $\begin{array}{c}44985 \\
(99,1)\end{array}$ \\
\hline Total & $\begin{array}{l}24801 \\
(100,0)\end{array}$ & $\begin{array}{c}6918 \\
(100,0)\end{array}$ & $\begin{array}{c}9814 \\
(100,0)\end{array}$ & $\begin{array}{c}3860 \\
(100,0)\end{array}$ & $\begin{array}{l}45393 \\
(100,0)\end{array}$ \\
\hline
\end{tabular}

* Nascimento prematuro: idade gestacional de até 36 semanas;

** Baixo peso: peso de nascimento inferior a $2.500 \mathrm{~g}$ 
Houve um aumento estatisticamente significativo $(p<0,05)$ entre 0 risco de ocorrência de baixo peso de nascimento, parto prematuro e presença de malformações congênitas nos municípios de São Vicente, Cubatão e Guarujá comparados com o município de Bertioga (Tabela 5).

Tabela 5: Odds ratio ajustado dos eventos gestacionais segundo o município de residência da mãe no período de 2003 a 2007.

\begin{tabular}{|c|c|c|c|}
\hline & OR & IC 95\% & Valor de $p$ \\
\hline \multicolumn{4}{|c|}{$\begin{array}{l}\text { Baixo peso de nascimento } \\
(<2.500 \mathrm{~g})^{\star}\end{array}$} \\
\hline São Vicente & 2,25 & $1,93-2,62$ & 0,00 \\
\hline Guarujá & 2,14 & $1,80-2,56$ & 0,00 \\
\hline Cubatão & 2,06 & $1,75-2,43$ & 0,00 \\
\hline \multicolumn{4}{|c|}{$\begin{array}{l}\text { Controlado por: idade, estado civil e escolaridade da mãe, número de } \\
\text { consultas pré-natal, e malformações congênitas. }\end{array}$} \\
\hline \multicolumn{4}{|c|}{ Parto prematuro ( $\leq 36$ semanas) } \\
\hline São Vicente & 2,24 & $1,89-2,65$ & 0,00 \\
\hline Guarujá & 2,31 & $1,91-2,80$ & 0,00 \\
\hline Cubatão & 2,51 & $2,09-3,00$ & 0,00 \\
\hline \multicolumn{4}{|c|}{$\begin{array}{l}\text { Controlado por: idade, estado civil e escolaridade da mãe, número de } \\
\text { consultas pré-natal, e malformações congênitas. }\end{array}$} \\
\hline \multicolumn{4}{|c|}{$\begin{array}{l}\text { Presença de malformação } \\
\text { congênita* }\end{array}$} \\
\hline São Vicente & 1,30 & $-1,97$ & 0,21 \\
\hline Guart & 2,24 & $-3,50$ & 0,00 \\
\hline Cubatão & 1,62 & $1,04-2,52$ & 0,03 \\
\hline \multicolumn{4}{|c|}{$\begin{array}{l}\text { Controlado por: idade e estado civil da mãe, número de consultas pré- } \\
\text { natal, e nascimento múltiplo. }\end{array}$} \\
\hline
\end{tabular}

Pela regressão logística bivariada houve uma redução estatisticamente significativa na ocorrência de nascimentos múltiplos em São Vicente $(O R=0,71 ; I C 95 \% 0,55-0,91 ; p=0,00)$ quando comparado a 
Bertioga. Os outros dois municípios não foram associados significativamente com a ocorrência de nascimentos múltiplos, Guarujá apresentou uma redução na ocorrência de nascimentos múltiplos $(\mathrm{OR}=0,82$; IC95\% 0,63$1,05 ; p=0,12)$ e Cubatão um aumento $(O R=1,09 ; \operatorname{IC} 95 \%$ 0,82 - 1,45; $\mathrm{p}=0,53$ ), comparados com Bertioga. A regressão logística múltipla não mostrou resultados significativos entre nascimentos múltiplos e o município de residência materna.

\subsection{FASE 2}

Do número previsto de domicílios entrevistados (4.100 nas cinco áreas) houve perda das informações de 180 domicílios (cerca de 8\%). Dos 3.920 domicílios entrevistados nas cinco áreas moravam 4.296 mulheres em idade fértil, 788 na área 1, 883 na área 2, 868 na área 3, 837 na área 4, e 920 na área 5 (Figura 9). 


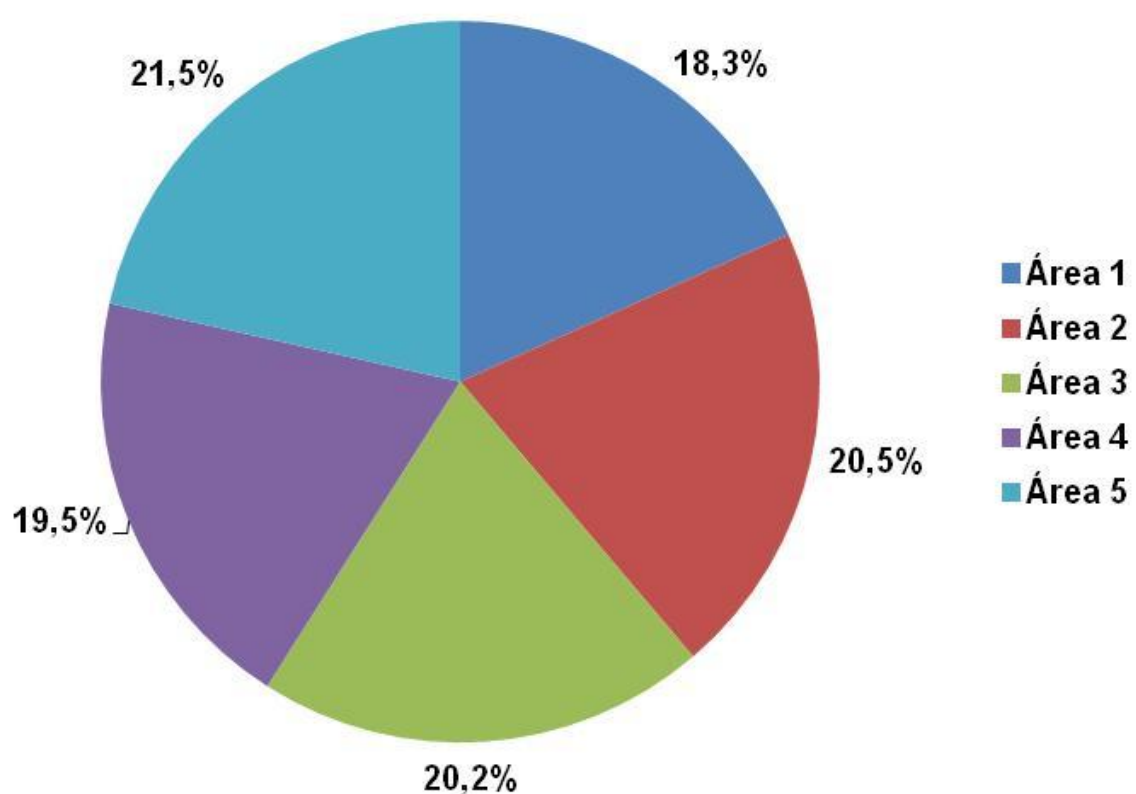

Figura 9: Distribuição percentual das mulheres em idade fértil segundo a área.

Mais de $70 \%$ das mulheres em idade fértil entrevistadas moravam na mesma região há cinco anos ou mais (86,9\% na área 1, 92,5\% na área 2 , 88,6\% na área 3, 91,8\% na área 4, e 76,7\% na área 5), com associação estatisticamente significativa entre morar na área 2 e morar na mesma região por 5 anos ou mais $(p=0,00)$ (Figura 10$)$. 


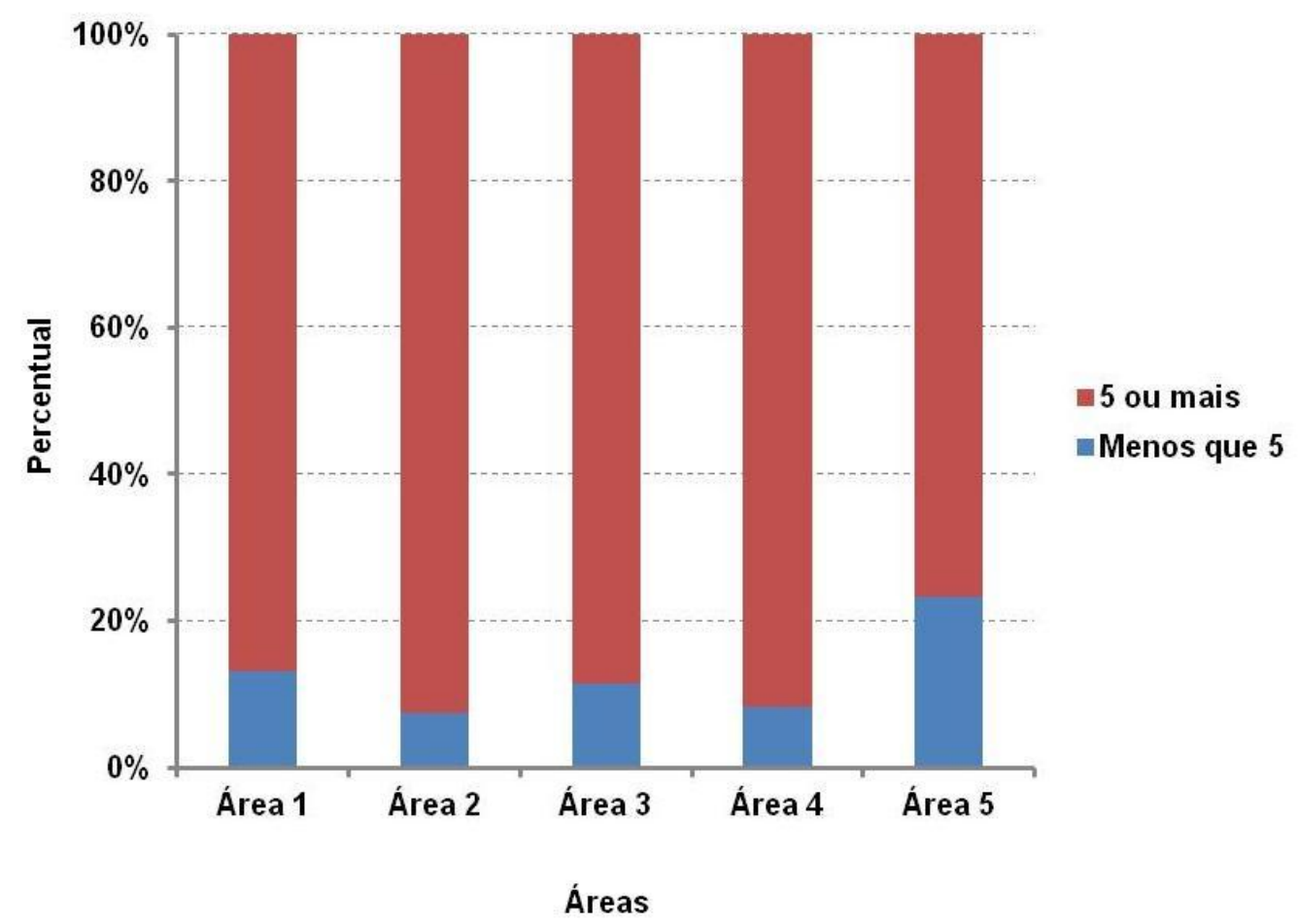

Figura 10: Percentual de mulheres em idade fértil segundo o tempo de moradia na região.

Um grande percentual de mulheres em idade fértil moram na mesma região por pelo menos cinco anos, $86,9 \%$ na área 1, 92,5\% na área 2, 88,6\% na área 3, 91,8\% na área 4, e 76,7\% na área 5. Mesmo assim, houve associação significativa $(p=0,00)$ entre morar na área 2 e morar na região por mais de cinco anos (Tabela 6).

Todas as áreas apresentaram altos percentuais de domicílios de alvenaria, com associação significativa entre morar em um domicílio de alvenaria e a área $5(\mathrm{p}=0,00)$. Na área 1 e na área 5 (controle) mesmo ocorrendo uma predominância de casas de alvenaria, observa-se um maior percentual de casas de não-alvenaria quando comparado com as demais áreas (Tabela 6). 
Houve associação significativa entre morar na área 1 e não ter um sistema de esgoto adequado $(p=0,00)$. A maioria dos domicílios entrevistados $(58,1 \%)$ não tem um sistema de esgotamento sanitário adequado (Tabela 6).

Conforme a tabela 6 , exceto pela área $1(47,2 \%)$, as demais áreas apresentam um percentual grande de domicílios com coleta de lixo $(94,7 \%$ na área 2, 99,0\% na área 3, 81,6\% na área 4, e 95,9\% na área 5. Houve associação significativa $(p=0,00)$ entre residir na área 5 e ter coleta de lixo.

Tabela 6: Características dos domicílios das mulheres em idade fértil segundo a área.

\begin{tabular}{|c|c|c|c|c|c|c|}
\hline & \multicolumn{5}{|c|}{ Áreas* } & \multirow[b]{2}{*}{ Total } \\
\hline & Área 1 & Área 2 & Área 3 & Área 4 & Área 5 & \\
\hline & & & & $\mathrm{N}(\%)$ & & \\
\hline \multicolumn{7}{|l|}{$\begin{array}{l}\text { Tempo de } \\
\text { residência na } \\
\text { região }\end{array}$} \\
\hline $\begin{array}{l}\text { Menos de cinco } \\
\text { anos }\end{array}$ & $\begin{array}{c}103 \\
(13,1)\end{array}$ & $\begin{array}{c}66 \\
(7,5)\end{array}$ & $\begin{array}{c}99 \\
(11,4)\end{array}$ & $\begin{array}{c}68 \\
(8,2)\end{array}$ & $\begin{array}{c}211 \\
(23,3)\end{array}$ & $\begin{array}{c}547 \\
(12,8)\end{array}$ \\
\hline $\begin{array}{l}\text { Cinco ou mais } \\
\text { anos }\end{array}$ & $\begin{array}{c}683 \\
(86,9)\end{array}$ & $\begin{array}{c}815 \\
(92,5)\end{array}$ & $\begin{array}{c}767 \\
(88,6)\end{array}$ & $\begin{array}{c}763 \\
(91,8)\end{array}$ & $\begin{array}{c}696 \\
(76,7)\end{array}$ & $\begin{array}{l}3724 \\
(87,2)\end{array}$ \\
\hline Total & $\begin{array}{c}786 \\
(100,0)\end{array}$ & $\begin{array}{c}881 \\
(100,0)\end{array}$ & $\begin{array}{c}866 \\
(100,0)\end{array}$ & $\begin{array}{c}831 \\
(100,0)\end{array}$ & $\begin{array}{c}907 \\
(100,0)\end{array}$ & $\begin{array}{c}4271 \\
(100,0)\end{array}$ \\
\hline \multicolumn{7}{|l|}{$\begin{array}{l}\text { Tipo de } \\
\text { moradia }\end{array}$} \\
\hline Alvenaria & $\begin{array}{c}563 \\
(71,9)\end{array}$ & $\begin{array}{c}820 \\
(93,8)\end{array}$ & $\begin{array}{c}826 \\
(96,3)\end{array}$ & $\begin{array}{c}678 \\
(81,2)\end{array}$ & $\begin{array}{c}828 \\
(92,0)\end{array}$ & $\begin{array}{l}3715 \\
(87,4)\end{array}$ \\
\hline Não-alvenaria** & $\begin{array}{c}220 \\
(28,1)\end{array}$ & $\begin{array}{c}54 \\
(6,2)\end{array}$ & $\begin{array}{c}32 \\
(3,7)\end{array}$ & $\begin{array}{c}157 \\
(18,8)\end{array}$ & $\begin{array}{c}72 \\
(8,0)\end{array}$ & $\begin{array}{c}535 \\
(12,6)\end{array}$ \\
\hline Total & $\begin{array}{c}783 \\
(100,0)\end{array}$ & $\begin{array}{c}874 \\
(100,0)\end{array}$ & $\begin{array}{c}858 \\
(100,0)\end{array}$ & $\begin{array}{c}835 \\
(100,0)\end{array}$ & $\begin{array}{c}900 \\
(100,0)\end{array}$ & $\begin{array}{c}4250 \\
(100,0)\end{array}$ \\
\hline
\end{tabular}


conclusão Tabela 6: Características dos domicílios das mulheres em
idade fértil segundo a área.

Areas*

\begin{tabular}{lcccccc}
\hline & \multicolumn{5}{c}{ Áreas $^{*}$} \\
\cline { 2 - 5 } & Área 1 & Área 2 & Área 3 & Área 4 & Área 5 & Total \\
\hline Esgoto & \multicolumn{7}{c}{${ }^{* \star}$} & & & & & \\
Adequado & 28 & 614 & 496 & 337 & 264 & 1739 \\
& $(3,7)$ & $(71,4)$ & $(59,8)$ & $(41,6)$ & $(29,7)$ & $(41,9)$ \\
Inadequado & 734 & 246 & 333 & 473 & 624 & 2410 \\
& $(96,3)$ & $(28,6)$ & $(40,2)$ & $(58,4)$ & $(70,3)$ & $(58,1)$ \\
Total & 762 & 860 & 829 & 810 & 888 & 4149 \\
& $(100,0)$ & $(100,0)$ & $(100,0)$ & $(100,0)$ & $(100,0)$ & $(100,0)$ \\
\hline Lixo & & & & & & \\
Coleta & 369 & 834 & 853 & 680 & 882 & 3618 \\
& $(47,2)$ & $(94,7)$ & $(99,0)$ & $(81,6)$ & $(95,9)$ & $(84,6)$ \\
Sem coleta & 413 & 47 & 9 & 153 & 38 & 660 \\
& $(52,8)$ & $(5,3)$ & $(1,0)$ & $(18,4)$ & $(4,1)$ & $(15,4)$ \\
& 782 & 881 & 862 & 833 & 920 & 4278 \\
& $(100,0)$ & $(100,0)$ & $(100,0)$ & $(100,0)$ & $(100,0)$ & $(100,0)$ \\
\hline
\end{tabular}

* Área 1 a 4, áreas contaminadas; Área 5, área controle; ** Não-alvenaria: palafitas, madeira, e/ou outros materiais; ${ }^{* * *}$ Esgoto: adequado - ligado a rede coletora de esgoto; inadequado - não está ligado a rede coletora de esgoto (céu aberto, solo, encanado, e outros).

Em todas as áreas houve um predomínio na origem principal da água utilizada proveniente da Companhia de Saneamento Básico do Estado de São Paulo (SABESP) (variando de $88,5 \%$ na área 1, até 100,0\% na área 3). A iluminação elétrica e o uso de fogão a gás ocorreu em de $99,7 \%$ nos domicílios das mulheres em idade fértil.

A média de idade das mulheres em idade fértil foi de 29 anos na área 1 e 5 , e de 30 anos nas demais áreas. Não houve associação entre a faixa etária e o local de residência $(p=0,11)$ (Tabela 7$)$. 
A maioria das mulheres em idade fértil tem ensino fundamental e médio em todas as áreas, com distribuição diferente entre elas. Na área 2, 3 e $4(51,0 \%, 51,5 \%$ e $46,3 \%$, respectivamente) tiveram mais mulheres com ensino médio que na área 1 e 5 (33,4\% e 42,3\%,respectivamente). A área 1 mostrou um maior percentual de mulheres na categoria analfabeta funcional (7,6\%)que as outras áreas (2,7\% na área 2, 3,2\% na área 3, 3,8\% na área 4, e 4,9\% na área 5). Também, a área 1 mostrou o menor percentual de mulheres com nível universitário de escolaridade $(1,2 \%)$, comparado com as outras áreas (9,3\% na área 2, 5,0\% na área 3, 5,4\% na área 4, e 4,3\% na área 5). Uma associação estatisticamente significante foi encontrada entre residir na área 1 e ter nível fundamental de educação $(p=0,00)$ (Tabela 7).

Mesmo com mais da metade das mulheres sendo casadas ou morando com o companheiro em todas as áreas (63,9\% na área 1, 51,7\% na área 2, 53,2\% na área 3, 52,7\% na área 4, e 57,3\% na área 5), um grande percentual de mulheres em idade fértil são solteiras ou divorciadas $(34,7 \%$ na área 1, 45,5\% na área 2, 45,0\% na área 3, 46,1\% na área 4, e 41,6\% na área 5). Menos de $2 \%$ das mulheres em idade fértil era viúva em todas as áreas. Associação entre viver na área 5 e ser casada foi estatisticamente significante $(p=0,00)$ (Tabela 7$)$.

Associação estatisticamente significantes entre residir na área 1 e ter renda familiar de três ou menos salários mínimos foi encontrada $(p=0,00)$. A maioria das mulheres em idade fértil tiveram renda familiar de três ou menos salários mínimos em todas as áreas $(86,2 \%$ na área $1,53,6 \%$ na área 2 , $57,9 \%$ na área 3, 71,2\% na área 4, e 65,2\% na área 5), mas foi observado 
que a área 1 apresenta um percentual de renda familiar menor que as demais áreas (Tabela 7).

Tabela 7: Características sociodemográficas das mulheres em idade fértil segundo a área estudada.

\begin{tabular}{|c|c|c|c|c|c|c|}
\hline & \multicolumn{5}{|c|}{ Areas* } & \multirow[b]{2}{*}{ Total } \\
\hline & Área 1 & Área 2 & Área 3 & Área 4 & Área 5 & \\
\hline & \multicolumn{6}{|c|}{$\mathrm{N}(\%)$} \\
\hline \multicolumn{7}{|l|}{ Faixa etária } \\
\hline 15 a 20 anos & $\begin{array}{c}134 \\
(17,0)\end{array}$ & $\begin{array}{c}147 \\
(16,6)\end{array}$ & $\begin{array}{c}150 \\
(17,3)\end{array}$ & $\begin{array}{c}142 \\
(17,0)\end{array}$ & $\begin{array}{c}161 \\
(17,5)\end{array}$ & $\begin{array}{c}734 \\
(100,0)\end{array}$ \\
\hline 21 a 30 anos & $\begin{array}{c}261 \\
(33,1)\end{array}$ & $\begin{array}{c}279 \\
(31,6)\end{array}$ & $\begin{array}{c}278 \\
(32,0)\end{array}$ & $\begin{array}{c}279 \\
(33,3)\end{array}$ & $\begin{array}{c}331 \\
(36,0)\end{array}$ & $\begin{array}{l}1428 \\
(33,2)\end{array}$ \\
\hline 31 a 40 anos & $\begin{array}{c}241 \\
(30,6)\end{array}$ & $\begin{array}{c}234 \\
(26,5)\end{array}$ & $\begin{array}{c}231 \\
(26,6)\end{array}$ & $\begin{array}{c}220 \\
(26,3)\end{array}$ & $\begin{array}{c}245 \\
(26,6)\end{array}$ & $\begin{array}{l}1171 \\
(27,3)\end{array}$ \\
\hline 41 a 49 anos & $\begin{array}{c}152 \\
(19,3)\end{array}$ & $\begin{array}{c}223 \\
(25,3)\end{array}$ & $\begin{array}{c}209 \\
(24,1)\end{array}$ & $\begin{array}{c}196 \\
(23,4)\end{array}$ & $\begin{array}{c}183 \\
(19,9)\end{array}$ & $\begin{array}{c}963 \\
(22,4)\end{array}$ \\
\hline Total & $\begin{array}{c}788 \\
(100,0)\end{array}$ & $\begin{array}{c}883 \\
(100,0)\end{array}$ & $\begin{array}{c}868 \\
(100,0)\end{array}$ & $\begin{array}{c}837 \\
(100,0)\end{array}$ & $\begin{array}{c}920 \\
(100,0)\end{array}$ & $\begin{array}{c}4296 \\
(100,0)\end{array}$ \\
\hline \multicolumn{7}{|l|}{ Educação } \\
\hline $\begin{array}{l}\text { Analfabeta } \\
\text { funcional }\end{array}$ & $\begin{array}{c}59 \\
(7,6)\end{array}$ & $\begin{array}{c}23 \\
(2,7)\end{array}$ & $\begin{array}{c}27 \\
(3,2)\end{array}$ & $\begin{array}{c}31 \\
(3,8)\end{array}$ & $\begin{array}{c}44 \\
(4,9)\end{array}$ & $\begin{array}{c}184 \\
(4,4)\end{array}$ \\
\hline $\begin{array}{l}\text { Ensino } \\
\text { fundamental }\end{array}$ & $\begin{array}{c}451 \\
(57,9)\end{array}$ & $\begin{array}{c}319 \\
(36,8)\end{array}$ & $\begin{array}{c}345 \\
(40,4)\end{array}$ & $\begin{array}{c}363 \\
(44,5)\end{array}$ & $\begin{array}{c}434 \\
(48,5)\end{array}$ & $\begin{array}{r}1912 \\
(45,4)\end{array}$ \\
\hline Ensino médio & $\begin{array}{c}260 \\
(33,4)\end{array}$ & $\begin{array}{c}442 \\
(51,0)\end{array}$ & $\begin{array}{c}440 \\
(51,5)\end{array}$ & $\begin{array}{c}378 \\
(46,3)\end{array}$ & $\begin{array}{c}378 \\
(42,3)\end{array}$ & $\begin{array}{l}1898 \\
(45,1)\end{array}$ \\
\hline $\begin{array}{l}\text { Ensino } \\
\text { universitário }\end{array}$ & $\begin{array}{c}9 \\
(1,2)\end{array}$ & $\begin{array}{c}83 \\
(9,3)\end{array}$ & $\begin{array}{c}43 \\
(5,0)\end{array}$ & $\begin{array}{c}44 \\
(5,4)\end{array}$ & $\begin{array}{c}38 \\
(4,3)\end{array}$ & $\begin{array}{l}217 \\
(5,2)\end{array}$ \\
\hline Total & $\begin{array}{c}779 \\
(100,0)\end{array}$ & $\begin{array}{c}867 \\
(100,0)\end{array}$ & $\begin{array}{c}855 \\
(100,0)\end{array}$ & $\begin{array}{c}816 \\
(100,0)\end{array}$ & $\begin{array}{c}894 \\
(100,0)\end{array}$ & $\begin{array}{c}4211 \\
(100,0)\end{array}$ \\
\hline
\end{tabular}


conclusão Tabela 7: Características sociodemográficas das mulheres em idade fértil segundo a área estudada.

\begin{tabular}{|c|c|c|c|c|c|c|}
\hline & \multicolumn{5}{|c|}{ Areas* } & \multirow[b]{2}{*}{ Total } \\
\hline & Área 1 & Área 2 & Área 3 & Área 4 & Área 5 & \\
\hline & \multicolumn{6}{|c|}{$\mathrm{N}(\%)$} \\
\hline \multicolumn{7}{|l|}{ Estado civil } \\
\hline $\begin{array}{l}\text { Casada/Morand } \\
\text { o com } \\
\text { companheiro }\end{array}$ & $\begin{array}{c}500 \\
(63,9)\end{array}$ & $\begin{array}{c}455 \\
(51,7)\end{array}$ & $\begin{array}{c}461 \\
(53,2)\end{array}$ & $\begin{array}{c}439 \\
(52,7)\end{array}$ & $\begin{array}{c}525 \\
(57,3)\end{array}$ & $\begin{array}{l}2380 \\
(55,6)\end{array}$ \\
\hline $\begin{array}{l}\text { Solteira/ } \\
\text { Divorciada }\end{array}$ & $\begin{array}{c}272 \\
(34,7)\end{array}$ & $\begin{array}{c}400 \\
(45,5)\end{array}$ & $\begin{array}{c}390 \\
(45,0)\end{array}$ & $\begin{array}{c}384 \\
(46,1)\end{array}$ & $\begin{array}{c}381 \\
(41,6)\end{array}$ & $\begin{array}{l}1827 \\
(42,7)\end{array}$ \\
\hline Viúva & $\begin{array}{c}11 \\
(1,4)\end{array}$ & $\begin{array}{c}25 \\
(2,8)\end{array}$ & $\begin{array}{c}16 \\
(1,8)\end{array}$ & $\begin{array}{c}10 \\
(1,2)\end{array}$ & $\begin{array}{c}10 \\
(1,1)\end{array}$ & $\begin{array}{c}72 \\
(1,7)\end{array}$ \\
\hline Total & $\begin{array}{c}783 \\
(100,0)\end{array}$ & $\begin{array}{c}880 \\
(100,0)\end{array}$ & $\begin{array}{c}867 \\
(100,0)\end{array}$ & $\begin{array}{c}833 \\
(100,0)\end{array}$ & $\begin{array}{c}916 \\
(100,0)\end{array}$ & $\begin{array}{r}4279 \\
(100,0)\end{array}$ \\
\hline \multicolumn{7}{|l|}{$\begin{array}{l}\text { Renda familiar } \\
\text { (salário } \\
\text { mínimo) }\end{array}$} \\
\hline Três ou menos & $\begin{array}{c}638 \\
(86,2)\end{array}$ & $\begin{array}{c}443 \\
(53,6)\end{array}$ & $\begin{array}{c}448 \\
(57,0)\end{array}$ & $\begin{array}{c}552 \\
(71,2)\end{array}$ & $\begin{array}{c}553 \\
(65,2)\end{array}$ & $\begin{array}{l}2634 \\
(66,4)\end{array}$ \\
\hline Mais de três & $\begin{array}{c}102 \\
(13,8)\end{array}$ & $\begin{array}{c}384 \\
(46,4)\end{array}$ & $\begin{array}{c}326 \\
(42,1)\end{array}$ & $\begin{array}{c}223 \\
(28,8)\end{array}$ & $\begin{array}{c}295 \\
(34,8)\end{array}$ & $\begin{array}{l}1330 \\
(33,6)\end{array}$ \\
\hline Total & $\begin{array}{c}740 \\
(100,0)\end{array}$ & $\begin{array}{c}827 \\
(100,0)\end{array}$ & $\begin{array}{c}774 \\
(100,0)\end{array}$ & $\begin{array}{c}775 \\
(100,0)\end{array}$ & $\begin{array}{c}848 \\
(100,0)\end{array}$ & $\begin{array}{c}3964 \\
(100,0)\end{array}$ \\
\hline
\end{tabular}

* Área 1 a 4, áreas contaminadas; Área 5, área controle.

A maioria das mulheres em idade fértil não teve contato com produtos químicos e poeiras no trabalho $(94,5 \%$ na área $1,94,6 \%$ na área $2,92,6 \%$ ma área $3,97,7 \%$ na área 4 , e 93,5\% na área 5$)$. A associação $(p=0,00)$ foi encontrada entre morar na área 4 e não ter contato com produtos químicos e poeiras. Em relação à exposição ocupacional anterior, um grande percentual de não contato foi mantido $(94,5 \%$ na área $1,96,0 \%$ na área 2, 94,7\% na 
área 3, 96,3\% na área 4, e 94,4\% na área 5), mas não foi encontrada associação $(p=0,50)$ (Tabela 8)

Associação estatística significativa $(p=0,00)$ entre morar na área 2 e não fumar foi encontrada. A maioria das mulheres não fuma em todas as áreas $(73,0 \%$ na área $1,80,8 \%$ na área 2, 80,7\% na área 3, 76,6\% na área 4, e 75,8\% na área 5). Um percentual ainda maior de mulheres também não tinham histórico tabagista $(81,6 \%$ na área $1,87,9 \%$ na área $2,85,7 \%$ na área 3, 92,5\% na área 4 , e $80,7 \%$ na área 5), contudo houve associação estatisticamente significativa $(p=0,00)$ entre morar na área 4 e ter sido fumante (Tabela 8).

A maioria das mulheres em idade fértil não bebia em todas as áreas (77,3\% na área $1,84,8 \%$ na área $2,75,5 \%$ na área $3,79,7 \%$ na área 4 , e 75,8\% na área 5). Associação estatisticamente significativa entre morar na área 2 e não consumir bebida alcoolica foi encontrada $(p=0,00)$ Um percentual ainda maior de mulheres em idade fértil alegou não ter consumido álcool no passado $(90,4,5 \%$ na área $1,97,9 \%$ na área $2,97,0 \%$ na área 3, 97,3\% na área 4, e 93,8\% na área 5). Associação estatisticamente significativa $(p=0,00)$ entre morar na área 2 e beber no passado foi encontrada (Tabela 8$)$. 
Tabela 8: Hábitos das mulheres em idade fértil segundo a área analisada.

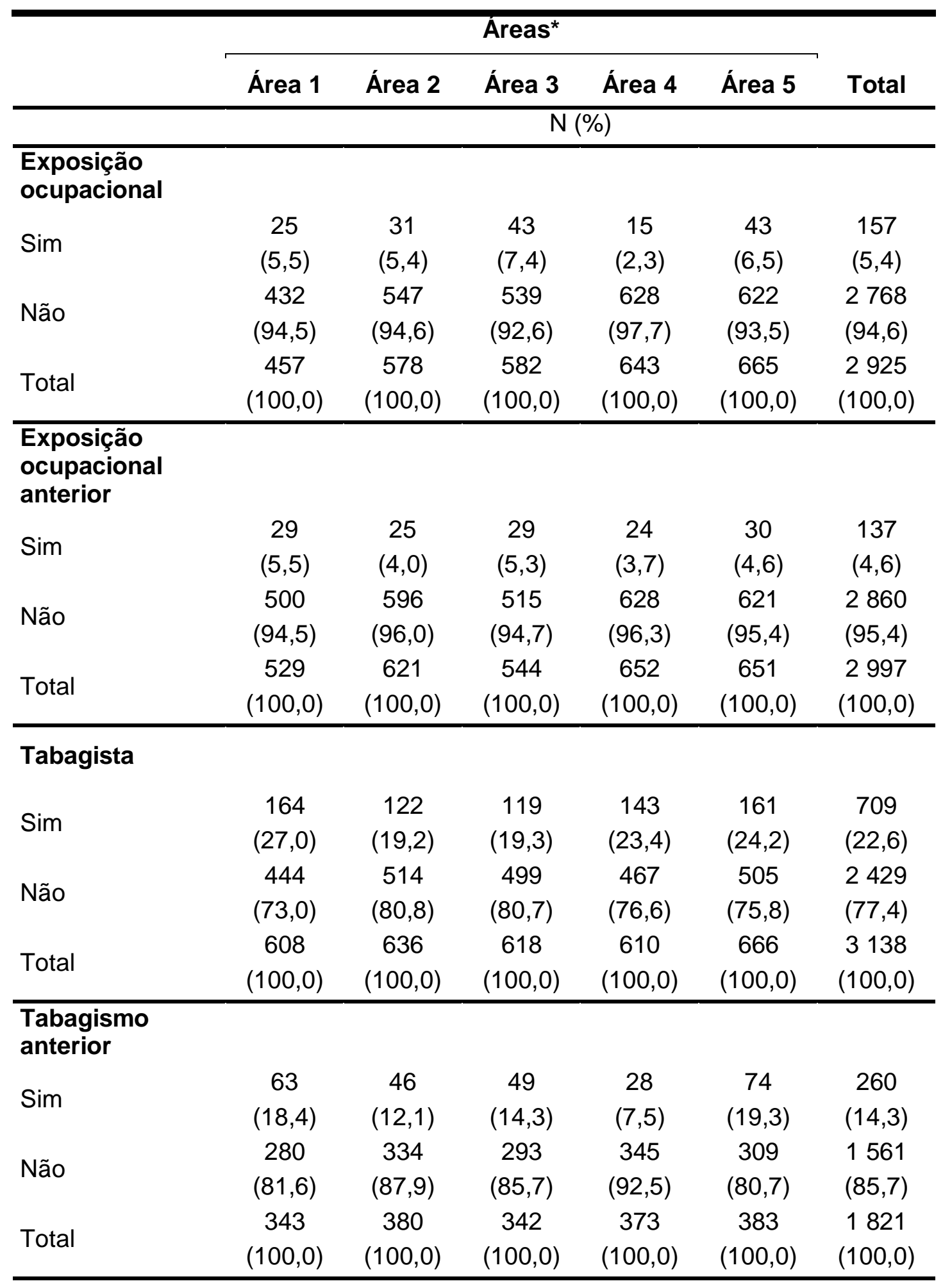


conclusão Tabela 8: Hábitos das mulheres em idade fértil segundo a área analisada.

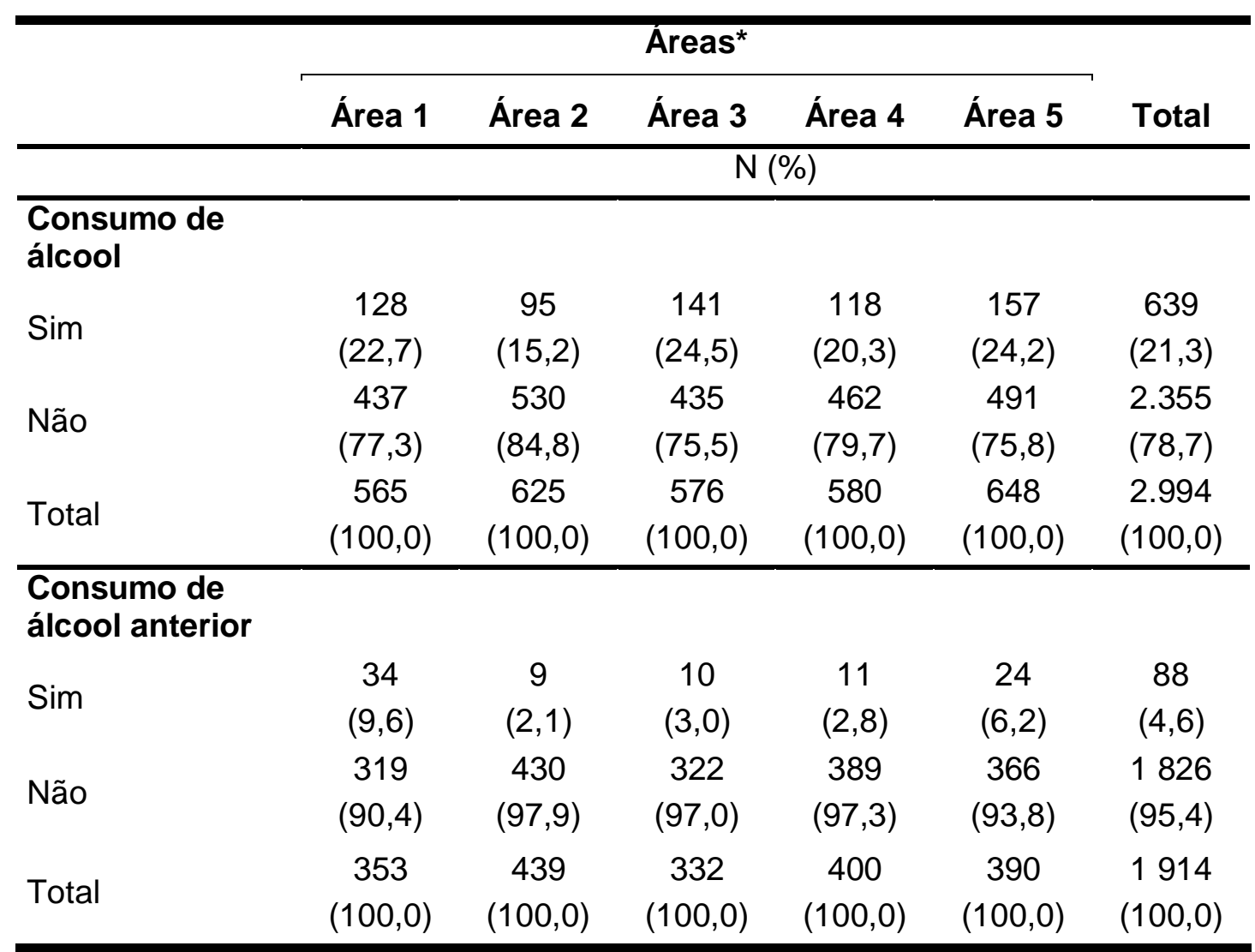

* Área 1 a 4, áreas contaminadas; Área 5, área controle.

Nos últimos cinco anos, 1.362 mulheres em idade fértil engravidaram em todas as áreas (314 na área 1, 230 na área 2, 247 na área 3, 245 na área 4, e 326 na área 5). Associação estatisticamente significativa $(p=0,00)$ entre morar na área 2 e não ter engravidado foi encontrada (Tabela 9).

Nenhuma associação entre viver em qualquer das áreas e atendimento pré-natal foi encontrada $(p=0,21)$. Quase todas as grávidas realizaram ao menos um atendimento Pré-natal em todas as áreas $(96,7 \%$ 
na área 1, 99,1\% na área 2, 96,3\% na área 3, 97,1\% na área 4, e 95,7\% na área 5) (Tabela 9).

Tabela 9: Mulheres grávidas e atendimento pré-natal nos últimos cinco anos segundo a área analisada.

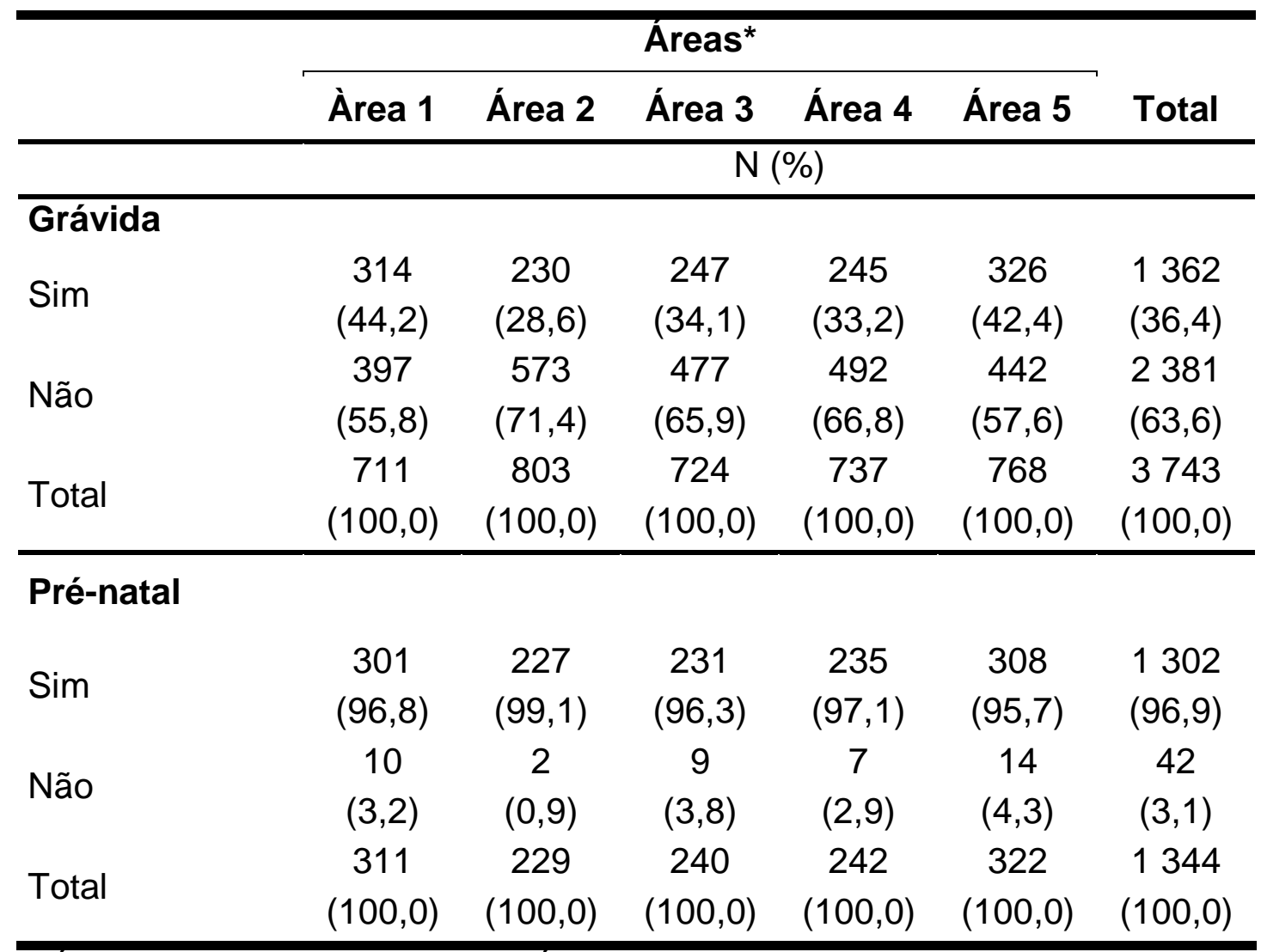

* Área 1 a 4, áreas contaminadas; Área 5, área controle.

A prevalência de nascimento múltiplo foi de 1,9\% na área $1,4,4 \%$ na área 2, 3,0\% na área 3, 2,1\% na área 4 e 1,9\% na área controle (Tabela 10). Em relação aos desfechos adversos da gestação, a prevalência de aborto foi maior nas áreas contaminadas $(14,1 \%$ na área $1,14,3 \%$ na área $2,19,7 \%$ na área 3 e 15,1\% na área 4) em comparação com a área controle (13,6\% 
na área 5). Os partos prematuros foram menos frequentes na área 4 (3,8\%), mas nas demais áreas contaminadas $(9,2 \%$ na área $1,8,3 \%$ na área 2 e $8,1 \%$ na área 3$)$ foi maior que o encontrado na área controle $(6,5 \%$ na área 5). A prevalência de nascimentos com baixo peso foi menor na área controle (3,9\% na área 5) que nas áreas contaminadas (8,8\% na área $1,6,8 \%$ na área 2, 4,8\% na área 3 e 4,3\% na área 4). Ocorreram poucos casos de natimortos em todas as área $(1,7 \%$ na área $1,0,9 \%$ na área $2,2,6 \%$ na área 3, 2,9\% na área 4 e 0,6\% na área 5). Baixas prevalências de malformações congênitas também foram encontradas nas áreas (1,3\% na área 1, 0,9\% na área 2, 1,3\% na área 3, 0,8\% na área 4 e 1,6\% na área 5). Nenhuma associação $(p>0,05)$ entre viver em qualquer uma das áreas e ocorrência de nascimento múltiplo, aborto, parto prematuro, baixo peso de nascimento, natimorto e malformação congênita foi encontrada (Tabela 10).

Tabela 10: Desfechos gestacionais nos últimos cinco anos segundo a área analisada.

\begin{tabular}{lcccccc}
\hline & \multicolumn{5}{c}{ Áreas $^{*}$} \\
\cline { 2 - 5 } & Área 1 & Área 2 & Área 3 & Área 4 & Área 5 & Total \\
\hline $\begin{array}{l}\text { Nascimento } \\
\text { múltiplo }\end{array}$ & & & & & & \\
Sim & 6 & 10 & 7 & 5 & 6 & 34 \\
& $(1,9)$ & $(4,4)$ & $(3,0)$ & $(2,1)$ & $(1,9)$ & $(2,6)$ \\
Não & 302 & 217 & 230 & 236 & 312 & 1297 \\
& $(98,1)$ & $(95,6)$ & $(97,0)$ & $(97,9)$ & $(98,1)$ & $(97,4)$ \\
Total & 308 & 227 & 237 & 241 & 318 & 1331 \\
& $(100,0)$ & $(100,0)$ & $(100,0)$ & $(100,0)$ & $(100,0)$ & $(100,0)$ \\
\hline
\end{tabular}


continuação Tabela 10: Desfechos gestacionais nos últimos cinco anos segundo a área analisada.

\begin{tabular}{|c|c|c|c|c|c|c|}
\hline & \multicolumn{5}{|c|}{ Areas* } & \multirow[b]{2}{*}{ Total } \\
\hline & Área 1 & Área 2 & Área 3 & Área 4 & Área 5 & \\
\hline & \multicolumn{6}{|c|}{$\mathrm{N}(\%)$} \\
\hline \multicolumn{7}{|c|}{ Aborto } \\
\hline Sim & $\begin{array}{c}43 \\
(14,1)\end{array}$ & $\begin{array}{c}32 \\
(14,3)\end{array}$ & $\begin{array}{c}46 \\
(19,7)\end{array}$ & $\begin{array}{c}36 \\
(15,1)\end{array}$ & $\begin{array}{c}42 \\
(13,6)\end{array}$ & $\begin{array}{c}199 \\
(15,2)\end{array}$ \\
\hline Não & $\begin{array}{c}261 \\
(85,9)\end{array}$ & $\begin{array}{c}191 \\
(85,7)\end{array}$ & $\begin{array}{c}187 \\
(80,3)\end{array}$ & $\begin{array}{c}203 \\
(84,9)\end{array}$ & $\begin{array}{c}266 \\
(86,4)\end{array}$ & $\begin{array}{r}1108 \\
(84,8)\end{array}$ \\
\hline Total & $\begin{array}{c}304 \\
(100,0)\end{array}$ & $\begin{array}{c}223 \\
(100,0)\end{array}$ & $\begin{array}{c}233 \\
(100,0)\end{array}$ & $\begin{array}{c}239 \\
(100,0)\end{array}$ & $\begin{array}{c}308 \\
(100,0)\end{array}$ & $\begin{array}{c}1307 \\
(100,0)\end{array}$ \\
\hline \multicolumn{7}{|c|}{ Prematuro } \\
\hline Sim & $\begin{array}{c}28 \\
(9,2)\end{array}$ & $\begin{array}{c}18 \\
(8,3)\end{array}$ & $\begin{array}{c}19 \\
(8,1)\end{array}$ & $\begin{array}{c}9 \\
(3,8)\end{array}$ & $\begin{array}{c}20 \\
(6,5)\end{array}$ & $\begin{array}{c}94 \\
(7,2)\end{array}$ \\
\hline Não & $\begin{array}{c}275 \\
(90,8)\end{array}$ & $\begin{array}{c}200 \\
(91,7)\end{array}$ & $\begin{array}{c}216 \\
(91,9)\end{array}$ & $\begin{array}{c}230 \\
(96,2)\end{array}$ & $\begin{array}{c}290 \\
(93,5)\end{array}$ & $\begin{array}{l}1211 \\
(92,8)\end{array}$ \\
\hline Total & $\begin{array}{c}303 \\
(100,0) \\
\end{array}$ & $\begin{array}{c}218 \\
(100,0) \\
\end{array}$ & $\begin{array}{c}235 \\
(100,0) \\
\end{array}$ & $\begin{array}{c}239 \\
(100,0) \\
\end{array}$ & $\begin{array}{c}310 \\
(100,0) \\
\end{array}$ & $\begin{array}{r}1305 \\
(100,0) \\
\end{array}$ \\
\hline \multicolumn{7}{|c|}{ Baixo peso } \\
\hline Sim & $\begin{array}{c}26 \\
(8,8)\end{array}$ & $\begin{array}{c}15 \\
(6,8)\end{array}$ & $\begin{array}{c}11 \\
(4,8)\end{array}$ & $\begin{array}{c}10 \\
(4,3)\end{array}$ & $\begin{array}{c}18 \\
(3,9)\end{array}$ & $\begin{array}{c}80 \\
(6,2)\end{array}$ \\
\hline Não & $\begin{array}{c}270 \\
(91,2)\end{array}$ & $\begin{array}{c}206 \\
(93,2)\end{array}$ & $\begin{array}{c}218 \\
(95,2)\end{array}$ & $\begin{array}{c}225 \\
(95,7)\end{array}$ & $\begin{array}{c}288 \\
(94,1)\end{array}$ & $\begin{array}{c}1207 \\
(93,8)\end{array}$ \\
\hline Total & $\begin{array}{c}296 \\
(100,0) \\
\end{array}$ & $\begin{array}{c}221 \\
(100,0) \\
\end{array}$ & $\begin{array}{c}229 \\
(100,0) \\
\end{array}$ & $\begin{array}{c}235 \\
(100,0) \\
\end{array}$ & $\begin{array}{c}306 \\
(100,0) \\
\end{array}$ & $\begin{array}{c}1287 \\
(100,0) \\
\end{array}$ \\
\hline \multicolumn{7}{|c|}{ Natimorto } \\
\hline Sim & $\begin{array}{c}5 \\
(1,7)\end{array}$ & $\begin{array}{c}2 \\
(0,9)\end{array}$ & $\begin{array}{c}6 \\
(2,6)\end{array}$ & $\begin{array}{c}7 \\
(2,9)\end{array}$ & $\begin{array}{c}2 \\
(0,6)\end{array}$ & $\begin{array}{c}22 \\
(1,7)\end{array}$ \\
\hline Não & $\begin{array}{c}297 \\
(98,3)\end{array}$ & $\begin{array}{c}219 \\
(99,1)\end{array}$ & $\begin{array}{c}227 \\
(97,4)\end{array}$ & $\begin{array}{c}232 \\
(97,1)\end{array}$ & $\begin{array}{c}316 \\
(99,4)\end{array}$ & $\begin{array}{l}1291 \\
(98,3)\end{array}$ \\
\hline Total & $\begin{array}{c}302 \\
(100,0)\end{array}$ & $\begin{array}{c}221 \\
(100,0)\end{array}$ & $\begin{array}{c}233 \\
(100,0)\end{array}$ & $\begin{array}{c}239 \\
(100,0)\end{array}$ & $\begin{array}{c}318 \\
(100,0)\end{array}$ & $\begin{array}{c}1313 \\
(100,0)\end{array}$ \\
\hline
\end{tabular}


concluão Tabela 10: Desfechos gestacionais nos últimos cinco anos segundo a área analisada.

\begin{tabular}{lcccccc}
\hline \multicolumn{7}{c}{ Areas* $^{*}$} \\
\cline { 2 - 5 } & Área 1 & Área 2 & Área 3 & Área 4 & Área 5 & Total \\
\hline Malformação \\
congênita & & & & & \\
\multirow{2}{*}{ Sim } & 4 & 2 & 3 & 2 & 5 & 16 \\
& $(1,3)$ & $(0,9)$ & $(1,3)$ & $(0,8)$ & $(1,6)$ & $(1,2)$ \\
Não & 301 & 227 & 231 & 238 & 311 & 1308 \\
& $(98,7)$ & $(99,1)$ & $(98,7)$ & $(99,2)$ & $(98,4)$ & $(98,8)$ \\
Total & 305 & 229 & 234 & 240 & 316 & 1324 \\
& $(100,0)$ & $(100,0)$ & $(100,0)$ & $(100,0)$ & $(100,0)$ & $(100,0)$ \\
\hline
\end{tabular}

* Area 1 a 4, áreas contaminadas; Area 5, área controle.

Houve aumento do risco de não engravidar entre as mulheres em idade fértil nas quatro áreas contaminadas, sendo significativa na área 2 (OR=1,47; IC95\%:1,16 - 1,85), na área $3(\mathrm{OR}=1,31$; IC95\%: 1,03 - 1,66), e na área $4(\mathrm{OR}=1,40 ; \mathrm{IC} 95 \%: 1,10$ - 1,77), quando comparadas com a área 5 e controlado para idade escolaridade materna e renda familiar (Figura 11). 


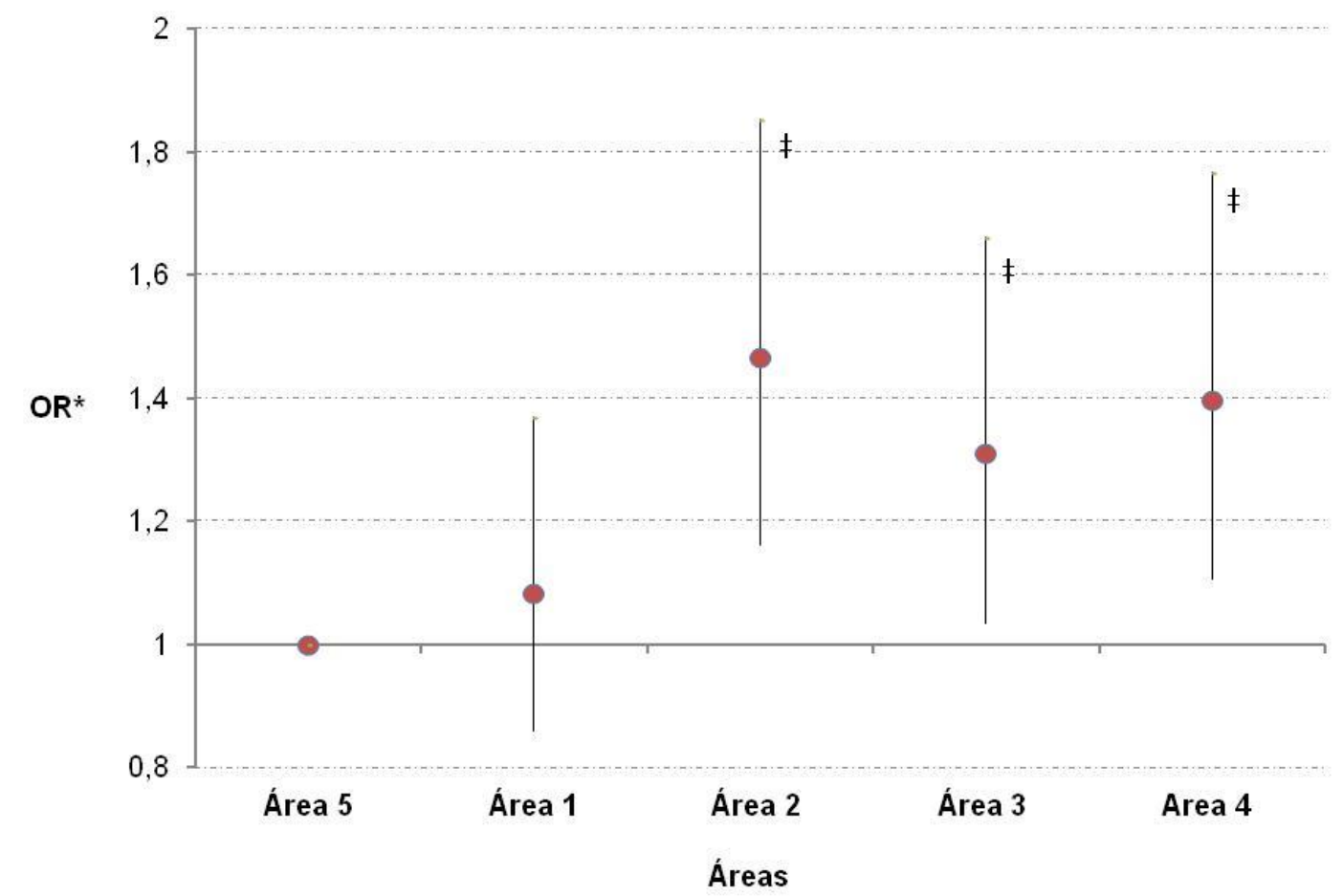

* Odds ratio controlado para idade e escolaridade materna, e renda familiar.

$\neq \mathrm{p}<0,05$

Figura 11: Odds ratio ajustado de não engravidar segundo a área analisada.

Em relação ao risco de ocorrência de abortos, houve aumento estatisticamente significativo do risco na área 3 (OR=1,83; IC95\%: 1,07 3,12) comparado coma a área controle (área 5), controlado para anos morando na região, idade e escolaridade materna, renda familiar e uso de tabaco materno passado (Figura 12). 


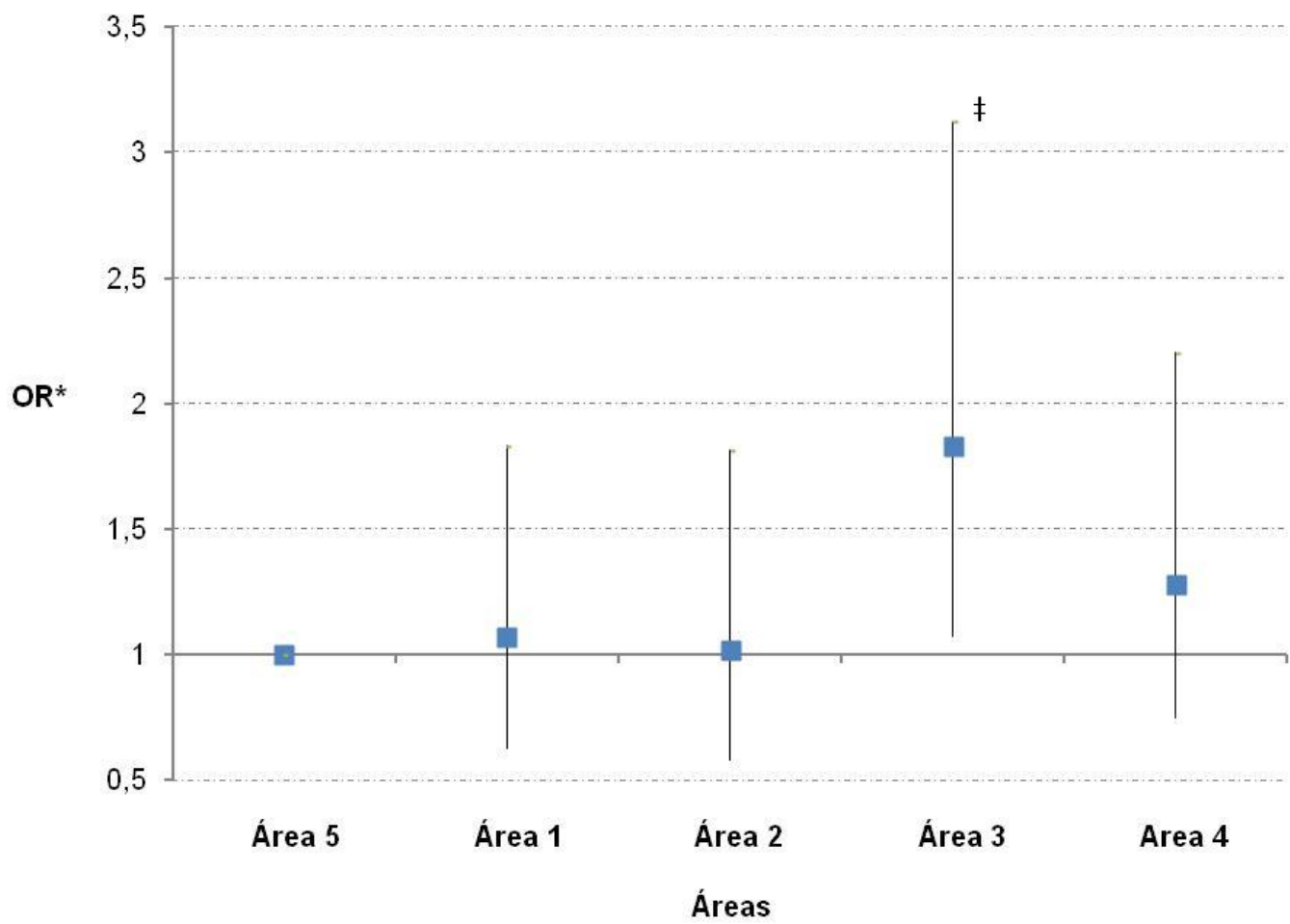

* Odds ratio controlado para anos morando na região, idade materna e escolaridade materna, renda familiar e tabagismo materno anterior.

$\neq p<0,05$

Figura 12: Odds ratio ajustado de abortos segundo a área analisada.

Não houve aumento estatisticamente significativo no risco dos demais desfechos da gravidez estudados, tanto no modelo de regressão logística bivariada (tabela 11), como no modelo múltiplo ( $p>0,05)$. 
Tabela 11: Odds ratio bruto dos desfechos gestacionais segundo as áreas analisadas.

\begin{tabular}{|c|c|c|c|}
\hline & OR & IC 95\% & Valor de $p$ \\
\hline \multicolumn{4}{|c|}{ Nascimentos múltiplos ${ }^{*}$} \\
\hline Área 1 & 1,03 & $0,33-3,23$ & 0,95 \\
\hline Área 2 & 2,39 & $0,85-6,69$ & 0,09 \\
\hline Área 3 & 1,58 & $0,52-4,77$ & 0,41 \\
\hline Área 4 & 1,10 & $0,33-3,65$ & 0,87 \\
\hline \multicolumn{4}{|c|}{ Baixo peso ao nascer* } \\
\hline Área 1 & 1,54 & $0,82-2,87$ & 0,17 \\
\hline Área 2 & 1,16 & $0,57-2,36$ & 0,67 \\
\hline Área 3 & 0,80 & $0,37-1,74$ & 0,58 \\
\hline Área 4 & 0,71 & $0,32-1,57$ & 0,39 \\
\hline \multicolumn{4}{|c|}{ Parto prematuro* } \\
\hline Área 1 & 1,47 & $0,81-2,68$ & 0,20 \\
\hline Área 2 & 1,30 & $0,67-2,52$ & 0,43 \\
\hline Área 3 & 1,27 & $0,66-2,44$ & 0,46 \\
\hline Área 4 & 0,56 & $0,25-1,27$ & 0,16 \\
\hline \multicolumn{4}{|c|}{ Natimorto* } \\
\hline Área 1 & 2,66 & $0,51-13,81$ & 0,24 \\
\hline Área 2 & 1,44 & $0,20-10,32$ & 0,71 \\
\hline Área 3 & 4,17 & $0,83-20,88$ & 0,08 \\
\hline Área 4 & 4,76 & $0,98-23,15$ & 0,05 \\
\hline \multicolumn{4}{|c|}{ Malformação congênita* } \\
\hline Área 1 & 0,82 & $0,22-3,10$ & 0,77 \\
\hline Área 2 & 0,54 & $0,10-2,85$ & 0,47 \\
\hline Área 3 & 0,80 & $0,19-3,41$ & 0,77 \\
\hline Área 4 & 0,52 & $0,10-2,71$ & 0,44 \\
\hline
\end{tabular}

${ }^{*}$ Categoria de referência: Bertioga (área controle).

\subsection{FASE 3}

Nos últimos cinco anos do período estudado, do total de 43 mulheres que abortaram na área 3 (São Vicente continental), 25 moravam dentro do raio de $1 \mathrm{~km}$ do centro das cavas mapeadas pela CETESB, e 18 residiam 
fora do "buffer". Entre as 180 grávidas que não sofreram aborto, 100 residiam dentro do "buffer" e 80 fora. Não houve associação entre ocorrência de aborto e residir na área do "buffer" em São Vicente $(p=0,44)$ (Figura 13).

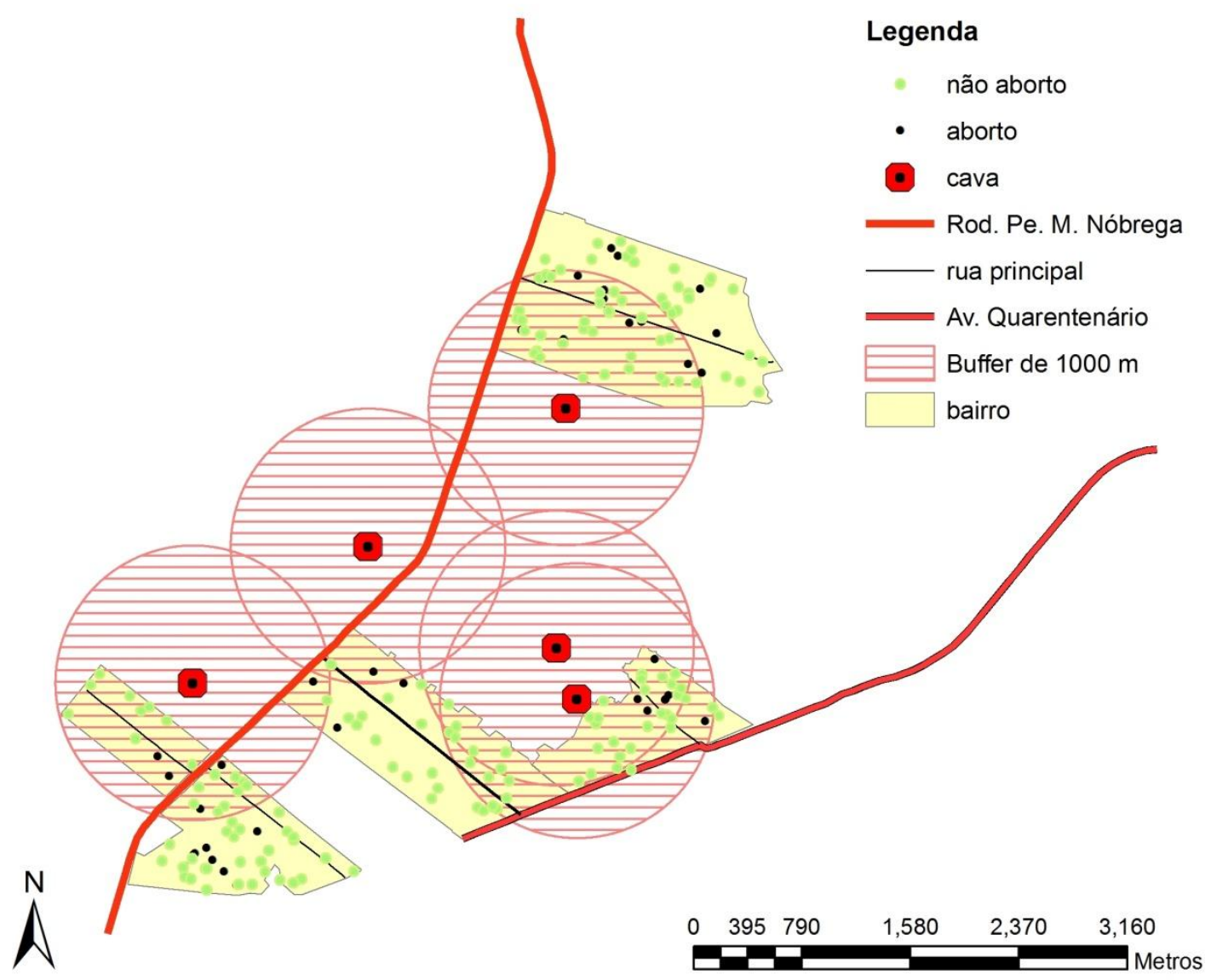

Figura 13: Mapa de distribuição dos casos de aborto e não-aborto na área 3 (São Vicente continental) nos últimos cinco anos.

Não houve associação entre ocorrência de gravidez e residir na área do "buffer" em São Vicente $(p=0,36)$. Nos últimos cinco anos do período estudado, 373 mulheres em idade fértil engravidaram na área 3. Destas, 213 
residiam dentro do raio de $1 \mathrm{~km}$ do centro das cavas mapeadas pela CETESB, e 160 que engravidaram residiam fora do "buffer" (Figura 14). As mulheres em idade fértil que não engravidaram na área 3 foram 463, mas 271 residiam dentro do "buffer" e 192 fora (Figura 15).

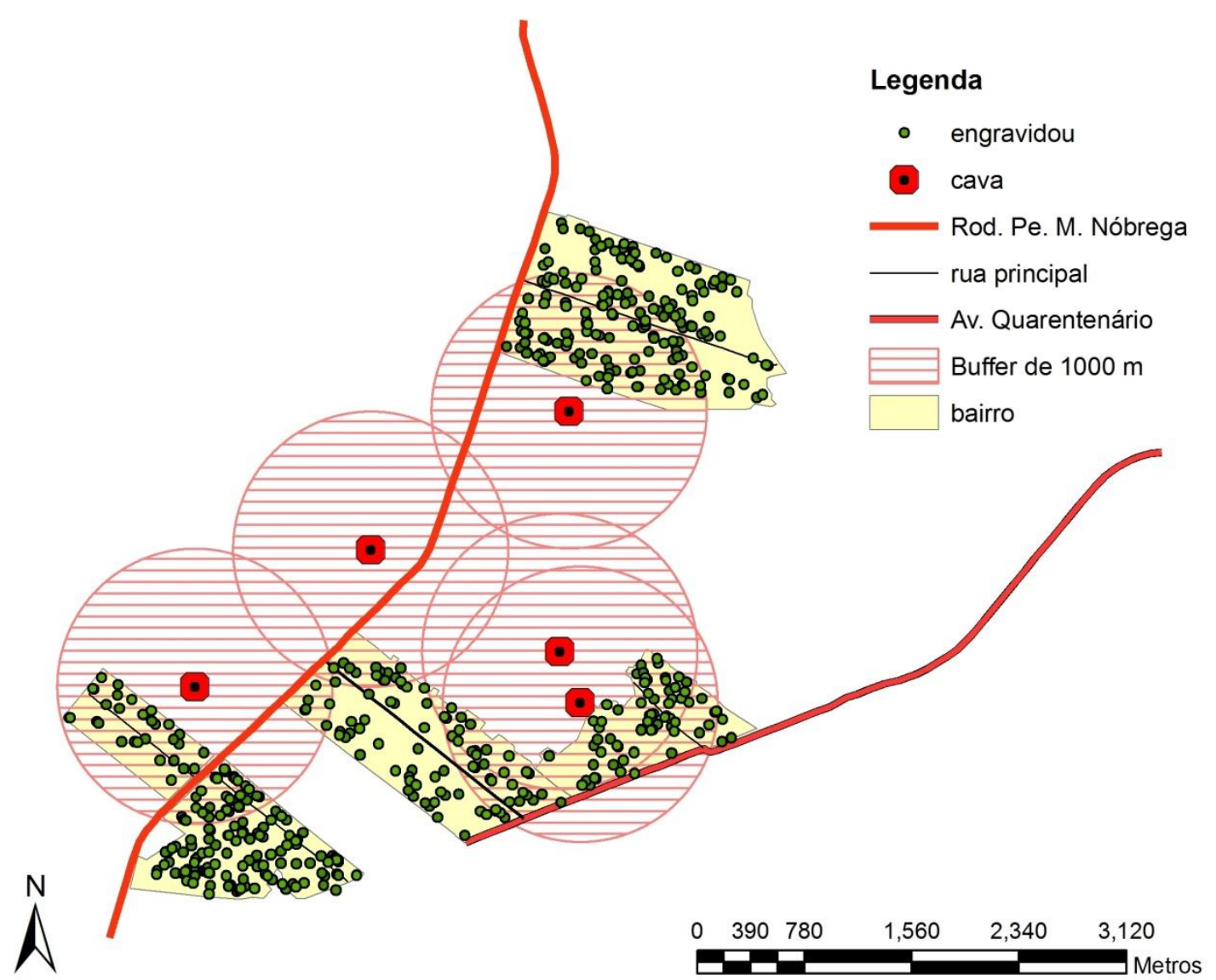

Figura 14: Mapa de distribuição dos casos de gestantes na área 3 (São Vicente continental) nos últimos cinco anos. 


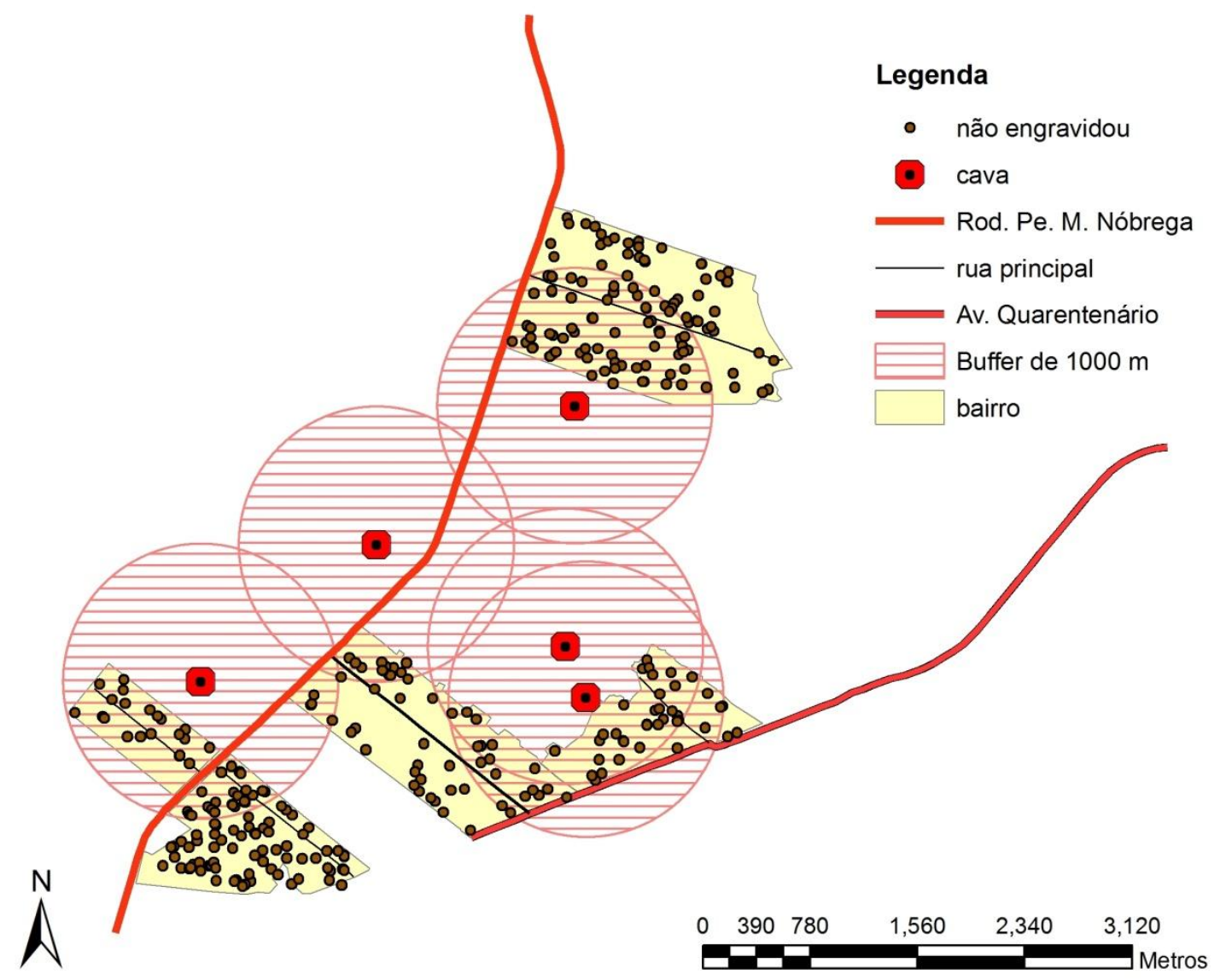

Figura 15: Mapa de distribuição dos casos de não gestantes na área 3 (São Vicente continental) nos últimos cinco anos. 


\section{DISCUSSÃo}

\subsection{FASE 1}

Por fornecer características relacionadas à gestação, ao parto, ao recém-nascido e a mãe, as informações do SINASC permitem uma análise epidemiológica dos nascimentos. Foi observada uma redução na taxa bruta de natalidade nos quatro municípios entre 2003 e 2007. Em 2007, para cada 1.000 habitantes, houve 15,75 nascidos vivos em São Vicente, 15,86 em Guarujá, 15,75 em Cubatão, e 18,71 em Bertioga, mas comparações diretas devem ser realizadas com cautela devido a diferenças na composição etária das populações. Estas taxas brutas de natalidade são maiores, quando comparadas com as taxas da região metropolitana da Baixada Santista (14,65 nascidos vivos para cada 1.000 habitantes) e do Estado de São Paulo (14,59 nascidos vivos para cada 1.000 habitantes) no ano de $2010^{7}$ e, em geral, estão associadas a condições socioeconômicas precárias.

Nos últimos anos, a consolidação da estrutura urbana no Brasil, após intensos fluxos migratórios fez com que mais de $80 \%$ da população residisse em áreas urbanas. A urbanização, somada ao aumento da renda, atua no declínio da taxa de natalidade ${ }^{52}$.

A taxa de fecundidade total, juntamente com a migração, são os principais determinantes da dinâmica populacional, níveis elevados de taxas 
de fecundidade total estão associados a estruturas etárias muito jovens e baixa proporção de pessoas idosas ${ }^{52}$. No mundo todo, mais cedo ou mais tarde, mais rapidamente ou mais lentamente, os níveis de fecundidade estão caindo $^{53}$. No Brasil, a fecundidade vem diminuindo aceleradamente a partir da segunda metade dos anos 60, chegando em 2004 a uma taxa de fecundidade total de 2,1, nível limite considerado pela OMS de reposição populacional. A diminuição da taxa de fecundidade pode estar associada a vários fatores, tais como: urbanização crescente, redução da mortalidade infantil, melhoria do nível educacional, ampliação do uso de métodos contraceptivos, entre outros ${ }^{52}$.

Nos quatro municípios observou-se uma tendência de decréscimo da taxa de fecundidade total entre 2003 e 2007, estando no último ano abaixo do nível de reposição populacional, 1,74 em Cubatão, 1,80 em São Vicente, e 1,94 em Bertioga, e 1,75 no Guarujá.

O padrão de fecundidade brasileiro em relação à idade da mulher, que até a década de 1970 era tardio, passou a ser tipicamente jovem, com maior taxa específica entre as mulheres de 20 a 24 anos, a partir da década de $1990^{52}$. Berquó e Cavenaghi ${ }^{54}$ constatam que as taxas específicas de fecundidade reduziram-se em todos os grupos etários, com base censitária no período entre 1980 e 2000, exceto o segmento de 15 a 19 anos, o que não foi percebido nos resultados encontrados neste estudo, onde existiu uma redução das taxas específicas de fecundidade semelhante entre as faixas etárias. 
Existem diferenças na estrutura etária da fecundidade conforme a condição socioeconômica das mulheres, sendo a fecundidade menor nos grupos menos instruídos, bem como nos menos favorecidos economicamente. Quanto maior o nível de desenvolvimento humano, menor o nível da fecundidade ${ }^{55}$. O Índice de Desenvolvimento Humano (IDH) dos quatro municípios é de médio desenvolvimento e foram semelhantes entre si para o ano 2000 (Bertioga 0,792, Cubatão 0,772, São Vicente 0,798, Guarujá 0,788 , médio desenvolvimento humano $)^{7}$. Os resultados confirmam a associação entre posição socioeconômica da população e níveis de fecundidade, onde os grupos menos instruídos apresentam taxas de fecundidade mais elevadas que grupos intermediários e mais instruídos ${ }^{54}$.

O baixo peso ao nascer constitui o mais importante determinante da mortalidade neonatal, perinatal e infantil. Nove entre 10 óbitos neonatais em 2000 por afecções no período perinatal no Estado de São Paulo foram de nascidos vivos que apresentaram baixo peso ao nascer e/ou prematuridade ${ }^{56}$.

De modo geral, nos países desenvolvidos, a prevalência do baixo peso ao nascer situa-se entre $4 \%$ e $6 \%$. No Brasil, em 2005, a prevalência foi de $8,1 \%$ e de $8,9 \%$ no Estado de São Paulo ${ }^{57}$. Neste estudo, a prevalência de baixo peso ao nascer, entre os nascidos vivos a termo, foi de 9,1\% em São Vicente, 9,2\% no Guarujá, 8,3\% em Cubatão, e de 7,1\% em Bertioga, no período entre 2003 e 2007.

O baixo peso ao nascer como indicador de saúde e das condições de vida da população tem merecido atenção crescente no campo da saúde 
coletiva $^{58}$. Sadeck e colaboradores ${ }^{59}$ num estudo sobre a variação secular do peso de recém-nascidos em São Paulo afirmam que melhoras econômicas no país são responsáveis pelo aumento do peso dos recém-nascidos, confirmando a influência da situação socioeconômica no baixo peso ao nascer.

O risco de ocorrência de baixo peso ao nascer entre 2003 e 2007 foi maior e significativo nos municípios de São Vicente, Guarujá e Cubatão, quando comparados com Bertioga, controlando para importantes fatores de risco (idade, estado civil e escolaridade materna, número de consultas prénatal e presença de malformações congênitas).

A complexa rede de variáveis envolvidas na ocorrência do baixo peso ao nascer tem sua gênese nas precárias condições de vida e trabalho em parcelas consideráveis da população brasileira ${ }^{60}$. A idade, estado civil e escolaridade da mãe, ordem de nascimento do filho e número de consultas pré-natais são destacados como fatores de risco para baixo peso e prematuridade em várias pesquisas nacionais ${ }^{61}$.

Minagawa e colaboradores ${ }^{60}$ encontraram diferenças significativas entre a proporção de crianças com baixo peso ao nascer em São Paulo, ocorrendo mais casos nos grupos de mães sem companheiro e mais jovens. Kilsztain e colaboradores ${ }^{56}$ encontraram como fatores de risco para baixo peso ao nascer no Estado de São Paulo, a idade mais jovem da mãe, a escolaridade baixa (zero a sete anos de estudo), primíparas e multíparas gestando o quarto filho ou mais. Estes fatores também se mostraram importantes neste estudo. 
Prematuridade é um problema de saúde que afeta todos os países do mundo, sendo a principal causa de mortalidade perinatal, responsável por mais de um milhão de mortes todos os anos ${ }^{62,63}$.

A prevalência em São Vicente foi de $7,2 \%$, no Guarujá de $6,7 \%$, em Cubatão 7,6\%, e 6,2\% em Bertioga no período de 2003 a 2007. Taxas menores que as da Região Metropolitana da Baixada Santista $(7,82 \%)$ e do Estado de São Paulo (8,67\%) no ano de $2010^{7}$.

É observado um aumento na ocorrência de partos prematuros visto em diversos estudos, tendo como principal causa o aumento dos partos cesáreos. Martin e colaboradores ${ }^{64}$ observaram um aumento na prevalência de partos prematuros nos Estados Unidos, com prevalência em 2006 de $12,8 \%$. No Brasil, na coorte de Pelotas, Barros e colaboradores ${ }^{65}$ mostraram um aumento entre 1982 (6,3\%) e 2004 (14,7\%).

O risco de ocorrência de parto prematuro foi mais de duas vezes em São Vicente, Guarujá e Cubatão, quando comparados com Bertioga, excluídos os casos de gestações múltiplas, e controlados para a idade, estado civil e escolaridade materna, número de consultas pré-natal e malformações congênitas.

Vários estudos mostram que a ocorrência de partos prematuros são mais frequentes entre populações pobres ${ }^{65,66,67}$.

Numa revisão, Silveira e colaboradores ${ }^{62}$ apontam como fatores de risco para ocorrência de partos prematuros: baixo peso materno prégestacional, extremos de idade materna, história prévia de natimorto, tabagismo na gravidez, ganho de peso materno insuficiente, hipertensão 
arterial, sangramento vaginal, infecção do trato geniturinário, cinco ou menos consultas pré-natal, stress materno, e baixa escolaridade materna.

No presente estudo a idade da mãe exerceu influência na ocorrência de prematuridade, independentemente de outros fatores analisados. Cascaes e colaboradores ${ }^{68}$ encontraram associação entre partos prematuros e mães com idades inferiores a 20 anos e/ou superiores a 40 anos.

Mulheres solteiras ou separadas foram associadas com a ocorrência de parto prematuro entre 2003 e 2007, associação esta também encontrada por Kilsztajn e colaboradores ${ }^{56}$. Já Cascaes e colaboradores ${ }^{68}$ perderam a significância estatística após a análise ajustada entre o estado civil das mães e ocorrência de prematuridade.

A prevalência de malformações congênitas varia muito de acordo com o critério e a metodologia empregada, sendo que varia de $0,5 \%$ e $2 \%$ do total de gestações. A maior parte das malformações congênitas é de etiologia desconhecida ou multifatorial, enquanto que em apenas $20 \%$ dos casos pode-se identificar o fator causal genético, materno ou ambiental, e pesam de modo considerável nas estatísticas de morbidade e mortalidade perinatais ${ }^{69}$.

Entre 2003 e 2007 a prevalência de malformações congênitas foi de 0,8\% em São Vicente, 1,3\% no Guarujá, 1,0\% em Cubatão e 0,8\% em Bertioga teve prevalência de $0,8 \%$.

Houve aumento do risco de ocorrência de malformações congênitas no Guarujá e em Cubatão no período de 2003 a 2007, quando comparado 
com Bertioga, controlados para idade e estado civil da mãe, número de consultas pré-natal e nascimento múltiplo.

A prevalência de nascimentos múltiplos foi de 2,3\% em São Vicente, 2,0\%, no Guarujá e de 1,5\% em Bertioga entre 2003 e 2007. Prevalência bem menor foi encontrada em Pelotas em uma coorte de nascimentos até 2003 de $0,89 \%{ }^{70}$. Houve leve redução no risco de nascimentos múltiplos em São Vicente quando comparado com Bertioga, mas quando controlado para possíveis fatores de confusão, não houve significância estatística.

A análise dos nascimentos por tipo de parto permite avaliar, em parte, as práticas obstétricas no Brasil. A recomendação da Organização Mundial da Saúde (OMS) é para que as cirurgias cesáreas sejam, no máximo, 15\% do total dos partos, limitando-se a situações de risco tanto da mãe quanto da crianç $^{52}$. Os resultados do presente estudo mostraram que nos quatro municípios (média de 50,9\%) estão muito longe do recomendado pela OMS.

De toda maneira, a prevalência encontrada não difere da realidade encontrada em outros estudos e não se mostrou associada com nenhum dos desfechos analisados. Cascaes e colaboradores ${ }^{68}$ encontraram prevalência de partos cesáreos de 49,6\% em Santa Catarina em 2005 e Giglio e colaboradores $^{71}$ encontraram prevalência de $44,1 \%$ dos atendimentos do Sistema Único de Saúde (SUS), em Goiânia, em 2000.

Mais de $90 \%$ das mães tiverem quatro ou mais consultas de pré-natal. Alguns estudos mostram que a maioria das mortes por causas maternas são evitáveis se ações que objetivam a qualidade da assistência pré-natal e o acesso aos serviços de saúde da gestante forem tomadas ${ }^{72}$. Desde 2000, a 
recomendação do Ministério da Saúde é de que a mãe realize, no mínimo, seis consultas pré-natais e as inicie tão logo comece a gravidez, embora as informações derivadas do SINASC não possibilitem avaliar o momento do início do acompanhamento pré-natal e a desagregação do número de consultas não seja totalmente possível ${ }^{52}$.

A quantidade de consultas pré-natais foi um fator importante e significante para $\mathrm{o}$ baixo peso de nascimento, parto prematuro, e malformações congênitas.

A assistência pré-natal permite o diagnóstico e tratamento de várias complicações durante a gestação ${ }^{56}$ e 0 atendimento inadequado está relacionado a prematuridade ${ }^{73}$, bem como a ocorrência de baixo peso ao nascer ${ }^{60}$.

\subsubsection{LIMITAÇõES}

Desde 1993, com a plena implantação no Estado de São Paulo da Declaração de Nascido Vivo (DNV), as informações sobre saúde permitem construir um retrato estatístico da situação em relação aos nascimentos ${ }^{61}$. Um grande problema, mas que apresenta queda constante é o número de sub-registros. Segundo o $\mathrm{IBGE}^{74}$, o percentual de sub-registros de nascimento no Brasil foi de 21,9\% em 2001 para 6,6\% em 2010, distribuídos de maneira desigual entre as Unidades da Federação. 
Erros ou falta de dados na DNV constituem um grande problema para o levantamento das informações. No período entre 2003 e 2007 houve perda de $7,17 \%$ das informações sobre estado civil, $5,63 \%$ sobre escolaridade, 0,23\% sobre tipo de parto, $1,12 \%$ sobre atendimento pré-natal, $5,31 \%$ sobre tempo de gestação, 5,03\% sobre peso de nascimento, 29,74\% sobre malformações congênitas e $0,15 \%$ sobre tipo de gestação. As prevalências de malformações congênitas podem estar subestimadas pelo alto percentual de perdas de informação desta variável no banco fornecido pela SEADE.

Outro problema das informações fornecidas tendo como base a DNV é em relação à acurácia de alguns indicadores específicos, entre os quais o tempo de gestação, podendo subestimar a prevalência de partos prematuros devido a erros de classificação. Uma revisão feita por Silveira e colaboradores $^{75}$, contestou a confiabilidade dos dados do SINASC sobre nascimentos prematuros por observar grande disparidade, para o mesmo período e local, nas prevalências encontradas nos estudos revisados.

\subsection{FASE 2}

As condições de moradia nas áreas foram bastante diferentes. Enquanto os dados referentes à origem da água pela SABESP, iluminação elétrica e uso de fogão a gás foram semelhantes em quase todos os domicílios e distribuídos uniformemente nas cinco áreas, a distribuição das 
demais variáveis de moradia não. A maioria das mulheres em idade fértil morava na região há cinco anos ou mais. $\mathrm{Na}$ área controle o percentual de mulheres em idade fértil que moravam na região há menos que cinco anos foi quase o dobro do encontrado nas outras áreas. Os percentuais de domicílios de alvenaria foram semelhantes nas cinco áreas, mas na área 1 e 4 também foram encontrados percentuais maiores de domicílios feitos de outros materiais, incluindo palafitas, que nas outras áreas. A coleta adequada de esgoto teve distribuição bastante heterogênea. Enquanto nas áreas 2 e 3 mais da metade dos domicílios tinham o esgoto coletado adequadamente, apenas 3,7\% na área 1 e 29,7\% na área 5 tinham. Quase a totalidade dos domicílios tinha coleta de lixo no bairro nas áreas 2, 3, 4 e controle, resultado não observado na área 1 , onde menos da metade tinha coleta de lixo nos domicílios. Esses resultados estão de acordo com os perfis municipais de Cubatão, São Vicente, Guarujá e Bertioga ${ }^{7}$.

Vettore e colaboradores $^{76}$ mostram que mulheres vivendo em condições de moradia inadequadas têm mais filhos com baixo peso de nascimento e prematuros comparados com aquelas que vivem em condições adequadas de moradia no Rio de Janeiro.

A idade média das mulheres em idade fértil foi semelhante nas áreas, de 29 anos nas áreas 1 e controle, e de 30 anos nas demais. Na área 2, seguida pela área 3, as mulheres em idade fértil apresentaram nível de escolaridade mais elevado que nas demais, sendo a área 1 o pior nível de escolaridade. Mais da metade das mulheres em idade fértil em todas as áreas eram casadas ou moravam com o companheiro. Em relação à renda 
familiar das mulheres em idade fértil, mais da metade das mulheres em todas as áreas pertenciam a famílias que viviam com até três salários mínimos, sendo as áreas 1,4 e controle com os piores perfis de renda.

Diferenças nas condições socioeconômicas podem afetar a ocorrência de desfechos à saúde em uma população, mesmo que esta população aparentemente esteja exposta aos mesmos riscos ${ }^{76}$.

Um pequeno percentual de mulheres em idade fértil relatou exposição ocupacional atual e passada a produtos químicos em todas as áreas. A exposição ocupacional é um importante fator de risco para ocorrência de desfechos de gestação ${ }^{77}$, e deve ser controlada ${ }^{78}$. Burdorf e colaboradores ${ }^{79}$ mostram aumento do risco de baixo peso ao nascer e na Holanda entre mulheres grávidas que tem exposição ocupacional a fosfatos e pesticidas.

A maioria das mulheres em idade fértil não fumava no momento da entrevista e também relataram que não fumavam anteriormente, mas um percentual de fumantes mais elevado foi encontrado nas áreas 1 e controle. Os efeitos adversos do cigarro não afetam somente a mãe, mas também o feto ${ }^{80}$, incluindo baixo peso de nascimento, partos prematuros e abortos espontâneos $^{81}$. Grillo e Freitas ${ }^{82}$ mostram que o tabagismo é um importante fator na ocorrência de prematuridade, sendo que mulheres que fumam mais de 20 cigarros por dia apresentam um risco aumentado. A exposição passiva ao tabaco também deve ser considerada ${ }^{83}$. Ribeiro e colaboradores $^{84}$ mostram que o risco de fumar durante a gravidez é maior entre mulheres que o companheiro também fume. 
Quase $80 \%$ das mulheres em idade fértil não consumiam bebida alcoólica e um percentual ainda maior destas mulheres alegaram não ter histórico de consumo de álcool. O álcool é uma substância com efeito teratogênico e a exposição fetal é ainda maior devido ao seu metabolismo e sistema de eliminação mais lentos interferindo no desenvolvimento fetal ${ }^{85}$. Freire e colaboradores ${ }^{86}$ observaram que o uso de álcool na gravidez esteve associado à restrição do crescimento fetal.

As áreas 1 e controle apresentaram uma prevalência maior de mulheres em idade fértil que engravidaram que nas outras áreas. O OR mostrou risco pequeno, mas significativo, de não engravidar nas áreas 2, 3 e 4 comparado com a área controle, ajustado para idade da mãe, escolaridade materna e renda familiar.

Os sistemas reprodutivos femininos e masculinos são susceptíveis a fatores ambientais, embora evidências epidemiológicas entre exposição a poluentes e fertilidade humana mostrem resultados pouco consistentes ${ }^{77,87}$. Em estudo preliminar na região do estuário de Santos e São Vicente foi possível observar um maior número de mulheres em idade fértil que engravidaram na área controle $(38,8 \%)$ que na área contaminada $(28,3 \%)$, com diferença significativa entre as áreas ${ }^{88}$.

$\mathrm{Na}$ Holanda, Burdorf e colaboradores ${ }^{79}$ mostram aumento do risco de maior tempo para engravidar entre mulheres com exposição ocupacional.

Quase todas as mulheres em idade fértil que engravidaram responderam que tiveram atendimento pré-natal durante a gravidez, mas o estudo não previa avaliar a quantidade de consultas, o local onde foram 
realizados os atendimentos e nem a qualidade destes atendimentos. A SEADE $^{7}$ mostra que em 2010 o percentual de mulheres grávidas que tiveram sete ou mais consultas de pré-natal foi de $71 \%$ no Guarujá, $82 \%$ em Cubatão, 78\% em São Vicente e de 58\% em Bertioga. A assistência prénatal é um importante fator de risco para mortalidade perinatal ${ }^{89,90}$, parto prematuro e baixo peso de nascimento ${ }^{91}$.

Diversos autores têm investigado a associação entre contaminantes ambientais e desfechos na gestação como, aborto espontâneo, parto prematuro e baixo peso ao nascer ${ }^{83}$.

A prevalência de nascimentos múltiplos nas áreas 1 e controle foram menores que nas demais áreas, mas sem associação significativa. O OR na análise bivariada é maior nas áreas contaminadas, mas sem significância estatística. Pouquíssimos trabalhos têm investigado a relação entre a frequência de nascimentos múltiplos e exposição a contaminantes ambientais $^{45}$.

A prevalência de baixo peso ao nascer foi maior na área 1, seguido da área 2, sendo menos prevalente na área controle. As prevalências encontradas foram menores que as estimativas para o ano de $2010^{7}$. O OR da análise bivariada mostrou risco maior de baixo peso ao nascer na área 1 e 2, e menor nas áreas 3 e 4, em relação a área controle, mas sem significância estatística.

Estudo realizado no Alaska mostra aumento do risco de nascimentos de baixo peso em mães residentes em vilarejos com perigo alto de exposição a lixões em comparação a vilarejos com perigo baixo ${ }^{92}$. Gouveia e 
colaboradores $^{25}$ mostram evidências que exposição materna a poluição do ar está associada à diminuição do peso de nascimento dos bebês, especialmente quando a exposição ocorre no primeiro trimestre de gestação em São Paulo.

A prevalência de parto prematuro foi maior na área 1, 2 e 3 que na área controle. As prevalências encontradas foram maiores nas áreas 1, 2 e controle em relação à estimativa dos municípios a que pertencem para o ano de 2010, e na área menor 4 foi menor ${ }^{7}$. O OR da análise bivariada mostrou risco maior de parto prematuro nas áreas 1, 2 e 3, e menor na área 4, em relação a área controle, mas sem significância estatística.

Gilbreath e Kass $^{92}$ não encontram aumento no risco de partos prematuros entre mães residentes em vilarejos com perigo alto de exposição a lixões e mães residentes em vilarejos com perigo baixo. Torres-Arreola e colaboradores ${ }^{93}$ mostram aumento do risco entre partos prematuros e nível sérico de organoclorados, mas sem significância estatística. Já Windham e Fenster $^{83}$ relatam uma relação dose-resposta entre aumento nos níveis de organoclorados (especificamente o dicloroetileno - DDE) e prematuridade. Leem e colaboradores ${ }^{94}$ mostram um aumento significativo do risco e uma relação dose-dependente entre partos prematuros e exposição à poluição do ar, principalmente no terceiro trimestre de gravidez.

A prevalência de natimortos foi maior nas áreas 1,3 e 4, que nas áreas 2 e controle, sendo que a área controle apresentou a prevalência mais baixa, mas sem associação significativa. O OR na análise bivariada foi de 4 vezes mais risco de natimortos na área 3 e 4, e de 2 vezes mais na área 1, 
em relação a área controle, contudo sem significância estatística. O Estudo Latino-Americano de Malformações Congênitas (ECLAMC) ${ }^{95}$ mostra uma prevalência geral de $1,3 \%$ nos nove países envolvidos na pesquisa (Argentina, Bolívia, Brasil, Chile, Colômbia, Equador, Paraguai, Uruguai e Venezuela), esta prevalência é maior que a encontrada nas áreas 1, 3 e 4 no presente estudo.

A prevalência de malformações congênitas foi menor nas áreas contaminadas que na área controle, mas sem associação significativa. O OR mostrou um menor risco de ocorrência de malformações congênitas nas áreas contaminadas, mas sem significância estatística. O ECLAMC ${ }^{95}$ mostra uma prevalência geral de malformações congênitas de 2,7\% nos nove países envolvidos na pesquisa, prevalência muito maior que a encontrada nas cinco áreas deste estudo. Os resultados dos estudos entre exposição à poluição e risco de malformações congênitas são inconclusivos. Numa revisão e meta-análise, Vrijheid e colaboradores ${ }^{96}$ investigam a associação entre poluição do ar e a ocorrência de malformações congênitas, evidenciando um aumento do risco de malformações cardíacas, mas sem significância estatística. No entanto, estudo conduzido na República Checa mostra que viver em áreas com maior nível de poluição industrial está associado com maiores taxas de anomalias congênitas ${ }^{36}$.

As áreas contaminadas apresentaram uma prevalência maior de abortos que na área controle. O OR mostrou aumento no risco de aborto na área 3 comparado com a área controle, ajustado para anos morando na 
região, idade e escolaridade materna, renda familiar e tabagismo materno anterior.

Cerca de $15 \%$ das gestações terminam em abortos espontâneos. Incluindo os casos que passam despercebidos ou não são reconhecidos, esse percentual chega a $50 \%$ de todas as concepções ${ }^{35}$.

$\mathrm{Na}$ Índia, Thakur e colaboradores ${ }^{97}$ encontram uma ocorrência de aborto maior em áreas poluídas por metais pesados e organoclorados. Numa revisão, Toft e colaboradores ${ }^{20}$ indicam que a exposição a organoclorados pode induzir abortos espontâneos em mulheres. Noguez e colaboradores $^{98}$ não encontraram associação entre aborto espontâneo e morar próximo a uma área industrial no sul do Brasil. No entanto, Korrick e colaboradores $^{35}$ mostram um aumento no risco de abortos espontâneos associados com nível sérico de DDE nas mães.

\subsubsection{LIMITAÇÕES}

A primeira limitação do estudo se deve ao desenho transversal, que não permite inferências causais, pois nenhuma relação temporal entre a exposição e ocorrência dos eventos gestacionais pode ser feita.

Mesmo os resultados indicando um aumento de aborto e de não gravidez nas áreas reconhecidamente contaminadas, a presença de contaminantes no ambiente não é suficiente para caracterizar a 
contaminação ou exposição de determinada população. O contato é fundamental para que se defina a presença de uma rota de contaminação. Além do contato, a concentração da substância nos compartimentos ambientais e a duração do contato com estas substâncias são fundamentais.

Estudos retrospectivos são mais susceptíveis ao viés de memória ${ }^{99}$, embora os desfechos relativos à gestação investigados tivessem um período de inferência curto. Os fatores de confusão podem ter sofrido erros de classificação, pois as condições foram as do momento da entrevista, desconhecendo se durante a gravidez as mulheres estavam expostas a tais fatores.

A área controle, juntamente com a área 1, apresentaram condições socioeconômicas piores que as demais áreas, fator que pode contribuir para uma maior prevalência de desfechos gestacionais, subestimando o risco encontrado.

A área controle foi escolhida como controle pela proximidade do município de Bertioga da região do estuário de santos e São Vicente, por não apresentar locais de depósito de resíduos industriais e com situação socioeconômica semelhante com as demais áreas. Em relatório feito em etapa posterior as entrevistas que foram foco deste estudo, Braga e colaboradores $^{49}$ mostram a presença de contaminação da poeira intradomiciliar, nos ovos de galinhas de algumas casas entrevistadas na região, no sangue dos moradores e no leite materno das mulheres entrevistadas, evidenciando a presença de compostos organoclorados e metais tóxicos. Alguns destes compostos foram encontrados em níveis bem 
acima dos toleráveis em moradores de todas as áreas sem histórico de contato ocupacional. Essa constatação mostra que a área controle não está livre da presença dos contaminantes, podendo interferir nas estimativas de risco.

A perda de informações pode subestimar os resultados do estudo. Houve perda inferior a $5 \%$ das informações sobre tempo de residência, tipo de moradia, esgoto, lixo, origem da água, tipo de iluminação, tipo de fogão, educação, estado civil, pré-natal, nascimentos múltiplos, aborto, parto prematuro, natimorto, e malformação congênita. Em relação às demais variáveis estudadas, houve perda de $7,72 \%$ na renda, $31,91 \%$ na exposição ocupacional, $30,23 \%$ na exposição ocupacional anterior, $26,95 \%$ no tabagismo, $25,03 \%$ no tabagismo anterior, $30,30 \%$ no uso do álcool, $10,26 \%$ no uso de álcool passado, 5,50\% no baixo peso ao nascer.

\subsection{FASE 3}

A contaminação do ar, água e solo por produtos químicos depositados em aterros pode representar risco à saúde da população que vive no entorno ${ }^{100}$. Existem poucos estudos disponíveis investigando o risco de desfechos na gestação levando em conta a proximidade da residência das gestantes com aterros domésticos e/ou industriais ${ }^{26,100,101,102 .}$ 
Não houve associação entre ocorrência de aborto entre as mulheres que engravidaram em São Vicente continental (área 3) e residência materna num raio de $1 \mathrm{Km}$ dos depósitos de resíduos industriais mapeados pela $\mathrm{CETESB}^{6}$. O mesmo ocorreu em relação à ocorrência de gravidez entre as mulheres em idade fértil.

Gouveia e Prado ${ }^{101}$ não encontraram aumento no risco de óbitos por câncer ou malformações congênitas em áreas vizinhas ("buffers" de 2 km) aos depósitos de resíduos urbanos no município de São Paulo. Dummer e colaboradores $^{102}$ também não encontraram aumento no risco de natimortos, óbitos neonatais e por malformações congênitas de filhos de mães que residem perto de aterros no noroeste da Inglaterra, entre 1950 e 1993.

Já Elliott e colaboradores ${ }^{26}$ encontraram um pequeno aumento no risco de malformações congênitas, baixo peso e muito baixo peso de filhos de mães que moram em um raio de $2 \mathrm{~km}$ de aterros no Reino Unido, englobando cerca de $80 \%$ da população. Um pequeno aumento no risco de malformações congênitas entre filhos de mães, que vivem num raio de $3 \mathrm{~km}$ de aterros com produtos perigosos foi encontrado em um estudo multicêntrico europeu ${ }^{100}$. 


\subsubsection{LIMITAÇÕES}

Existem diferenças entre os autores no tamanho da área de influência dos aterros, em relação à população que vive em seu entorno. A OMS sugere que a exposição potencial a contaminantes existentes em depósitos de resíduos sólidos tendo como rota de exposição o ar adotar um raio de 1 $\mathrm{km}$, e quando a rota de exposição for pela água, adotar um raio de $2 \mathrm{~km}^{103}$. Neste estudo foi escolhido um raio de $1 \mathrm{~km}$, porque toda a população da área de estudo reside a até $2 \mathrm{~km}$ das áreas de deposição de resíduo industrial mapeadas pela CETESB ${ }^{6}$.

Todas as cinco áreas de deposição de resíduo industrial da região de São Vicente continental são de responsabilidade da empresa Rhodia Brasil Ltda., que depositou por muitos anos de forma irregular resíduos da sua indústria química. Segundo a CETESB ${ }^{104}$, estas áreas estão com o solo, o subsolo e a água subterrânea dentro das propriedades, com solventes halogenados, fenóis, biocidas e poluentes orgânicos persistentes (POP's), e medidas de remediação e controle foram implantadas. Uma limitação do estudo é assumir que viver próximo às cavas significa estar exposto aos contaminantes ali presentes, embora não tenham sido mensuradas as concentrações destes produtos químicos em nenhum compartimento ambiental. 
Não foi possível controlar o efeito de fatores de confusão que possam estar relacionados com os desfechos gestacionais, como idade, condição socioeconômica, tabagismo, álcool, e exposição ocupacional, entre outros.

\subsection{CONSIDERAÇõES FINAIS}

Os resultados encontrados na fase 1 , baseados em dados secundários, abrangendo a população de todo o município e os resultados da fase 2, baseados em dados primários e população limitada às áreas contaminadas, mostraram coerência entre si, validando externamente seus resultados. A fase 3 , um recorte da fase 2 , analisou a distribuição dos eventos gestacionais espacialmente na área mais impactada, mostrando que toda a população está exposta.

A presença de compostos organoclorados e metais tóxicos na região, e em amostras biológicas na população reforçam a presença de contaminantes no solo das áreas e a existência de rota de exposição ${ }^{49,} 105$.

Mesmo com as medidas dos contaminantes, metodologicamente não foi possível cruzar os dados de exposição com a ocorrência de eventos gestacionais, devido a não representatividade das amostras coletadas nas áreas investigadas. Visto o risco aumentado de abortos e não gestações e prevalências maiores dos demais desfechos gestacionais nas áreas contaminadas, estudos longitudinais são necessários para confirmar se as 
rotas de exposição existentes estão afetando a saúde reprodutiva da população destas áreas.

A fase 3 consistiu uma abordagem preliminar da distribuição espacial dos desfechos gestacionais, sendo necessárias outras abordagens estatísticas espaciais na área para compreender melhor os padrões de distribuição destes eventos. E também é objeto de trabalho futuro estender as análises espaciais para as demais áreas, exceto a área 1, onde toda a população foi removida. 


\section{CONCLUSÕES}

A taxa bruta de natalidade e a taxa de fecundidade total diminuíram entre 2003 e 2007 nos quatro municípios, de forma mais acentuada no município de Bertioga. As taxas de fecundidade total em 2007 estavam abaixo da taxa de reposição populacional nos quatro municípios (Bertioga, Cubatão, Guarujá e São Vicente).

Com base nos dados do SINASC entre 2003 e 2007, houve risco duas vezes maior de ocorrência de baixo peso de nascimento e parto prematuro em São Vicente, Cubatão e Guarujá que em Bertioga, controlado por: idade, estado civil e escolaridade da mãe, número de consultas prénatal, e malformações congênitas. No Guarujá e em Cubatão houve risco maior de nascidos vivos com malformação congênita que em Bertioga entre 2003 e 2007, controlado por: idade e estado civil da mãe, número de consultas pré-natal, e nascimento múltiplo. Não houve diferença no risco de ocorrência de nascimentos múltiplos entre os municípios pela análise de regressão logística múltipla.

Risco pequeno, mas significativamente maior das mulheres em idade fértil não engravidar foi encontrado nas áreas contaminadas (área 2, 3 e 4) que na área não contaminada (área 5), controlado para idade e escolaridade materna, e renda familiar.

A ocorrência de aborto teve risco quase duas vezes maior na área 3 que na área controle (área 5), controlado para anos morando na região, 
idade materna e escolaridade materna, renda familiar e tabagismo materno anterior.

Não foi encontrado aumento no risco de ocorrência de baixo peso ao nascer, parto prematuro, natimorto, malformação congênita e nascimento múltiplo nas áreas contaminadas comparando com a área controle.

Não houve associação entre não engravidar e ocorrência de aborto entre as mulheres que moravam em um raio de $1 \mathrm{~km}$ dos locais de deposição de resíduos industriais na região de São Vicente continental (área 3) comparado com as mulheres que moravam fora do "buffer". 


\section{ANEXOS}

\subsection{Anexo A - Carta de Consentimento Livre e Esclarecido}

\section{CARTA PARA OBTENÇÃO DO CONSENTIMENTO LIVRE E ESCLARECIDO}

Caro(a) Senhor(a)

A Universidade Católica de Santos, através do grupo de pesquisa em Meio Ambiente e Saúde, do programa de pós-graduação em Saúde Coletiva, e em colaboração com o Laboratório de Poluição Atmosférica Experimental da Faculdade de Medicina da USP, Programa de Pediatria Ambiental da Faculdade de Medicina da UNISA, Laboratório de Biofísica da UFRJ e CEDEC, está desenvolvendo um estudo intitulado "Estudo Epidemiológico Na População Residente Na Baixada Santista - Estuário de Santos: Avaliação de Indicadores de Efeito e de Exposição A Contaminantes Ambientais" que tem por objetivo avaliar os impactos da contaminação por produtos químicos (metais pesados, organoclorados, PCBs e dioxinas e furanos) na gestação e no concepto, no desenvolvimento cognitivo (ganho de conhecimento) das crianças e adolescentes, nos sistemas reprodutivo e respiratório e no desenvolvimento de tumores nos moradores da região do Estuário de Santos e São Vicente.

Essa região tem sido alvo de contaminações de água, solo e ar ao longo dos últimos 50 anos. Apesar de todos estes contaminantes estarem presentes na região do estuário ainda não há estudos conclusivos sobre os seus efeitos sobre os moradores da região.

Em uma primeira fase aplicaremos questionários para obtenção de dados demográficos e de saúde.

A sua participação nesta pesquisa, bem como a de seus dependentes menores de idade é voluntária. Não haverá remuneração financeira para os participantes e também não haverá custo para os participantes. Todos os procedimentos necessários para a realização do estudo serão pagos com recursos específicos para este fim. Serão fornecidos a todos os participantes as informações de saúde coletadas durante a pesquisa.

Se, durante qualquer etapa do desenvolvimento do estudo houver alguma dúvida sobre procedimentos realizados ou informações coletadas pelos participantes do estudo, os pesquisadores responsáveis poderão ser contatados. 
Também é garantida a liberdade da retirada do consentimento de participação a qualquer momento, com a sua retirada e a de seus dependentes menores de idade do estudo. As informações referentes a você e aos seus serão excluídas e destruídas, deixando de serem analisadas.

Todas as informações obtidas serão analisadas em conjunto e não será divulgada a identidade de nenhum dos participantes. Os coordenadores do projeto ficarão responsáveis por contatar os participantes e seus dependentes, diretamente, caso algum resultado da pesquisa seja de interesse imediato para o participante e requeira ação imediata.

Pesquisadores Responsáveis (poderão ser contatados a qualquer momento)

Alfésio Luís Ferreira Braga (RG 8371855)

Universidade Católica de Santos - Rua Carvalho de Mendonça, 144, sala 401, Vila Mathias, CEP 11070-100, Santos, SP. Tel/Fax: (13) 3226-0505

Hospital Estadual do Grajaú / Faculdade de Medicina da Universidade de Santo Amaro - Av. Francisco Octávio Pacca, 180, Grajaú, São Paulo, SP.

Luiz Alberto Amador Pereira (RG)

Universidade Católica de Santos - Rua Carvalho de Mendonça, 144, sala 401, Vila Mathias, CEP 11070-100, Santos, SP. Tel/Fax: (13) 3226-0505 
Termo de Consentimento Livre e Esclarecido

Acredito ter sido suficiente informado à respeito do "Estudo Epidemiológico Na População Residente Na Baixada Santista - Estuário de Santos: Avaliação de Indicadores de Efeito e de Exposição A Contaminantes Ambientais". Ficaram claros para mim quais são os propósitos do estudo, os procedimentos a serem realizados, as garantias de confidencialidade e de esclarecimentos permanentes.

Ficou claro também que a minha participação é isenta de despesas e de remuneração; que tenho garantia do acesso aos resultados e de esclarecer minhas dúvidas a qualquer tempo.

Concordo voluntariamente em participar deste estudo e poderei retirar o meu consentimento a qualquer momento, antes ou durante o mesmo, sem penalidade ou prejuízo.

Nome:

Endereço:

RG:

Fone:

Data

1

Assinatura do informante

Assinatura do(a) pesquisador(a) 
9.2 ANEXO B - QUESTIONÁRIO

INQUÉRITO DOMICILIAR DE RISCO E MORBIDADE REFERIDA

PARTE 1

№ QUEST:

Entrevistador:

Data:

Área:
1) Pilões - Cubatão
2) Centro de Cubatão
3) São Vicente
4) Guarujá
5) Bertioga

End. do domicílio:

Compl.: CEP:

Setor censitário:

Telefone: 
PARTE 2 - IDENTIFICAÇÃO DO DOMICÍLIO

INÍCIO - ـ___ : : |__ horas min

1. Como você define o seu domicílio?

$1 \mid \_$alvenaria $\quad 2 \mid \_$palafita $3 \mid$ | madeira $4 \mid \_$outros $99\left|\_\right| N S / N R$

2. Quantos domicílios como o seu existem num raio de 250 metros de sua residência?
$1\left|\_\right| 1-3$
$2 \mid+4-6$
$3|+| 7-10$
$4 \mid+11-15$
$5\left|\_\right| 16-20$
$6\left|\_\right| 21$ ou
mais
99|_ NS/NR

3. Há quantos anos você reside nesse domicílio?
$1 \mid \_$menos de 1
$2 \mid-1-3$
$3\left|\_\right| 3-5$
$4 \mid$ | 5-10
$5 \mid \_10-15$
$6 \mid+15-$
20
$7 \mid$ | mais de $20 \quad 99\left|\_\right| N S / N R$

4. Há quantos anos você reside na região?
$1 \mid$ _ menos de 1
$2 \mid$ | 1-3
$3|+| 3-5$
$4 \mid+5-10$
$5\left|\_\right| 10-15$
$6 \mid+15-$ 20
$7\left|\_\right|$mais de $20 \quad 99\left|\_\right|$NS/NR

4a. Qual é o revestimento da sua rua?

$1\left|\_\right|$asfalto $\quad 2\left|\_\right|$bloquete de concreto $3\left|\_\right|$entulho $\quad 4\left|\_\right|$areia $5 \mid$ barro batido 6|_ paralelepípedo $7 \mid \_$palafita $99 \mid$ _ NS/NR

4b. Num raio de 500 metros da sua residência existem os seguintes estabelecimentos comerciais? 
1 __ lavanderia 2|_| posto de gasolina 3|__ oficina mecânica 4 __ oficina de funilaria/pintura 5 __ estabelecimentos c/forno a lenha $6\left|\_\right|$materiais de construção $7\left|\_\right|$outros $99\left|\_\right|$NS/NR

4c. Num raio de 500 metros da sua residência existem estabelecimentos com as seguintes atividades comerciais?

$1\left|\_\right|$revestimento de metais

$2 \mid$ _ terminais de

carga/descarga

3|__ armazenagem de fertilizantes/produtos químicos containers

$4 \mid$ _ pátio de

$5 \mid$ __ estabelecimentos $\mathrm{c} /$ forno a lenha

$6 \mid \_$aterros industriais

ou domésticos

$7 \mid \_$outros

$99 \mid \ldots N S / N R$

\section{COMO O DOMICÍLIO É CONSTITUÍDO?}

5. Parede (Resposta Múltipla)

1 __ barro 2 ___ madeira $3 \mid$ _ tijolo/bloco $4 \mid$ _ cimento $5 \mid$ _ massa corrida/tinta $6 \mid \_$outros $99\left|\_\right|$NS/NR

6. Piso (Resposta Múltipla)

1 __ terra $2\left|\_\right|$cimento $3\left|\_\right|$cerâmica $\quad 4\left|\_\right|$madeira $5\left|\_\right|$carpete nylon/fibra

$6 \mid \_$outros $99\left|\_\right| N S / N R$

6a. Telhado

1 __ barro 2 2__ amianto $3\left|\_\right|$zinco $4 \mid \_$outros $5\left|\_\right|$não existe

6b. Forro da casa

1|_ concreto/laje 2|_ madeira $3 \mid \_$gesso $\quad 4 \mid \_$outros $5 \mid \_$não existe (pule $\mathrm{p} / 7$ ) 
6c. Quais cômodos possuem forro? (Resposta Múltipla)

1 __ sala 2|_ cozinha $3 \mid$ _ quarto 4 |_ banheiro

7. A casa tem umidade?

$1\left|\_\operatorname{sim} 2\right| \_\mid$não (pule $p /$ questão 8a)

8. Em quais cômodos? (Resposta Múltipla)

$1 \mid \_$sala $2 \mid \_$quarto $3\left|\_\right|$cozinha $4 \mid \_$banheiro

8a. A caixa d'água é feita de que material?

1|_ amianto 2|_ plástico/polietileno 3 __ fibra de vidro 4 |_ outros

$5 \mid \_$não existe cx. d'água $6 \mid \_$não sei

SITUAÇÃO EM RELAÇÃO À ÁGUA, LUZ, ESGOTO E LIXO DOMICILIAR

9. Qual a origem da água utilizada em seu domicílio para beber? (Uso

Predominante)

1__ Sabesp 2|_| comprada 3|_l caminhão pipa 4 __ poço $\quad 5 \mid$ nascente

6|_ bica $\quad 7\left|\_\right|$córrego/riacho $8 \mid \_$rio/cachoeira $9 \mid \_$outros $99 \mid$ NS/NR

10. Há quanto tempo a origem é essa?

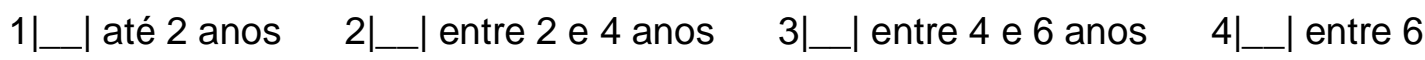
e 8 anos

$5\left|\_\right|$mais de 8 anos $99\left|\_\right|$NS/NR

11. Antes do consumo ela passa por algum tratamento? (Resposta Múltipla) 
1__ clorada 2|_ filtrada 3|_| fervida $4 \mid$ _ outro tratamento $5 \mid$ _ não existe tratamento $99 \mid$ _ NS/NR

12. Qual a origem da água utilizada em seu domicílio para o banho? (Uso Predominante)

1 __ Sabesp 2|_ comprada 3 __ caminhão pipa $4 \mid$ _ poço $5 \mid$ nascente

$6 \mid$ _ bica $\quad 7\left|\_\right|$córrego/riacho $8 \mid$ _ rio/cachoeira 9|_loutros $99 \mid$ NS/NR

13. Há quanto tempo a origem é essa?

$1{ }_{1} \_$até 2 anos $\quad 2\left|\_\right|$entre 2 e 4 anos $\quad 3\left|\_\right|$entre 4 e 6 anos $4 \mid$ _ entre 6 e 8 anos

$5\left|\_\right|$mais de 8 anos $99|\ldots|$ NS/NR

14. Antes da utilização ela passa por algum tratamento? (Resposta Múltipla)

$1 \mid$ _ clorada $2 \mid \_$filtrada $3\left|\_\right|$fervida $4 \mid$ _ outro tratamento $5 \mid$ _ não existe tratamento $99|\ldots|$ NS/NR

15. Qual a origem da água utilizada em seu domicílio para o preparo de alimentos? (Uso Predominante)

\begin{tabular}{|c|c|c|c|c|}
\hline $\begin{array}{l}1\left|\_\right| \text {Sabesp } \\
\text { nascente }\end{array}$ & $2\left|\_\right|$comprada & $3 \mid$ __ caminhão pipa & $\left.4\right|_{\_} \mid$poço & $5 \mid$ \\
\hline $6\left|\_\right|$bica & $7 \mid$ __ córrego/riacho & $8 \mid \_$rio/cachoeira & 9 9|_ outros & $99 \mid$ \\
\hline
\end{tabular}

16. Há quanto tempo a origem é essa?

$1{ }_{1} \_$até 2 anos $\quad 2\left|\_\right|$entre 2 e 4 anos $\quad 3\left|\_\right|$entre 4 e 6 anos $4 \mid$ _ entre 6 e 8 anos

$5 \mid \_$mais de 8 anos $99 \mid$ _ NS/NR 
17. Antes da utilização ela passa por algum tratamento? (Resposta Múltipla)

1 __ clorada 2|_ filtrada $3\left|\_\right|$fervida $4 \mid$ _ outro tratamento $5 \mid$ _ não existe tratamento $99|\ldots| N S / N R$

18. Qual a origem da água utilizada em seu domicílio para uso geral? (Uso Predominante)

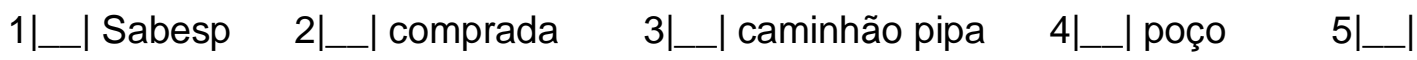
nascente

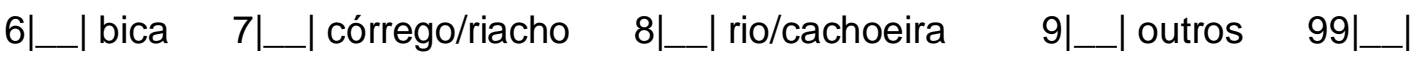
NS/NR

19. Há quanto tempo a origem é essa?

1 1__ até 2 anos $2|\ldots|$ entre 2 e 4 anos $3|\ldots|$ entre 4 e 6 anos $4 \mid$ _ entre 6 e 8 anos

$5\left|\_\right|$mais de 8 anos $99\left|\_\right|$NS/NR

20. Antes da utilização ela passa por algum tratamento? (Resposta Múltipla)

1 1_ clorada $2\left|\_\right|$filtrada $3\left|\_\right|$fervida $4 \mid \ldots$ outro tratamento $5\left|\_\right|$não existe tratamento $99|\ldots|$ NS/NR

20a. Nos últimos 12 meses, o fornecimento de água foi interrompido em alguma das 4 estações do ano? (Resposta Múltipla)

1 ___ primavera (23/09 a 20/12) 2|_| verão (21/12 a 19/03) 3|_| outono (20/03 a 20/06) 4 _ _ inverno (21/06 a 22/09) ـ| não houve interrupção 99| $\mid \mathrm{NS} / \mathrm{NR}$

21. Como é o esgoto de sua residência?

$1 \mid$ | fossa + rede de esgoto $\quad 2\left|\_\right|$fossa + solo $\quad 3\left|\_\right|$fossa + céu aberto

$4 \mid$ _ céu aberto $5\left|\_\right|$encanado $\quad 6 \mid \_$l outros $\quad 99\left|\_\right|$NS/NR 
22. Qual o destino do lixo gerado em seu domicílio? (Destino Predominante)

$1\left|\_\right|$coleta $\quad 2\left|\_\right|$terreno baldio $3 \mid$ _ queimado $4 \mid$ _ córrego $5 \mid$ caçamba

$6 \mid \_$outro $99\left|\_\right| N S / N R$

23. A coleta de lixo acontece

$1\left|\_\right|$todos os dias $2\left|\_\right| 2$ a $3 x$ semana $3\left|\_\right| 1 x$ semana $4\left|\_\right|$não acontece $99\left|\_\right| N S / N R$

24. A iluminação de sua residência é:

1 ___ elétrica 2 __ óleo ou querosene $3 \mid$ _ gás $4 \mid$ _ não tem iluminação $5 \mid \_$outros $99\left|\_\right| N S / N R$

25. O fogão é:

1|_ gás 2|__ lenha $3 \mid \_$carvão $4 \mid \_$querosene $5\left|\_\right|$não tem fogão $6 \mid \_$outros $99\left|\_\right| N S / N R$

\section{DADOS DOS MORADORES}

Espaço para 12 moradores, ou seja, as questões 27 a 36 serão repetidas em até 12 vezes, dependendo do número de moradores da residência.

26. Quantas pessoas moram na casa:

Morador 1:

Morador 7:

Morador 2:

Morador 8:

Morador 3:

Morador 9:

Morador 4:

Morador 10:

Morador 5:

Morador 11:

Morador 6:

Morador 12: 
27. Nome do morador 1 (INFORMANTE):

28. Relação com o chefe da família:

$1\left|\_\right|$chefe $2\left|\_\right|$cônjuge $3\left|\_\right|$filho(a) $4 \mid$ _ outras relações familiares

$5 \mid \_$agregado sem relação de parentesco $\quad 6 \mid \_$empregado

29. Sexo

1___ feminino 2|_ masculino

30. Idade

Resposta Anos:

Resposta Meses (Apenas menor de um ano):

31. Estado Civil

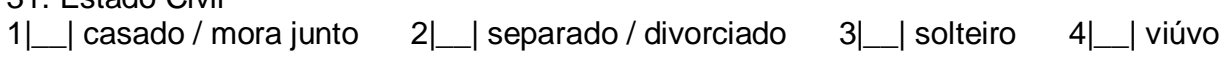

32. Qual sua cor?

1__| branco 2|_| negro 3|_| pardo 4|_ amarelo 5|_| indígena 6|_ outro

33. Escolaridade

1.__ Ensino Fundamental (Até $2^{\mathrm{a}}$ Série)

2|__ Ensino Fundamental $\left(3^{\mathrm{a}}-5^{\mathrm{a}}\right.$ Série $)$

3__ Ensino Fundamental $\left(6^{\mathrm{a}}-7^{\mathrm{a}}\right.$ Série)

4___ Ensino Fundamental completo

5___ Ensino Médio incompleto

6___ Ensino Médio completo

$7 \mid \_$S Superior incompleto

8|__ Superior completo

9) analfabeto

10|__ não se aplica

99|__ não sabe

34. Está trabalhando remuneradamente atualmente?

1 __ $\operatorname{sim}($ Pule para questão 36) 2|_| não

35. Por que não está trabalhando remuneradamente?

1|_ desempregado

2|__ afastado por doença ou acidente

3|__ aposentado / pensionista

4|__ dona de casa

5|_loutro

6|__ não se aplica

36. $\mathrm{O}(\mathrm{a}) \mathrm{sr}(\mathrm{a})$ tem direito a algum plano de saúde (médico ou odontológico)?

1|_| sim 2|__ não

37. Qual a renda familiar aproximadamente?

1___ menor que meio Salário Mínimo (190 Reais)

2___ entre meio e 1 Salário Mínimo (190 - 380 Reais)

3___ 1 a 3 Salários Mínimos (381 - 1140 Reais)

4|_ 3 a 5 Salários Mínimos (1141 - 1900 Reais)

5[_| 5 a 10 Salários Mínimos (1901 - 3800 Reais)

6|_ 10 a 20 Salários Mínimos (3801 - 7600 Reais)

7[_| mais que 20 Salários Mínimos (> 7600 Reais)

8|_| não sabe informar

9[_| não quer informar 


\section{USO DE SERVIÇOS DE SAÚDE}

Espaço para 12 moradores, ou seja, as questões 38 a 40 serão repetidas em até 12 vezes, dependendo do número de moradores da residência.

Alguém no domicílio freqüenta algum serviço de saúde pelo menos uma vez por ano?

Morador 1:

Morador 7:

Morador 2:

Morador 8:

Morador 3:

Morador 9:

Morador 4:

Morador 10:

Morador 5:

Morador 11:

Morador 6:

Morador 12:

\section{MORADOR 1}

38. Freqüenta algum serviço de saúde pelo menos uma vez por ano?

1 __ $\operatorname{sim} 2 \mid \_$não (pule $\mathrm{p} / 41$ ou passe para o próximo morador)

39. Quando foi a última vez?

$1 \mid$ _ menos de 1 mês

4 __ entre 6 e 12 meses

$2 \mid \_$entre 1 e 3 meses

$5 \mid$ _ mais de 1 ano

3|_ entre 3 e 6 meses

99|_| NS/NR

40. Que tipo de serviço utilizou?

1|_ Pronto Socorro

2|__ Ambulatório de Especialidades

6|__ Consultório Particular Médico

7___ Consultório do Convênio 
3|__ Centro de Reabilitação

8|_| Outro

4|__ Serviço de Saúde Mental

$5 \mid$ _ UBS

99|_ NS/NR

41. Alguém da casa foi internado no último ano?

$1\left|\_\operatorname{sim} 2\right| \_\mid$não (Pule para o próximo módulo)

42. Quem?

Morador 1:

Morador 7:

Morador 2:

Morador 8:

Morador 3:

Morador 9:

Morador 4:

Morador 10:

Morador 5:

Morador 11:

Morador 6:

Morador 12:

Espaço para 12 moradores, ou seja, as questões 43 e 44 serão repetidas em até 12 vezes, dependendo do número de moradores da residência.

\section{MORADOR 1}

43. Quantas vezes:

44. Qual o motivo da internação? (Caso tenha havido mais de uma, descreva o motivo no campo correspondente)

última internação:

penúltima internação:

antepenúltima internação: 
PARTE 3 - MÓDULO INGESTÃO ALIMENTAR.

INÍCIO DO MÓDULO - |___ : : |__ horas min

1. De onde vêm as verduras e legumes consumidos na residência? (Múltipla)

1 ___ horta própria 2 ___ horta da comunidade $3 \mid$

quitanda/mercado/sacolão

$4 \mid$ _ hiper e supermercado $5 \mid$ _ feira livre $\quad 6 \mid$ NS/NR

2. Quantas vezes por semana são consumidas verduras e legumes em sua residência?

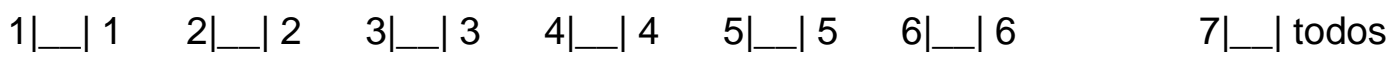
os dias

$8 \mid \_$não são consumidas $\quad 9 \mid \_$quinzenal $\quad 10\left|\_\right|$mensal $\quad 99\left|\_\right|$NS/NR

3. De onde vêm as frutas consumidas na residência? (Múltipla)

1 __ horta própria $\quad 2 \mid \_$horta da comunidade $3 \mid$ quitanda/mercado/sacolão

$4{ }_{1} \_$hiper e supermercado $5 \mid$ _ feira livre $\quad 6 \mid \_$outro NS/NR

4. Quantas vezes por semana são consumidas frutas em sua residência?
$1|+| 1$
$2\left|\_\right| 2 \quad 3\left|\_\right| 3$
$4|+| 4$
$5 \mid$
$6 \mid \_6$
$7 \mid$ _ todos
os dias
8|_ não são consumidas
$9 \mid \_$quinzenal $\quad 10\left|\_\right|$mensal
$99\left|\_\right| N S / N R$

5. De onde vêm o leite e derivados consumidos na residência? (Múltipla)
$1 \mid$ _ criação própria $2 \mid \_$| criação da comunidade $3 \mid$ quitanda/mercado/padaria
$4 \mid$ _ hiper e supermercado
$5\left|\_\right|$feira livre
$6 \mid \_$outro
$99\left|\_\right| N S / N R$ 
6. Quantas vezes por semana são consumidos leite e derivados em sua residência?

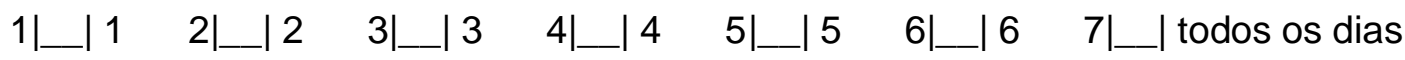
$8 \mid \_$não são consumidos $\quad 9 \mid$ _ quinzenal $\quad 10\left|\_\right|$mensal $\quad 99 \mid$ _ NS/NR

7. De onde vem o ovo consumido na residência? (Múltipla)

1 ___ criação própria $2 \mid \_$criação da comunidade $3 \mid$ quitanda/mercado/avícola

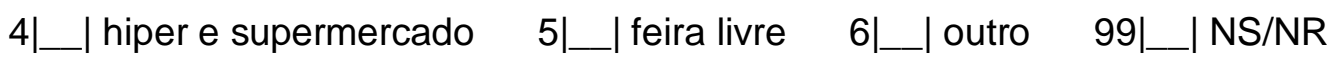

8. Quantas vezes por semana é consumido ovo em sua residência?

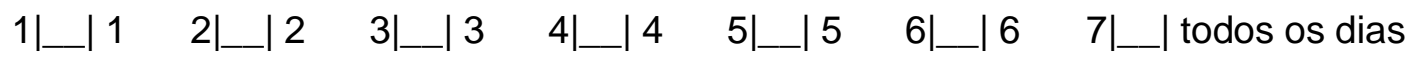

$8 \mid \_$não é consumido $9 \mid \_$quinzenal $\quad 10\left|\_\right|$mensal $99 \mid$ _ NS/NR

9. De onde vem a carne de frango ou galinha consumida na residência? (Múltipla)

$1 \mid \_$| criação própria $2 \mid \_$criação da comunidade $3 \mid$ __ mercado/avícola

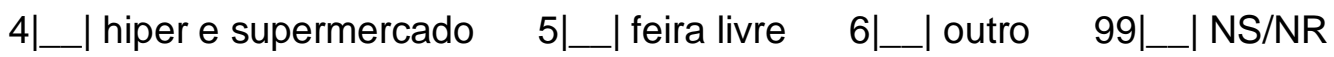

10. Quantas vezes por semana é consumida carne de frango ou galinha em sua residência?

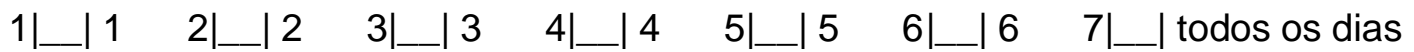
$8\left|\_\right|$não é consumida $9 \mid \_$quinzenal $10\left|\_\right|$mensal $99\left|\_\right|$NS/NR

11. De onde vem a carne de porco consumida na residência? (Múltipla)

1 ___ criação própria $2\left|\_\right|$criação da comunidade $3 \mid$ __ açougue/mercado

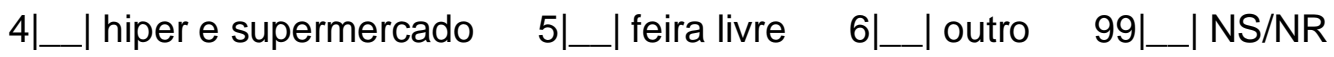


12. Quantas vezes por semana é consumida carne de porco em sua residência?

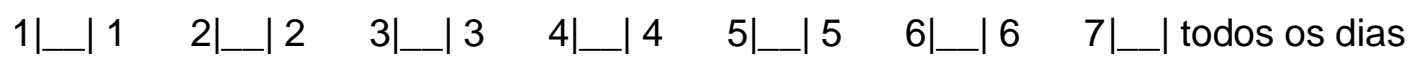
$8\left|\_\right|$não é consumida $9 \mid$ _ quinzenal $\quad 10\left|\_\right|$mensal $99\left|\_\right|$NS/NR

13. De onde vem a carne vermelha consumida na residência? (Múltipla) 1 ___ criação própria 2 __ criação da comunidade $3 \mid$ __ açougue/mercado

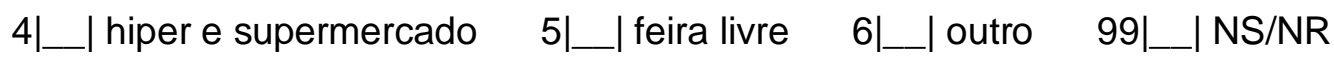

14. Quantas vezes por semana é consumida carne vermelha em sua residência?

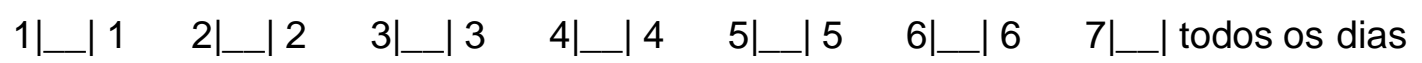
$8\left|\_\right|$não é consumida $9\left|\_\right|$quinzenal $\quad 10\left|\_\right|$mensal $99\left|\_\right|$NS/NR

15. De onde vem o peixe consumido na residência? (Múltipla)

1 ___ pescado na comunidade $2 \mid$ _ pescado em outra região $3 \mid$ peixaria/mercado

$4{ }_{1}$ | hiper e supermercado $\left.5\right|_{\ldots}$ feira livre $6 \mid \_$outro $99\left|\_\right|$NS/NR

16. Quantas vezes por semana é consumido peixe em sua residência?

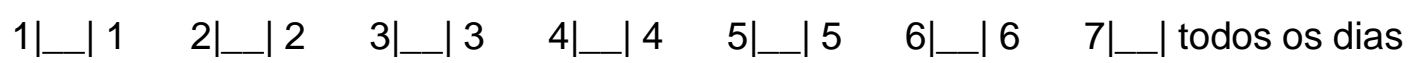
$8\left|\_\right|$não é consumido $9 \mid \_$quinzenal $\quad 10\left|\_\right|$mensal $99\left|\_\right| N S / N R$

17. De onde vem os moluscos e crustáceos consumidos na residência? (Múltipla)

1 __ pescado na comunidade $2 \mid \ldots$ pescado em outra região $3 \mid$ peixaria/mercado

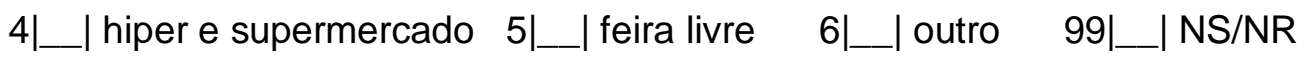

18. Quantas vezes por semana são consumidos moluscos e crustáceos em sua residência?

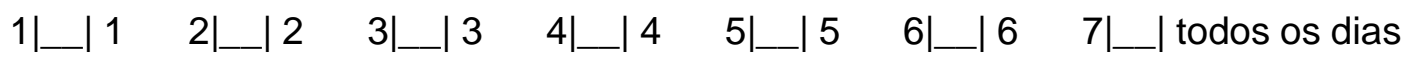


$8\left|\_\right|$não é consumido $9 \mid \_$quinzenal $10\left|\_\right|$mensal $99\left|\_\right| N S / N R$ 
PARTE 4 - MÓDULO EXPOSIÇÃO OCUPACIONAL ATUAL.

(Para responder as próximas questões, veja o número de identificação dos moradores da residência na pg. 4, questão 26)

1. Quais pessoas que moram nessa residência trabalham nos setores descritos e por quantos anos? (No campo correspondente ao indivíduo, indicado pelo informante, marque os anos trabalhados)

Indústria

Comércio

Prestação de Serviços

Outras

$$
1^{1 \mid-1}
$$

$1 \mid+1$

$1 \mid+1$

$1 \mid$

$2\left|\_\right| 2$

$2 \mid$

$2 \mid \_$

2|_ |

2

$3|+| 3$

$3 \mid 3$

$3 \mid$

3

3

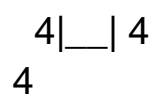

4

4

4|

$5\left|\_\right| 5$

5

5

5

5

$6\left|\_\right| 6$

$6 \mid$

$6 \mid 6$

$6 \mid$

6

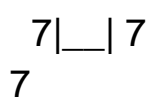

$7 \mid$

$7 \mid 7$

7

$8\left|\_\right| 8$

8

$8 \mid \_8$

8|

8

$$
9
$$

9

$9 \mid$

9

9

$10 \mid 10$

$10 \mid 10$

$10 \mid \_10$

10|

10

$11 \mid$ | 11

$11 \mid+11$

$11 \mid \_11$

11|

11

$12 \mid$

$12 \mid 12$

12|_ 12

12 
$99|\ldots| N S / N R$

$99|\ldots| N S / N R$

$99 \mid \_$NS/NR

$99 \mid$

$\mathrm{NS} / \mathrm{NR}$

2. Quais pessoas que moram em sua casa têm contato com produtos químicos no trabalho?

$1 \mid \begin{array}{ll}1 & 2\left|\_\right|\end{array}$

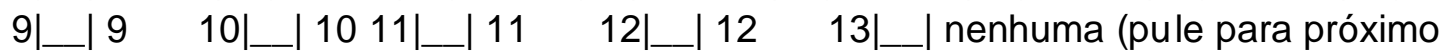
módulo) $99\left|\_\right| N S / N R$

3. Quais pessoas que moram em sua casa usam uniforme no trabalho?

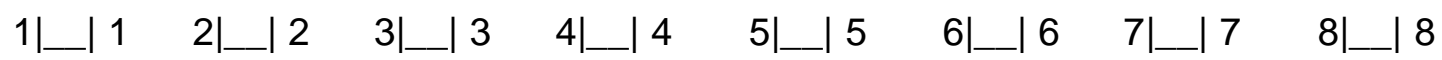

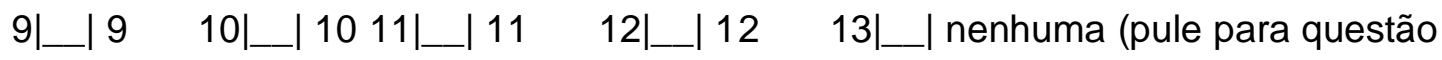
6) $99\left|\_\right| N S / N R$

4. Quais pessoas que moram em sua casa vão e voltam de uniforme?

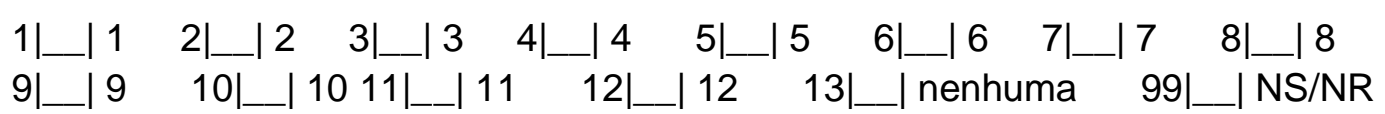

5. Quais pessoas que moram em sua casa vestem o uniforme apenas no trabalho?

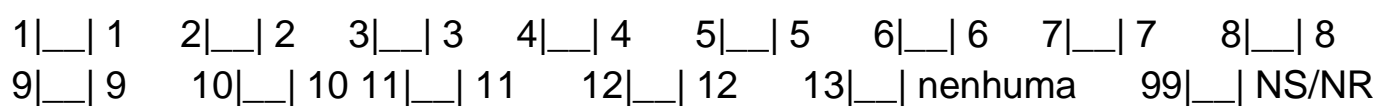
QUAIS PESSOAS SÃO EXPOSTAS AOS PRODUTOS DESCRITOS?

6. Combustível

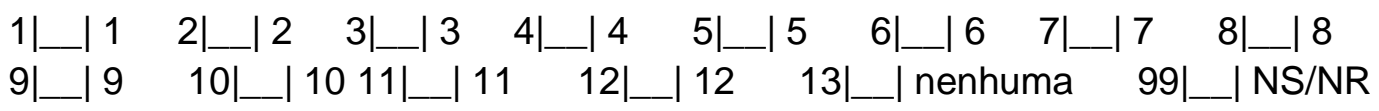

7. Pesticidas

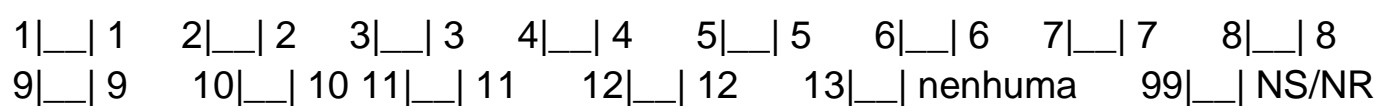


8. Inseticidas

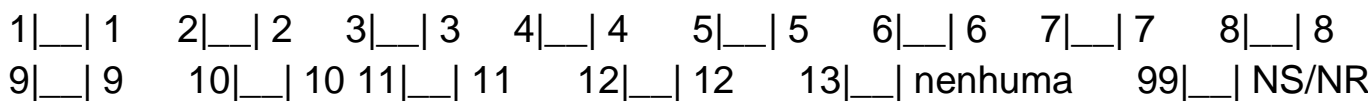

9. Fertilizantes

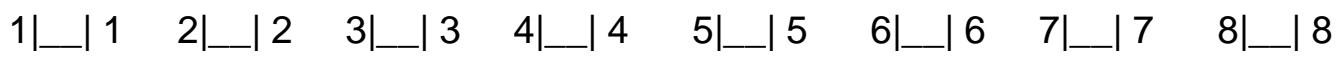

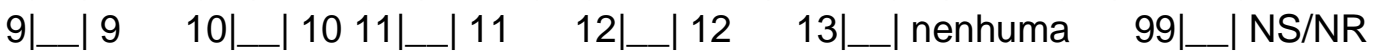

10. Adubos Químicos

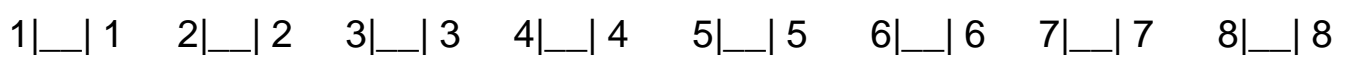
$9\left|\_\right| \begin{array}{ll}9 & 10\end{array}\left|\begin{array}{ll}10 & 11\end{array}\right| \_\left|\begin{array}{ll}11 & 12\end{array}\right| \begin{array}{ll}12 & 13\end{array}|\ldots|$ nenhuma $99|\ldots| N S / N R$

11. Tintas e Thiner

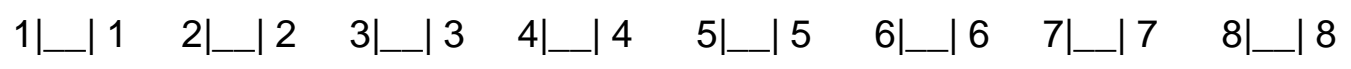

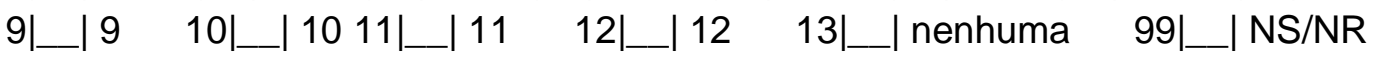

12. Querosene

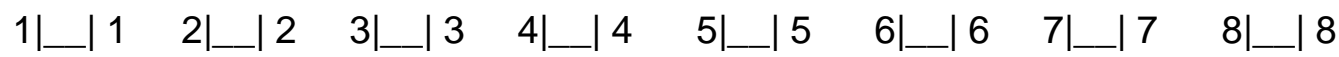

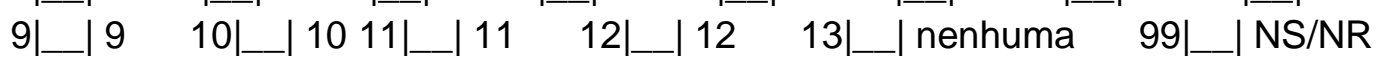

13. Outras

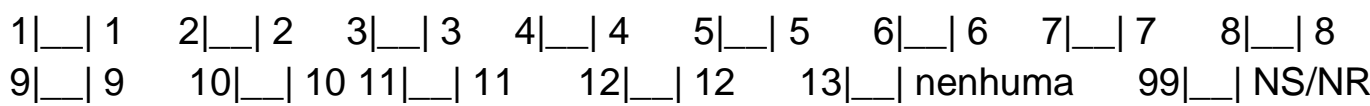

QUAIS PESSOAS SÃO EXPOSTAS AOS TIPOS DE POEIRA DESCRITOS?

14. Marcenaria

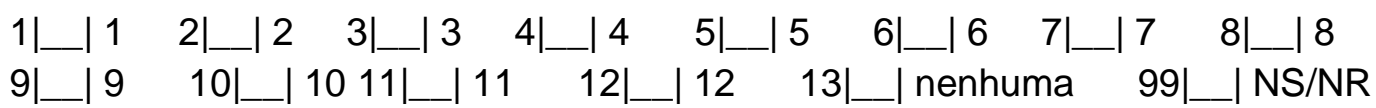


15. Serragem

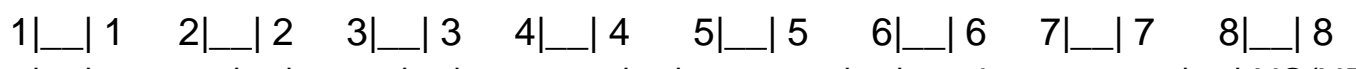

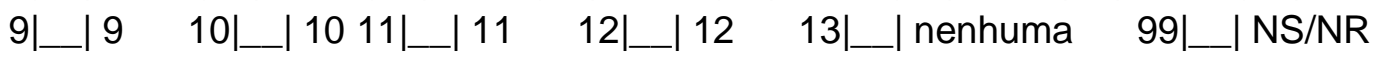

16. Pedreira

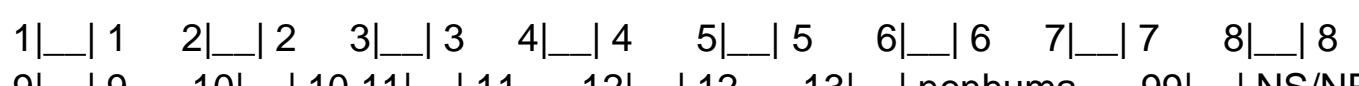

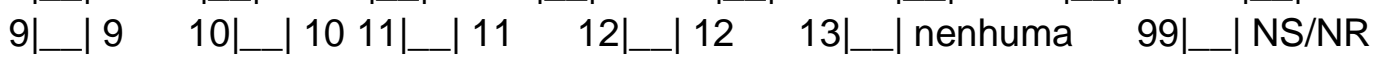

\section{Outras}

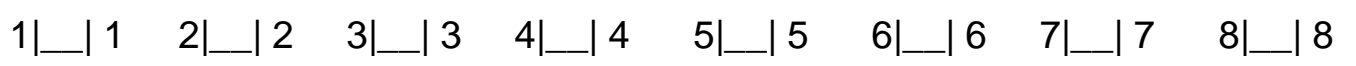

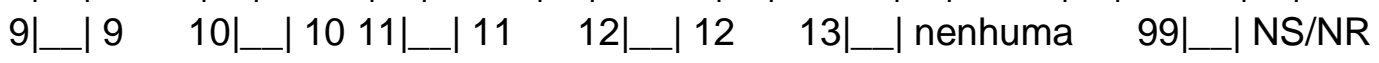


PARTE 5 - MÓDULO EXPOSIÇÃO OCUPACIONAL ANTERIOR.

(Para responder as próximas questões, veja o número de identificação dos moradores da residência na pg. 4, questão 26)

1. Quais pessoas que moram nessa residência trabalharam nos setores descritos e por quantos anos? (No campo correspondente ao indivíduo, indicado pelo informante, marque os anos trabalhados)

Indústria

Comércio

Prestação de Serviços

Outras$$
1\left|\_\right| 1
$$$$
1 \mid
$$$$
1 \mid+1
$$

1

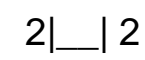

$2\left|\_\right| 2$

$2\left|\_\right| 2$

2|_

2

$3\left|\_\right| 3$

$3 \mid \_3$

$3 \mid$

$3 \mid$

3

$4 \mid$

$4 \mid$

4

4|

4

$$
5
$$

$5 \mid$

$5 \mid$

5

5

$6\left|\_\right| 6$

$6 \mid \_6$

$6 \mid \_6$

6

6

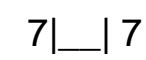

$7 \mid$

$7 \mid 7$

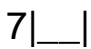

7

$8\left|\_\right| 8$

8

$8 \mid$

8|

8

$9 \mid$

$9 \mid$

$9 \mid \_9$

9|

9

10|_ 10

10| 10

$10 \mid 10$

10|

10

$11 \mid \_11$

$11 \mid \_11$

$11 \mid \_11$

11|_

11

12|_ 12

12|_ 12

12|_ 12

12| 
$99|\ldots| N S / N R$

NS/NR

$99\left|\_\right| N S / N R$

$99\left|\_\right| N S / N R$

$99 \mid$

2. Quais pessoas que moram em sua casa tiveram contato com produtos químicos no trabalho?

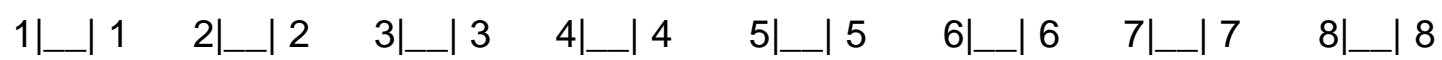

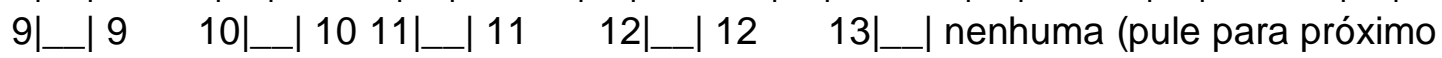
módulo) $\quad 99\left|\_\right| N S / N R$

3. Quais pessoas que moram em sua casa usavam uniforme no trabalho?

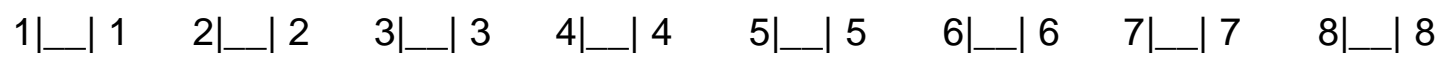

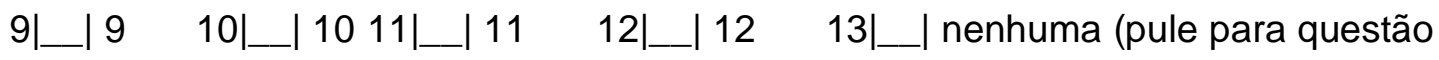
6) $99\left|\_\right| N S / N R$

4. Quais pessoas que moram em sua casa iam e voltavam de uniforme?

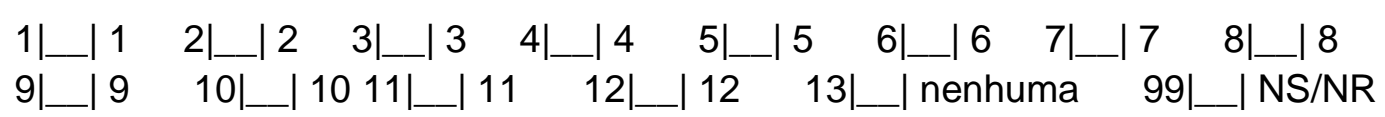

5. Quais pessoas que moram em sua casa vestiam o uniforme apenas no trabalho?

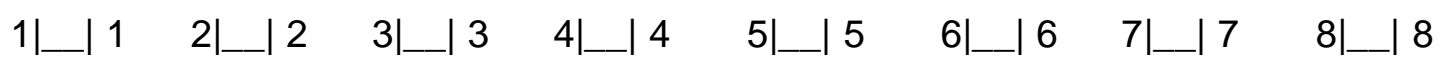

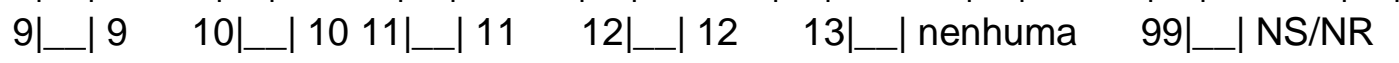

QUAIS PESSOAS FORAM EXPOSTAS AOS PRODUTOS DESCRITOS?

6. Combustível

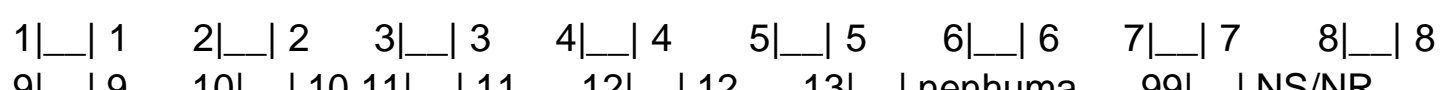

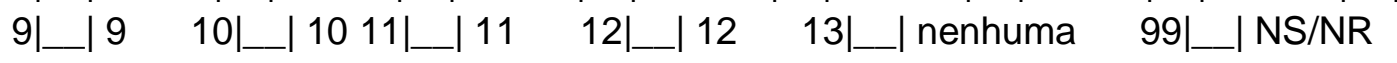

7. Pesticidas

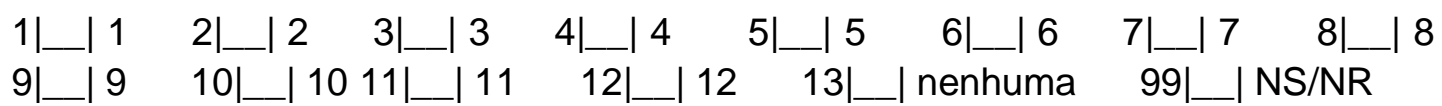


8. Inseticidas

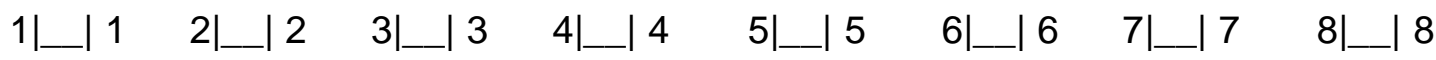

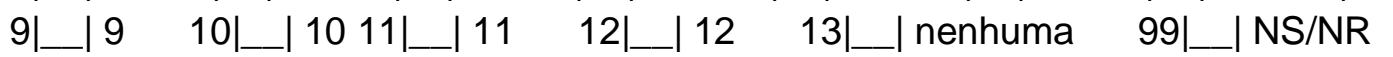

9. Fertilizantes

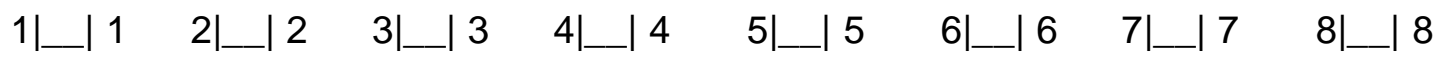

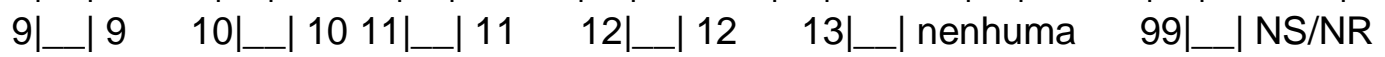

10. Adubos Químicos

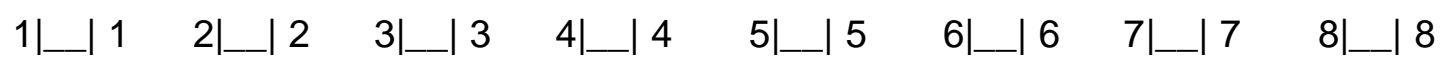

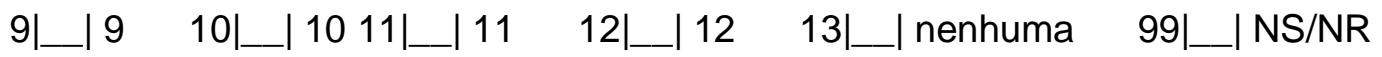

11. Tintas e Thiner

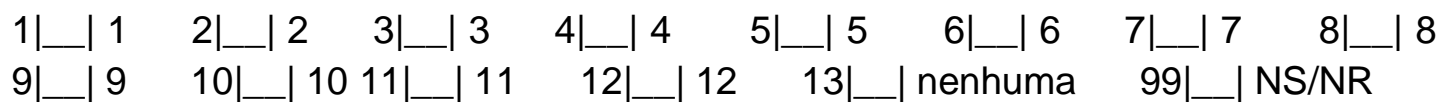

12. Querosene

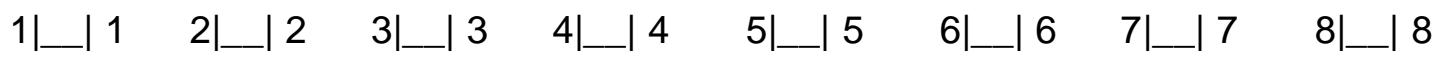

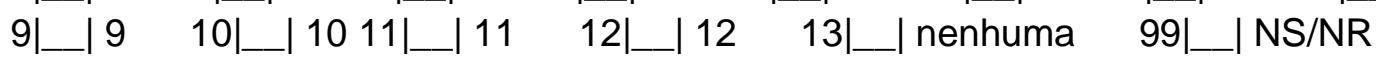

13. Outras

$1 \mid \begin{array}{ll}1 & 2\left|\_\right|\end{array}$

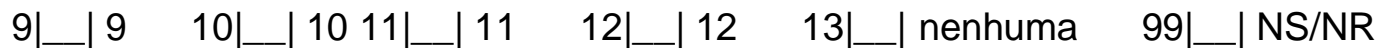

QUAIS PESSOAS FORAM EXPOSTAS AOS TIPOS DE POEIRA DESCRITOS?

14. Marcenaria

$1 \mid \begin{array}{ll}1 & 2\left|\_\right|\end{array}$

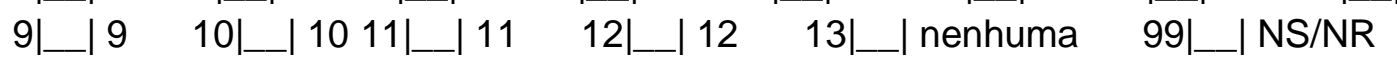


15. Serragem

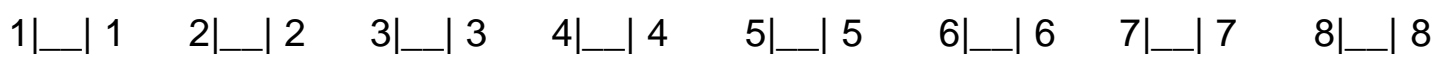

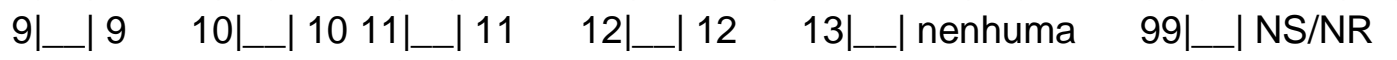

16. Pedreira

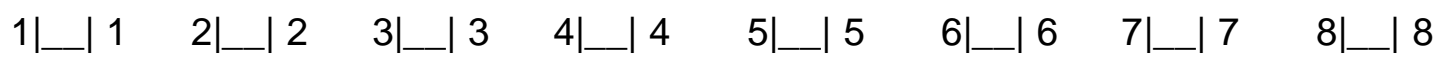

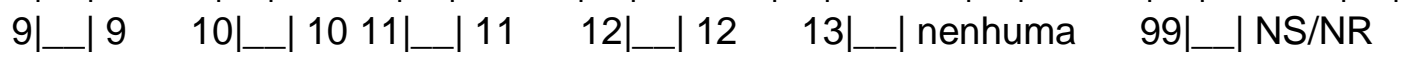

17. Outras

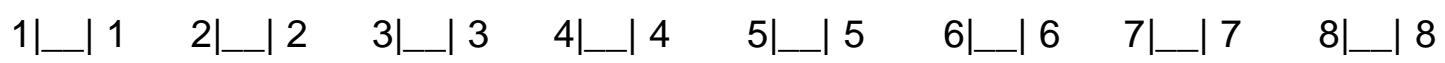

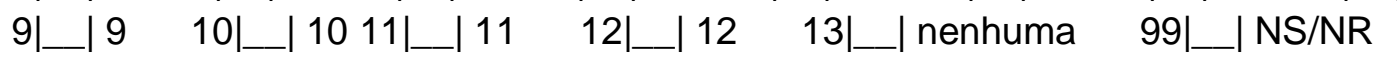




\section{PARTE 6 - MÓDULO TABAGISMO.}

(Para responder as próximas questões, veja o número de identificação dos moradores da residência na pg. 4, questão 26)

1. Quais pessoas que moram em sua casa fumam?

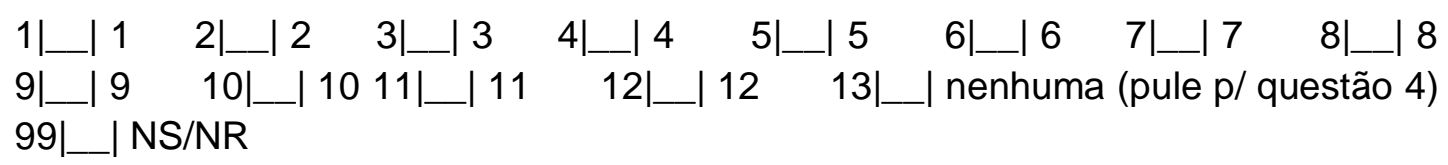

2. Há quantos anos essas pessoas fumam?

\begin{tabular}{|c|c|c|c|c|c|c|c|}
\hline $1 \mid 1$ & $\left.2\right|_{1} \mid 2$ & $3 \mid$ & $4 \mid 4$ & $5\left|\_\right| 5$ & $6 \mid \_6$ & $7 \mid$ & $8 \mid$ \\
\hline $9 \mid$ & $10 \mid$ & $11 \mid$ & 12 & $99 \mid$ & | NS/NR & & \\
\hline
\end{tabular}

3. Quantos cigarros elas fumam por dia?

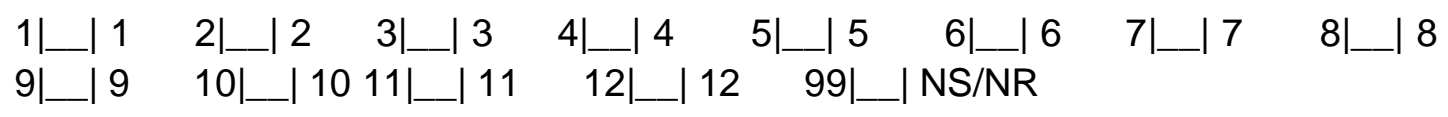

4. Quais pessoas que moram em sua casa já pararam de fumar?

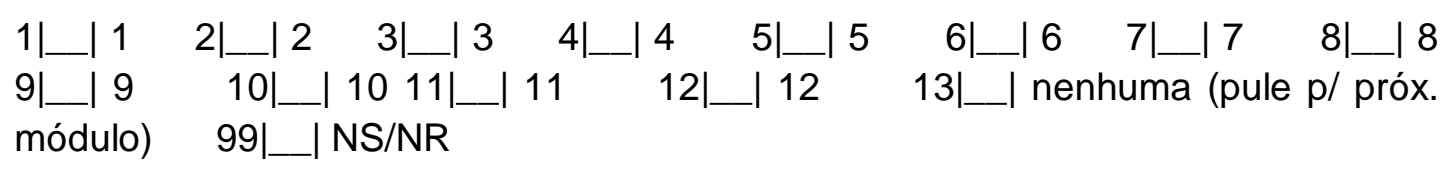

5. Quantos anos essas pessoas fumaram?

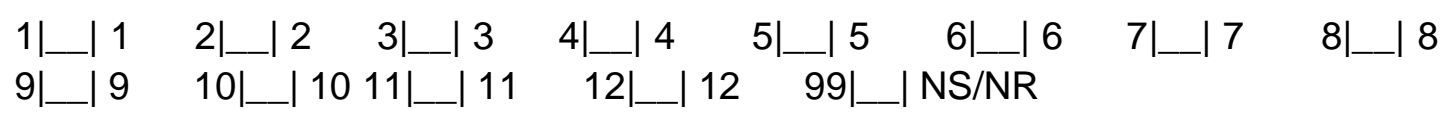

6. Há quantos anos essas pessoas deixaram de fumar?

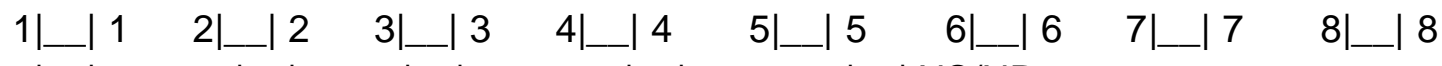

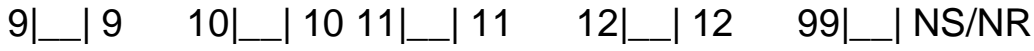

7. Quantos cigarros elas fumavam por dia? 


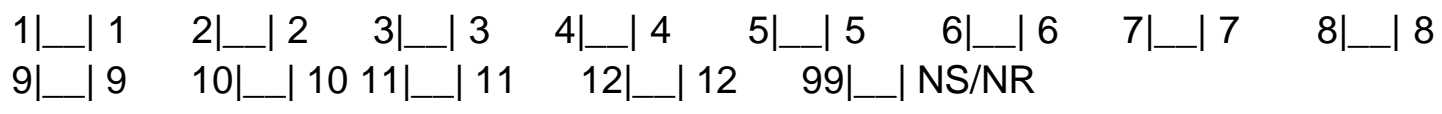


PARTE 7 - MÓDULO ALCOOLISMO.

(Para responder as próximas questões, veja o número de identificação dos moradores da residência na pg. 4, questão 26)

1. Quais pessoas que moram em sua casa consomem alguma bebida alcoólica como cerveja, vinho, cachaça, uísque, licores, etc?

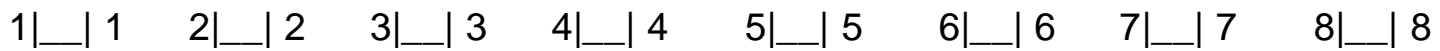

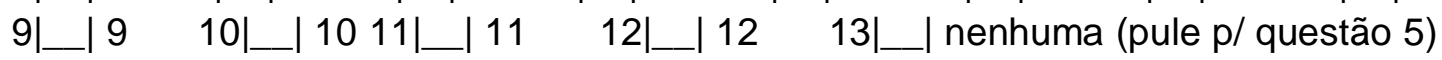
$99\left|\_\right| N S / N R$

2. Há quantos anos essas pessoas consomem alguma bebida alcoólica?

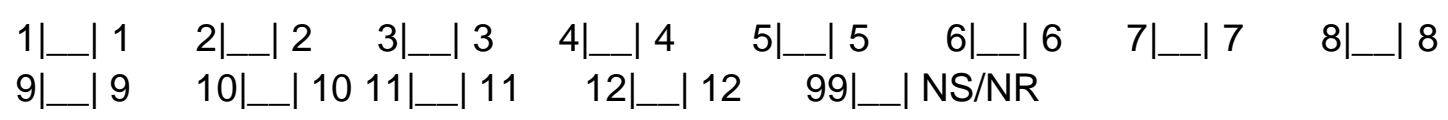

3. O consumo de bebida alcoólica é feito quantas vezes por semana?

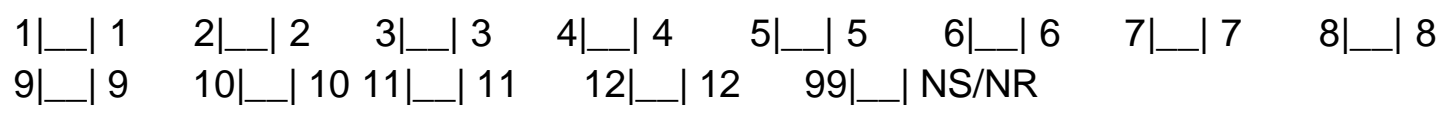

4. Quantas doses essas pessoas bebem por dia?

( 1 dose de bebida alcoólica = 1 lata de cerveja ou 1 taça de vinho ou 1 drinque ou 1 cocktail ou 1 dose de cachaça ou uísque. Considerar a média do consumo diário)

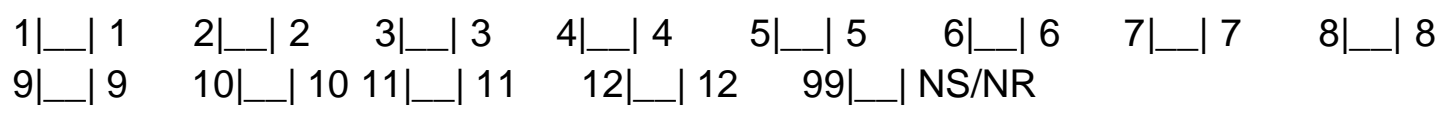

5. Alguém na sua casa parou de beber?

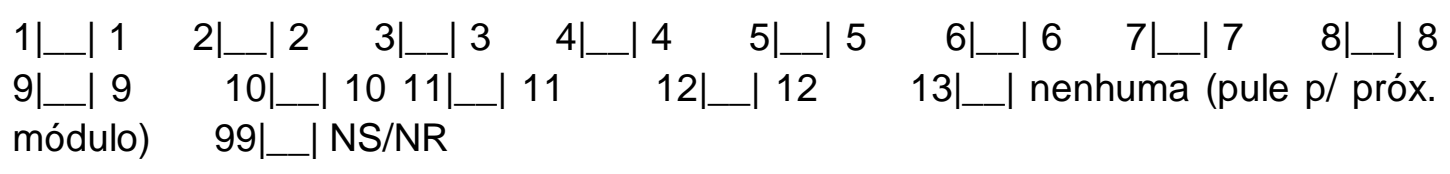

6. Quantos anos essas pessoas beberam? 


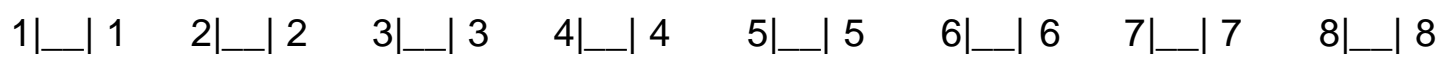

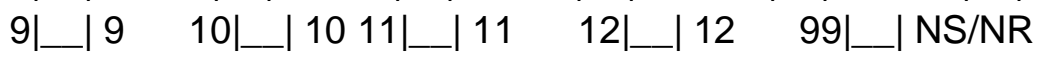

7. O consumo de bebida alcoólica era feito quantas vezes por semana?

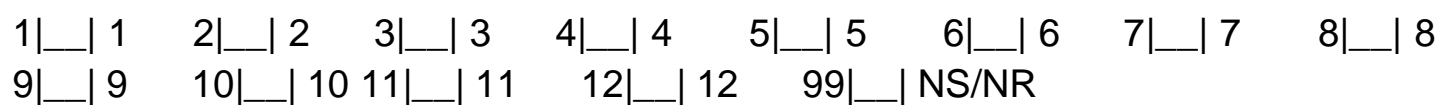

8. Há quantos anos essas pessoas deixaram de beber

\begin{tabular}{|c|c|c|c|c|c|c|c|}
\hline $1 \mid$ & $2\left|\_\right| 2$ & $3 \mid$ & $4 \mid$ & 5 & $6 \mid$ & $7 \mid 7$ & $8 \mid$ \\
\hline $9|\quad| 9$ & $10 \mid$ & $11 \mid 1$ & $12 \mid$ & $99 \mid$ & $\mathrm{NS} / \mathrm{NR}$ & & \\
\hline
\end{tabular}

9. Quantas doses essas pessoas bebiam por dia?

( 1 dose de bebida alcoólica = 1 lata de cerveja ou 1 taça de vinho ou 1 drinque ou 1 cocktail ou 1 dose de cachaça ou uísque. Considerar a média do consumo diário)
$1 \mid$
$2\left|\_\right| 2 \quad 3\left|\_\right| 3$
${ }_{12}|+| 12$
$5|+| 5$
$6\left|\_\right| \begin{array}{ll}6 & 7 \mid\end{array}$
$8 \mid$

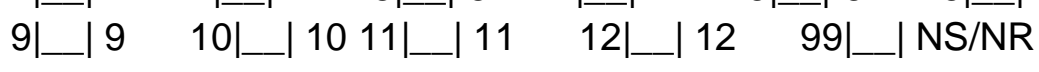


PARTE 8 - MÓDULO PERCEPÇÃO DE SAÚDE E MORBIDADE REFERIDA

(Para responder as próximas questões, veja o número de identificação dos moradores da residência na pg. 4, questão 26)

1. Na sua opinião, quantas pessoas que moram em sua casa têm uma saúde:

$1 \mid$ | Excelente $2 \mid \_$Muito boa $3\left|\_\right|$Boa $4 \mid$ | Regular $5 \mid$ | Ruim $99\left|\_\right| N S / N R$

ALGUM MÉDICO JÁ LHE DISSE QUE O(A) SR(A) OU AS PESSOAS QUE MORAM NA SUA CASA TÊM OU TIVERAM ALGUMAS DAS SEGUINTES DOENÇAS? (Marcando SIM em qualquer das seguintes questões, seu módulo correspondente será aberto)

2. Doenças do coração 1 __ $\mid \operatorname{Sim}$ (preencha Doenças do Coração) 2|_| Não

3. Doenças Respiratórias 1|_|Sim (preencha Doenças Respiratórias) 2|_| Não

4. Derrame (AVC)

1 1__ Sim (preencha Derrame)

2|_| Não

5. Doenças dos rins $1\left|\_\right| \operatorname{Sim}$ (preencha Doenças dos Rins)

$2 \mid \_$| Não

6. Doenças do fígado

1 1_ Sim (preencha Doenças do Fígado)

2|_| Não

7. Câncer

2|_| Não

$1\left|\_\right| \operatorname{Sim}$ (preencha Câncer)

8. Doenças do sangue

$1 \mid$ __ Sim (preencha Doenças do Sangue) 2|_ Não 
9. Depressão $\quad 1 \mid \_$Sim (preencha Depressão)

10. Doenças da pele 1__ Sim (preencha Doenças da Pele)

11. Pressão alta $\quad 1\left|\_\right| \operatorname{Sim}$ (preencha Pressão Alta)

12. Deficiência Mental $\left.\quad 1\right|_{\text {_ }}$ Sim (preencha Deficiência Mental) $2 \mid \_$Não

13. Distúrbios neurológicos $11_{\ldots} \mid \operatorname{Sim}$ (preencha Distúrbios Neurológicos) 2|_| Não

14. Distúrbios de aprendizagem (dificuldades na escola)

$1 \mid \_$Sim (preencha Distúrbios de aprendizagem) 2|_| Não

15. AIDS

$2\left|\_\right|$Não

$1 \mid \_$Sim (preencha AIDS)

16. Hanseníase

1__ Sim (preencha Hanseníase)

$2 \mid \_$Não

20. Outras: 
MÓDULO - DOENÇAS DO CORAÇÂO (referente à QUESTÃO 2).

(Para responder as próximas questões, veja o número de identificação dos moradores da residência na pg. 4, questão 26)

1. Quais pessoas que moram em sua casa têm ou tiveram doenças do coração?

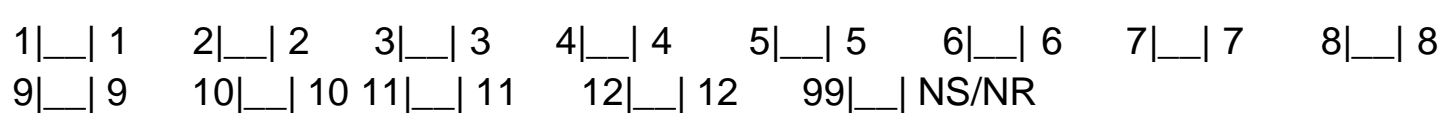

QUAIS PESSOAS APRESENTAM OU APRESENTARAM OS SEGUINTES PROBLEMAS NO CORAÇÃO?

2. Ataque do coração/Infarto

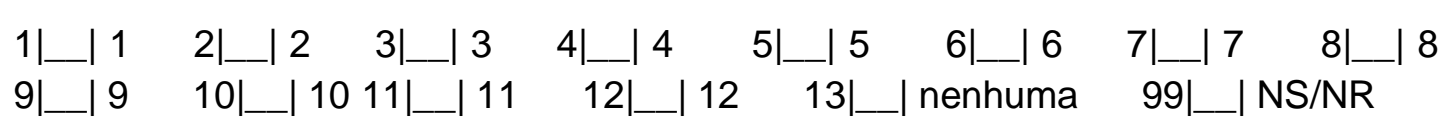

3. Angina ou doença das coronárias

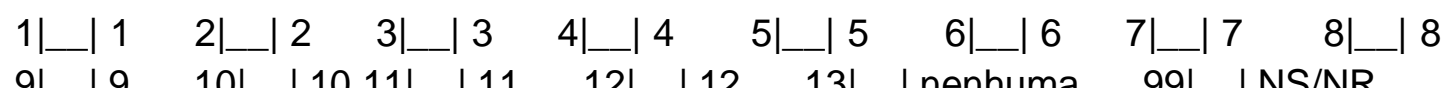

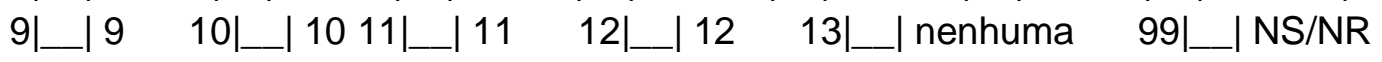

4. Insuficiência cardíaca/Coração grande

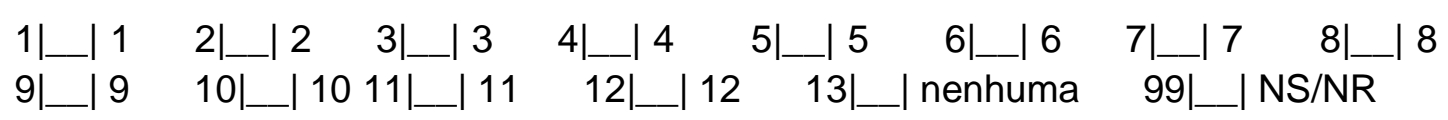

20. Outras

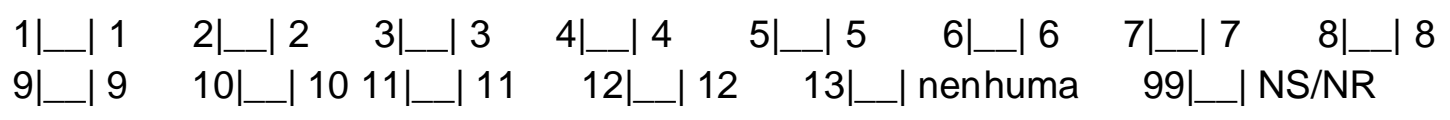

MÓDULO - DOENÇAS RESPIRATÓRIAS (referente à QUESTÃO 3). 
(Para responder as próximas questões, veja o número de identificação dos moradores da residência na pg. 4, questão 26)

1. Quais pessoas que moram em sua casa têm ou tiveram doenças respiratórias?

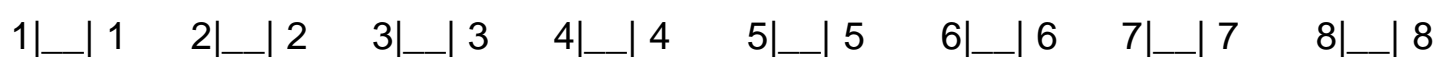

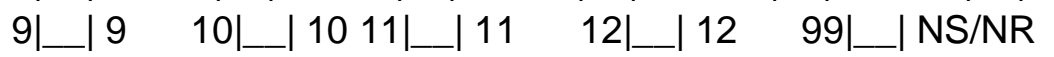

QUAIS PESSOAS APRESENTAM OU APRESENTARAM OS SEGUINTES PROBLEMAS NO PULMÃO?

\section{Enfisema}

$1 \mid \begin{array}{ll}1 & 2\left|\_\right|\end{array}$

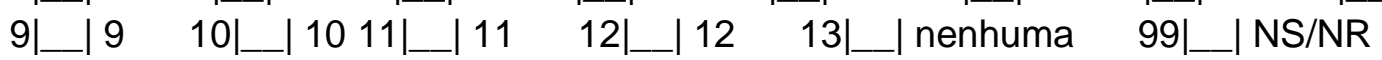

3. Bronquite crônica

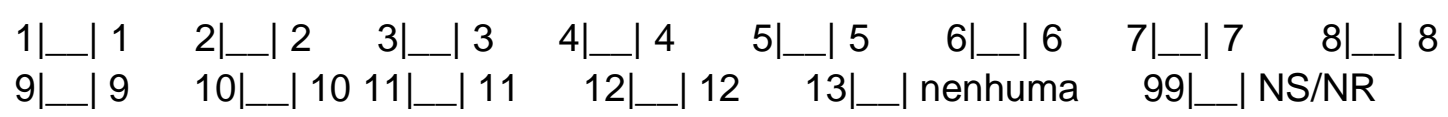

4. Asma

$1 \mid \begin{array}{ll}1 & 2\left|\_\right|\end{array}$

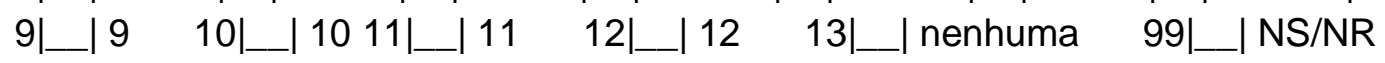

5. Repetição de infecções de vias superiores (sinusites, rinites, otites, faringites, amigdalites)

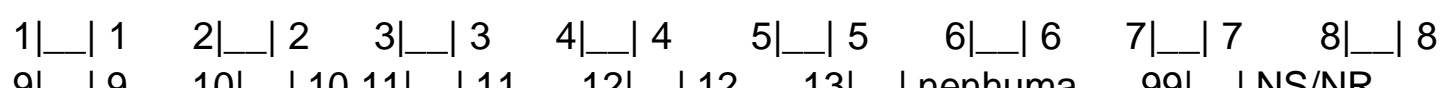

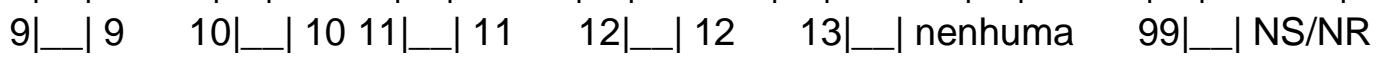

6. Tuberculose pulmonar

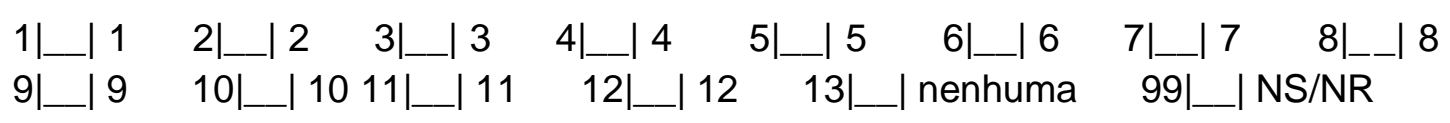


7. Pneumoconioses (fibrose do pulmão)

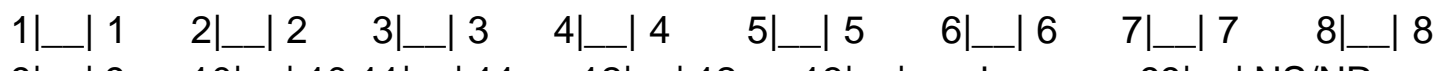

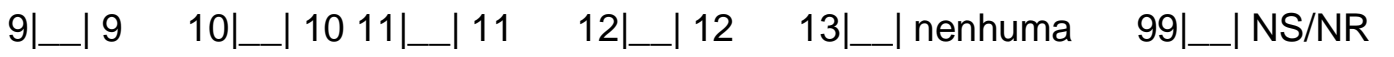

20. Outras

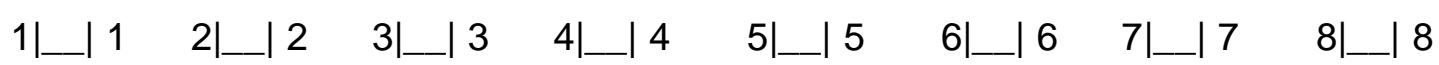

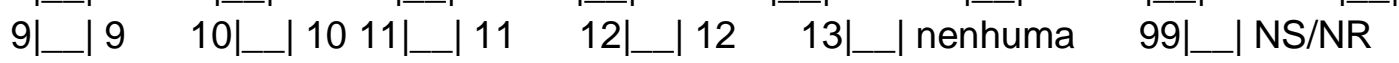

QUAIS PESSOAS QUE MORAM NESSA RESIDÊNCIA APRESENTAM OS SEGUINTES SINTOMAS RESPIRATÓRIOS COM FREQÜÊNCIA:

8. Tosse seca (irritativa)

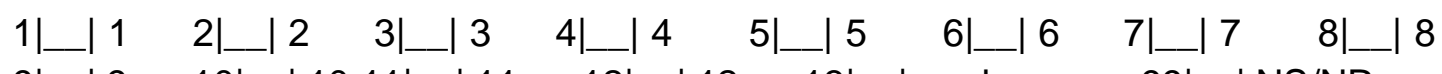

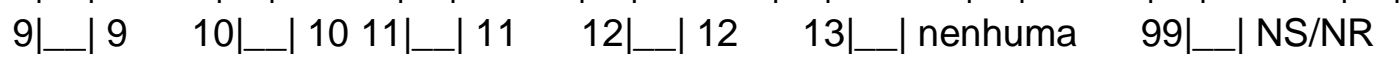

9. Tosse com catarro (expectoração)

$1 \mid \begin{array}{ll}1 & 2\left|\_\right|\end{array}$

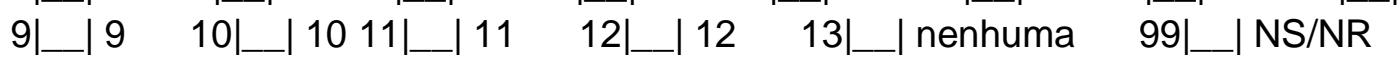

10. Chiado no peito (sibilância)

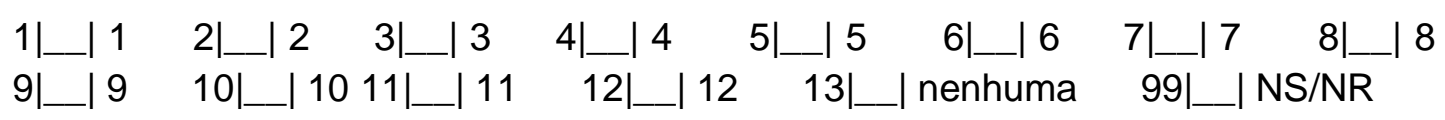

11. Falta de ar (dispnéia)

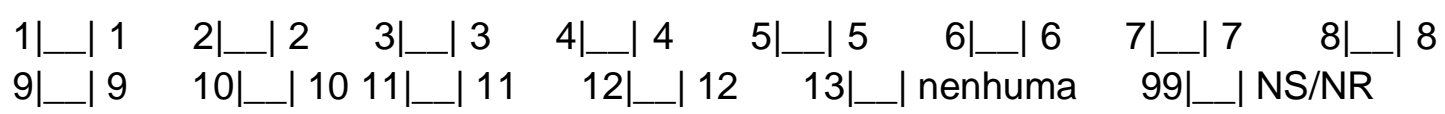


12. Cansaço nas atividades diárias

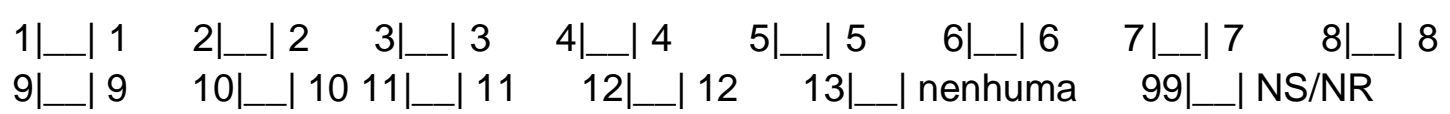

13. Conjuntivite (irritação nos olhos)

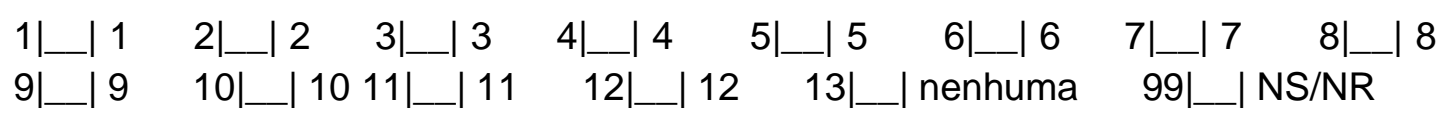

14. Espirros / coceira no nariz

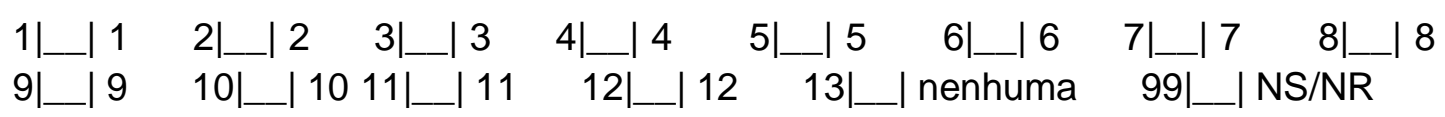

15. Entupimento nasal ou coriza

\begin{tabular}{|c|c|c|c|c|c|c|c|}
\hline $1 \mid$ & $2 \mid$ & $3 \mid$ & $4 \mid$ & $5 \mid$ & $6\left|\_\right| 6$ & $7 \mid 7$ & $8|\ldots| 8$ \\
\hline $9|\quad| 9$ & $10 \mid$ & $11 \mid$ & 12 & $13 \mid$ & nenhuma & $99 \mid$ & NS/NR \\
\hline
\end{tabular}

MÓDULO - DERRAME - AVC (referente à QUESTÃO 4).

(Para responder as próximas questões, veja o número de identificação dos moradores da residência na pg. 4, questão 26)

1. Quais pessoas que moram em sua casa têm ou tiveram derrame?

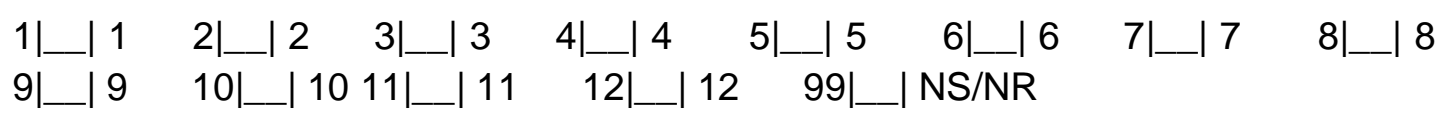

MÓDULO - DOENÇAS DOS RINS (referente à QUESTÃO 5). 
(Para responder as próximas questões, veja o número de identificação dos moradores da residência na pg. 4, questão 26)

1. Quais pessoas que moram em sua casa têm ou tiveram doenças dos rins?

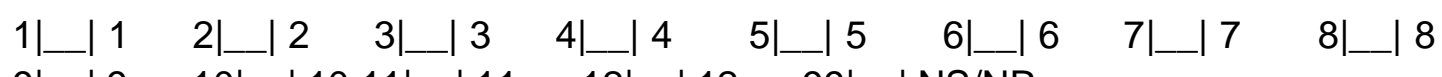

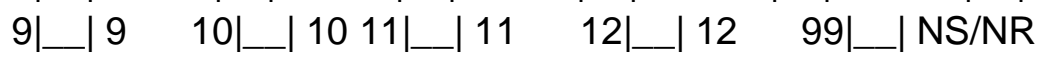

MÓDULO - DOENÇAS DO FÍGADO (referente à QUESTÃO 6).

(Para responder as próximas questões, veja o número de identificação dos moradores da residência na pg. 4, questão 26)

1. Quais pessoas que moram em sua casa têm ou tiveram doenças do fígado?

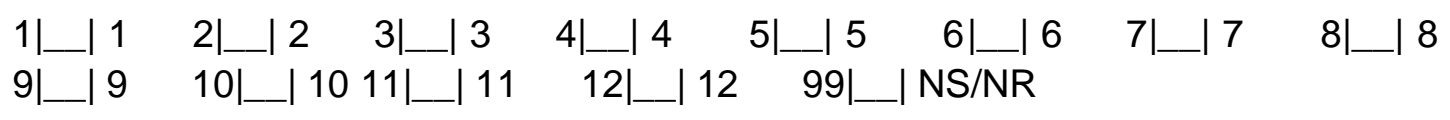

QUAIS PESSOAS APRESENTAM OU APRESENTARAM OS SEGUINTES PROBLEMAS NO FÍGADO?

2. Hepatite

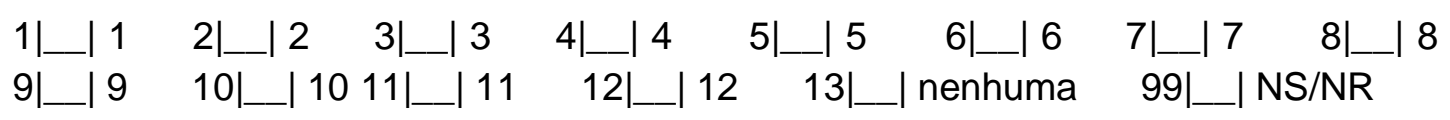

3. Cirrose

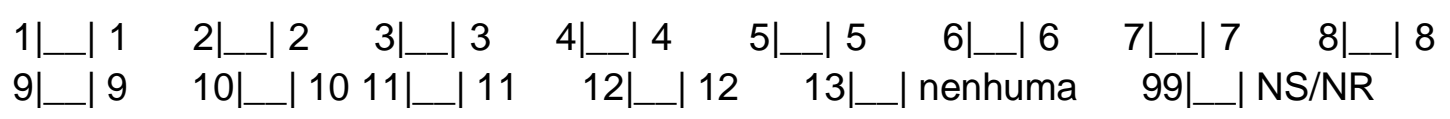

20. Outras

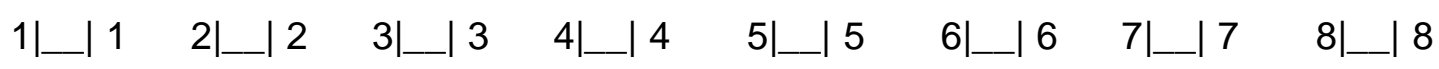

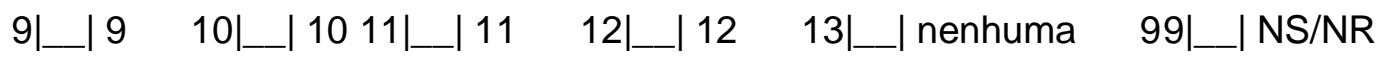


MÓDULO - CÂNCER (referente à QUESTÃO 7).

(Para responder as próximas questões, veja o número de identificação dos moradores da residência na pg. 4, questão 26)

1. Quais pessoas que moram em sua casa têm ou tiveram câncer?

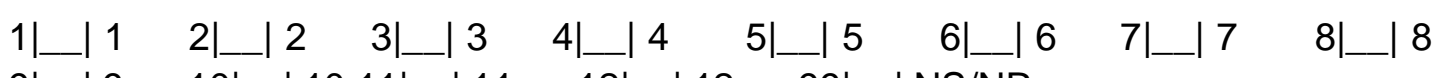

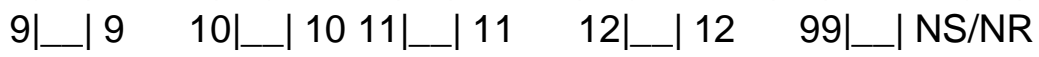

QUAIS PESSOAS APRESENTAM OU APRESENTARAM OS SEGUINTES TIPOS DE CÂNCER? (localização primária)

2. Pulmão

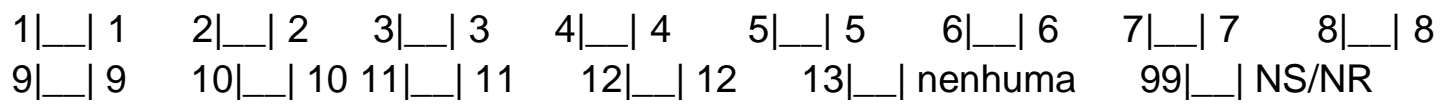

3. Mama

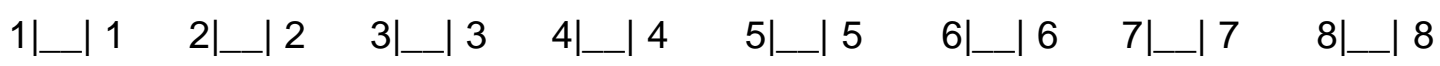

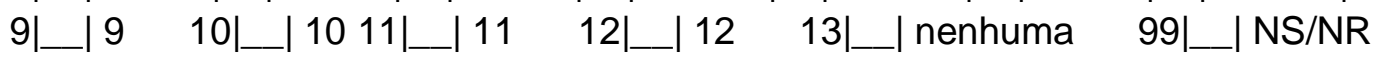

4. Aparelho reprodutor

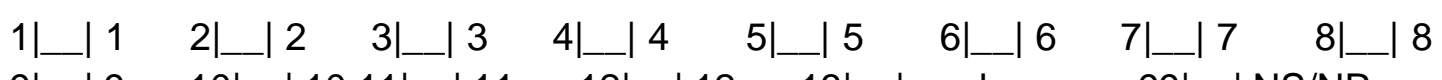

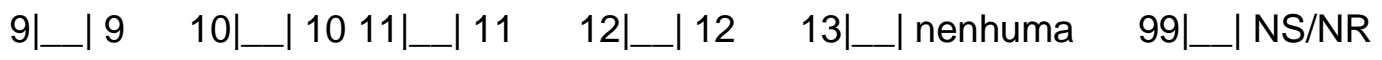

5. Tireóide

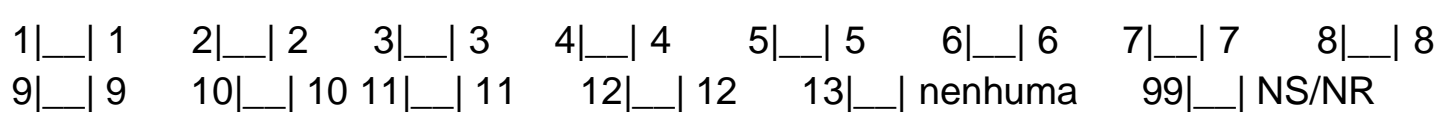

6. Leucemia

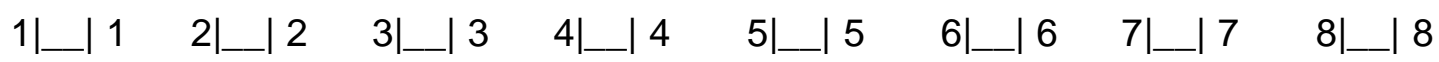

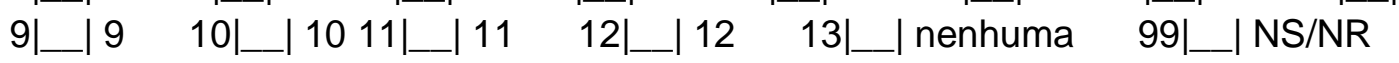


7. Gastro-intestinal

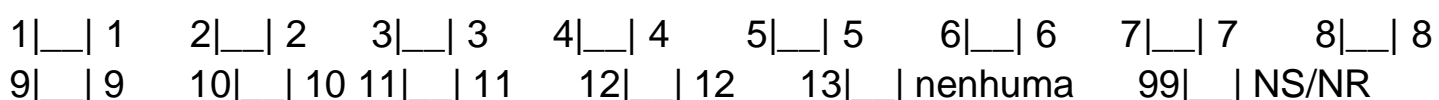

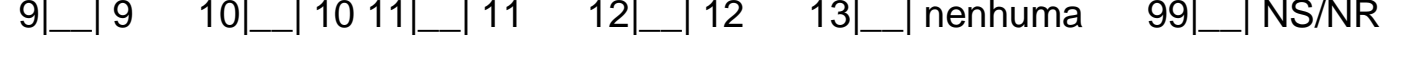

\section{Bexiga}

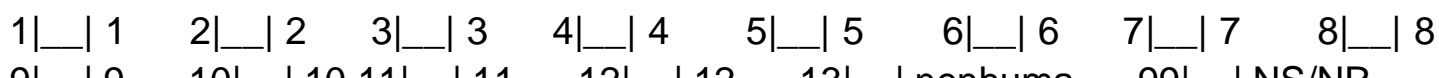
$9\left|\_\right| \begin{array}{ll}9 & 10\end{array}\left|\begin{array}{ll}10 & 11\end{array}\right| \begin{array}{ll}11 & 12\end{array}\left|\begin{array}{ll}12 & 13\end{array}\right|$ _ nenhuma $99\left|\_\right|$NS/NR

9. Fígado, vias biliares e pâncreas

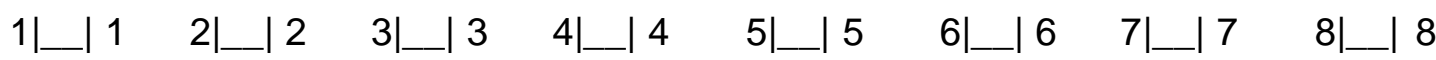

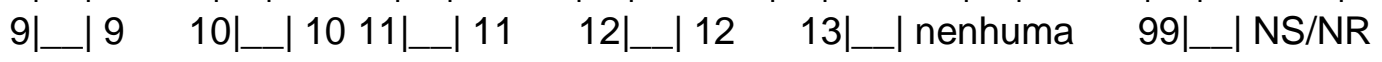

10. Tumores da infância (câncer na infância)

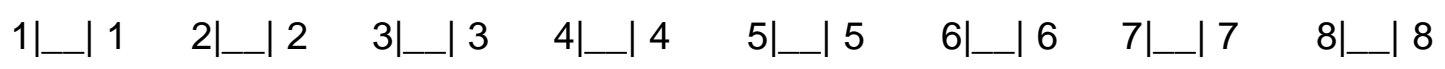

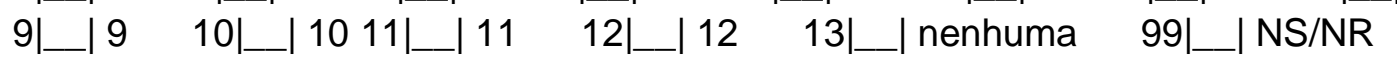

11. Rins

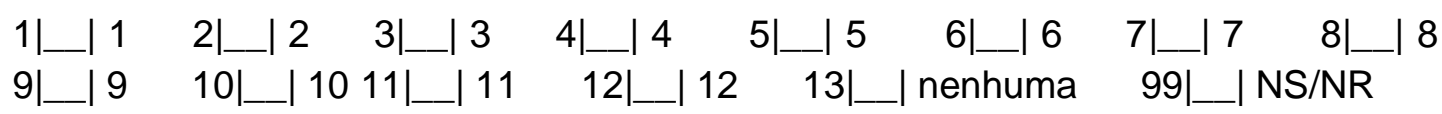

20. Outras

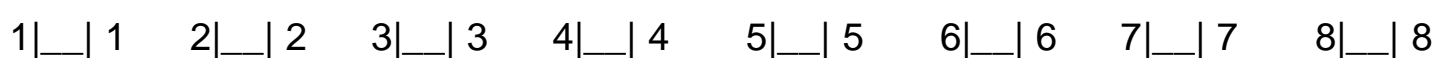

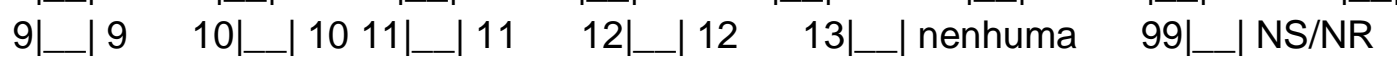


MÓDULO - DOENÇAS DO SANGUE (referente à QUESTÃO 8).

(Para responder as próximas questões, veja o número de identificação dos moradores da residência na pg. 4, questão 26)

1. Quais pessoas que moram em sua casa têm ou tiveram doenças do sangue?

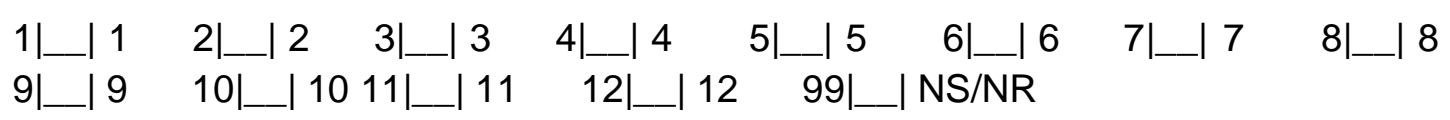

2. Quais pessoas que moram em sua casa têm ou tiveram leucopenia (diminuição dos glóbulos brancos)

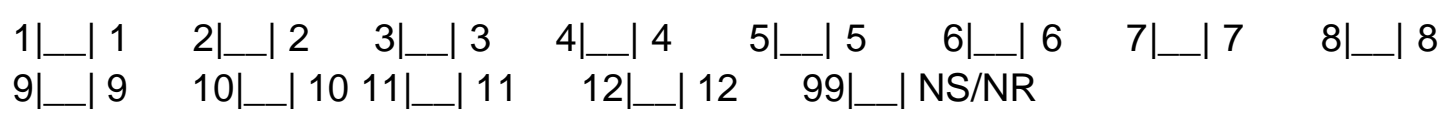

MÓDULO - DEPRESSÃO (referente à QUESTÃO 9).

(Para responder as próximas questões, veja o número de identificação dos moradores da residência na pg. 4, questão 26)

1. Quais pessoas que moram em sua casa têm ou tiveram depressão?

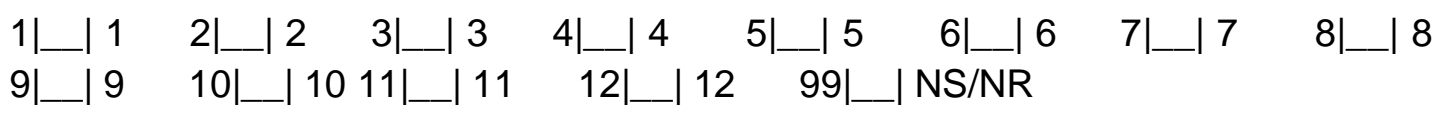

MÓDULO - DOENÇAS DA PELE (referente à QUESTÃO 10).

(Para responder as próximas questões, veja o número de identificação dos moradores da residência na pg. 4, questão 26) 
1. Quais pessoas que moram em sua casa têm ou tiveram doenças de pele?

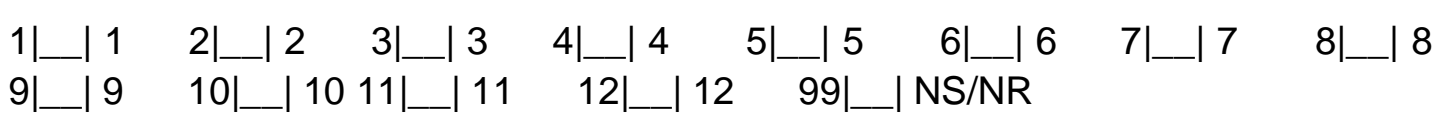

MÓDULO - PRESSÃO ALTA (referente à QUESTÃO 11).

(Para responder as próximas questões, veja o número de identificação dos moradores da residência na pg. 4, questão 26)

1. Quais pessoas que moram em sua casa têm ou tiveram pressão alta?

\begin{tabular}{|c|c|c|c|c|c|c|c|}
\hline $1 \mid 1$ & $2 \mid$ & $3 \mid$ & $\left.4\right|^{4}$ & $5\left|\_\right| 5$ & $6\left|\_\right| 6$ & $7 \mid$ & $8 \mid$ \\
\hline $9 \mid$ & 10| & $11 \mid 1$ & $12 \mid$ & $99 \mid$ & | NS/NR & & \\
\hline
\end{tabular}


MÓDULO - DEFICIÊNCIA MENTAL (referente à QUESTÃO 12).

(Para responder as próximas questões, veja o número de identificação dos moradores da residência na pg. 4, questão 26)

1. Quais pessoas que moram em sua casa apresentam deficiência mental?

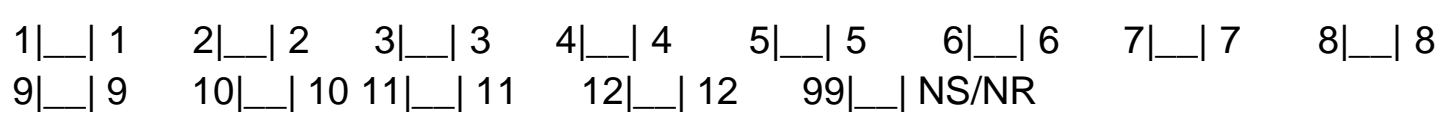

MÓDULO - DISTÚRBIOS NEUROLÓGICOS (referente à QUESTÃO 13).

(Para responder as próximas questões, veja o número de identificação dos moradores da residência na pg. 4, questão 26)

1. Quais pessoas que moram em sua casa têm ou tiveram problemas neurológicos?

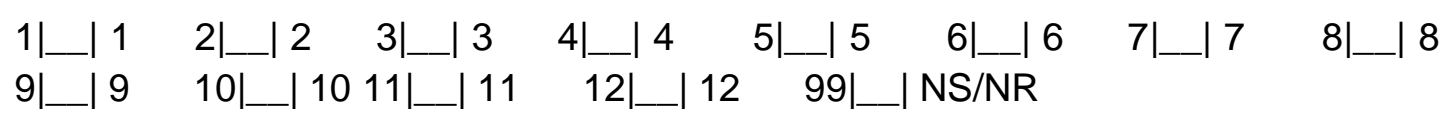

QUAIS PESSOAS APRESENTAM OU APRESENTARAM OS SEGUINTES PROBLEMAS?

2. Tremores

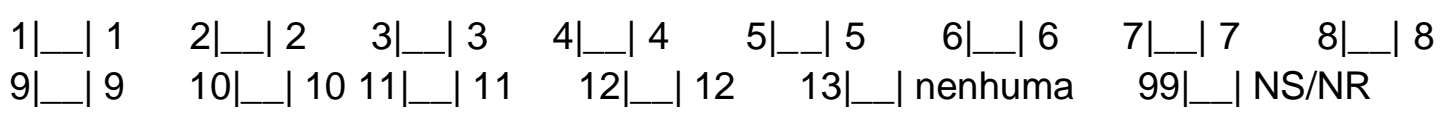

3. Falta de Equilíbrio
$1 \mid$
$2\left|\_\right| 2$
$3\left|\_\right| 3$
$\left.4\right|_{12} \mid 4$
$5\left|\_\right| 5$
$6|+| 6$

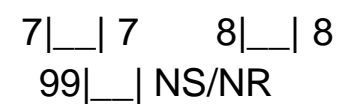


4. Tonturas

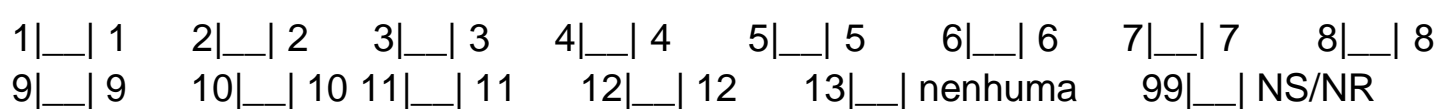

5. Dores de cabeça

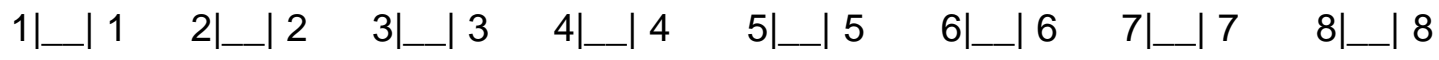

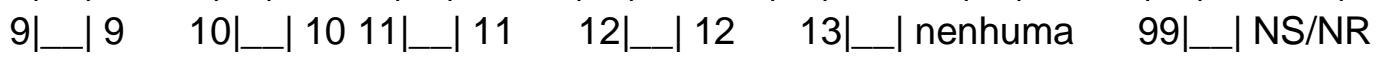

20. Outras

$1 \mid\left[\begin{array}{ll}1 & 2\left|\_\right|\end{array}\right.$

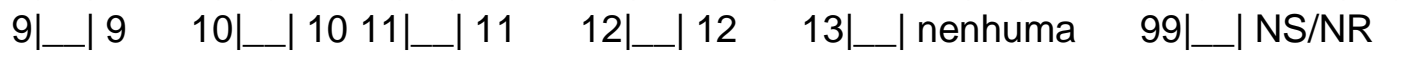


MÓDULO - DISTÚRBIOS DE APRENDIZAGEM (referente à QUESTÃO 14)

(Para responder as próximas questões, veja o número de identificação dos moradores da residência na pg. 4, questão 26)

1. Quais pessoas que moram em sua casa têm ou tiveram problemas de aprendizagem na escola?

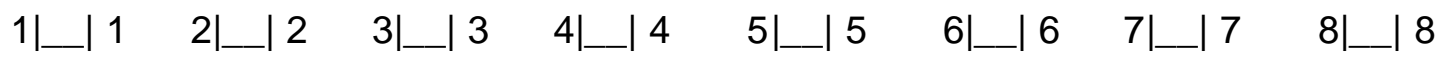

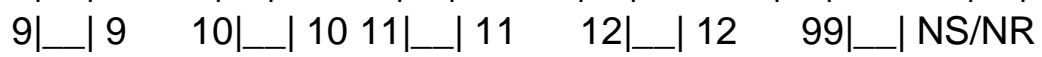

2. Quais pessoas que moram em sua casa têm ou tiveram problemas de comportamento na escola? (agressividade/indisciplina)

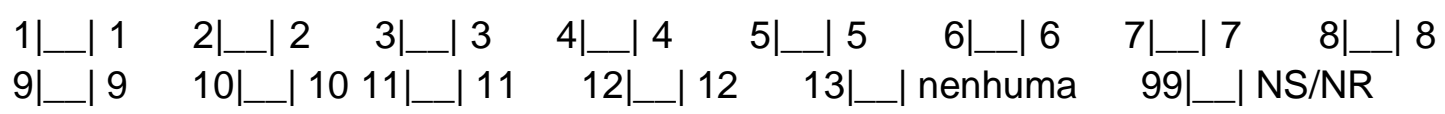

QUAIS PESSOAS APRESENTAM OU APRESENTARAM PROBLEMAS DE APRENDIZAGEM NAS SEGUINTES ATIVIDADES?

3. Leitura

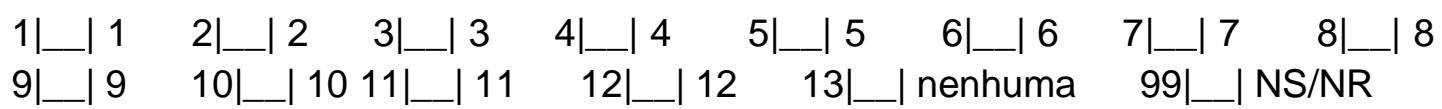

4. Escrita

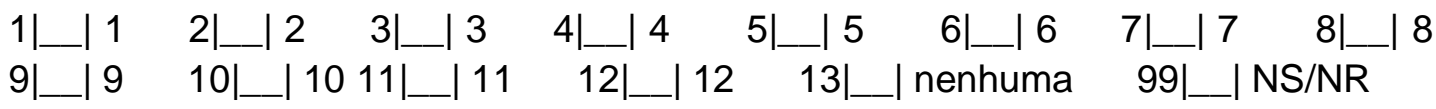

5. Cálculos matemáticos

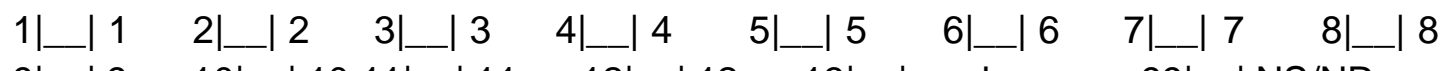

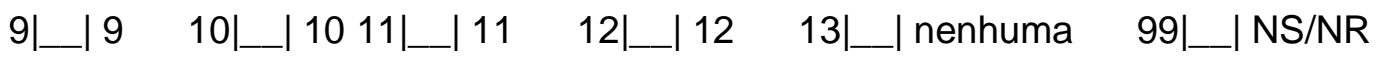

6. Fazer a lição de casa 


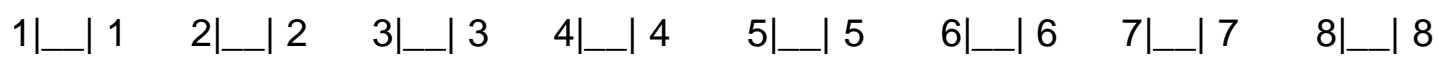

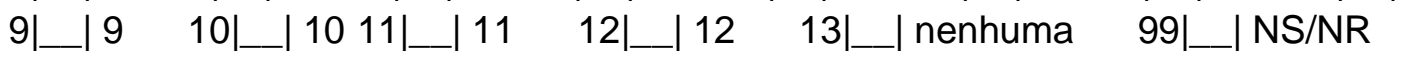

7. Assistir e acompanhar as aulas na escola

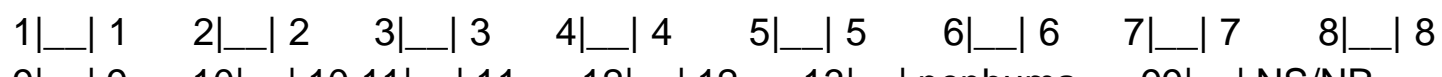

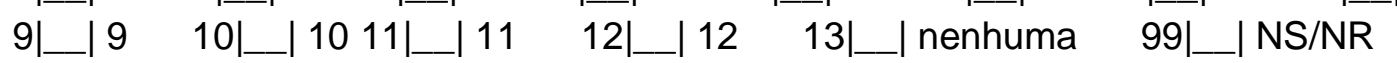

20. Outras

$1 \mid\left[\begin{array}{ll}1 & 2\left|\_\right|\end{array}\right.$

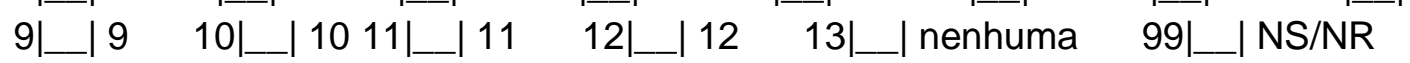


MÓDULO - AIDS (referente à QUESTÃO 15)

(Para responder as próximas questões, veja o número de identificação dos moradores da residência na pg. 4, questão 26)

1. Quais pessoas que moram em sua casa têm o vírus da aids?

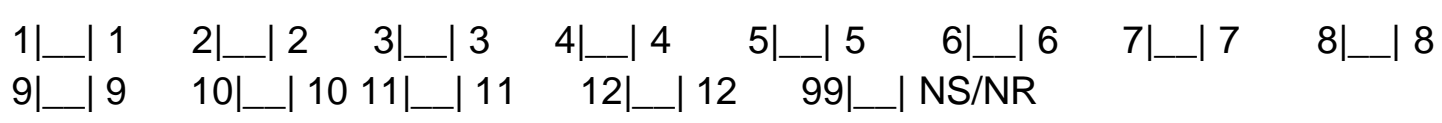

2. Alguém que morava em sua casa morreu por causa do vírus da aids?
$1 \_$_ Sim 2|_| Não $99\left|\_\right|$NS/NR

MÓDULO - HANSENÍASE (referente à QUESTÃO 16).

(Para responder as próximas questões, veja o número de identificação dos moradores da residência na pg. 4, questão 26)

1. Quais pessoas que moram em sua casa têm ou tiveram hanseníase?

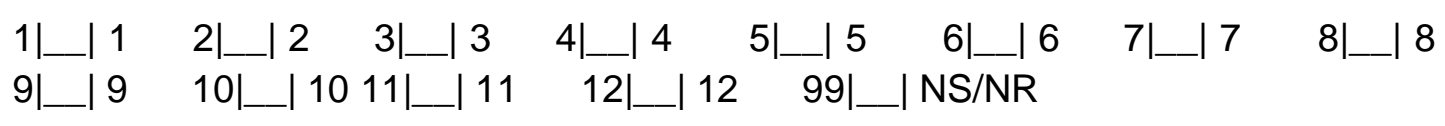


MÓDULO - GRAVIDEZ.

(Para responder as próximas questões, veja o número de identificação dos moradores da residência na pg. 4, questão 26)

1. Quais mulheres que moram em sua casa ficaram grávidas nos últimos cinco anos?

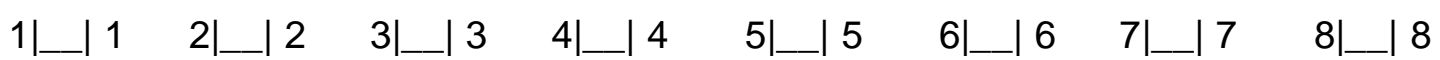

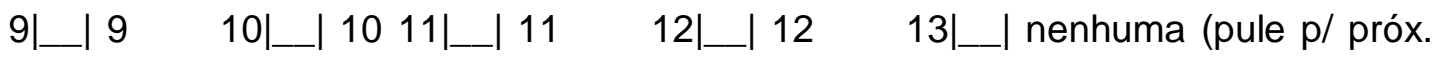
módulo)

$99\left|\_\right| N S / N R$

2. Nesses últimos cinco anos, quais mulheres fizeram o acompanhamento prénatal?

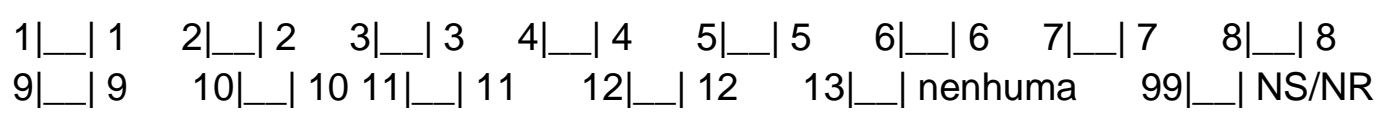

3. Nesses últimos cinco anos, quantas vezes elas ficaram grávidas?

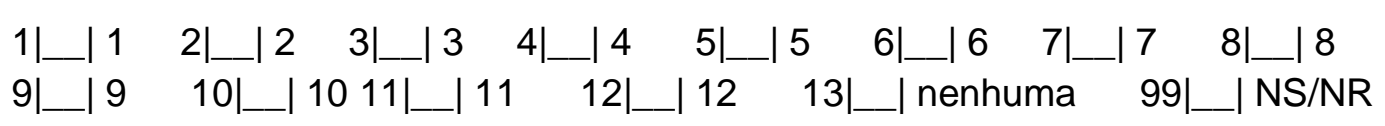

4. Em quantas dessas gestações essas mulheres fizeram o pré-natal?

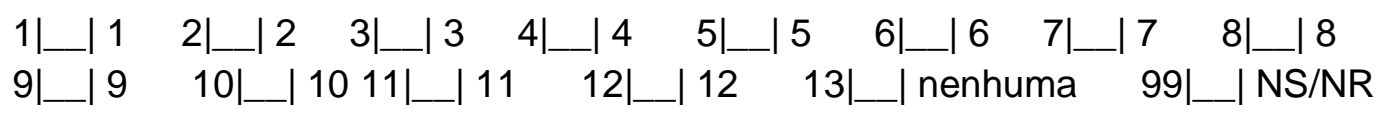

5. Essas mulheres tiveram quantos filhos gêmeos?

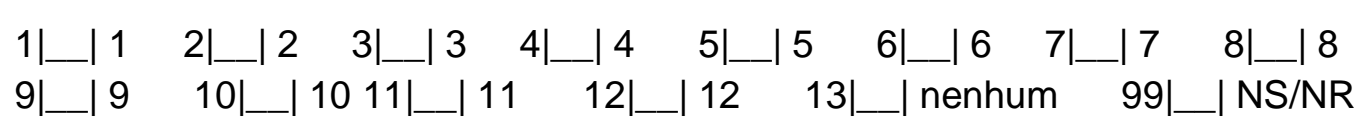

6. Quais mulheres sofreram aborto natural/espontâneo? 
$1\left|\_\right| \begin{array}{ll}1 & 2\left|\_\right|\end{array}$ $9\left|\_\right| \begin{array}{ll}9 & 10\left|\_\right| \\ 10 & 11\end{array}\left|\_\right| \begin{array}{ll}11 & 12\end{array}\left|\begin{array}{ll}12 & 13\end{array}\right| \_$nenhuma (pule $\mathrm{p} /$ questão 8) $99 \mid \_$NS/NR

7. Quantos abortos espontâneos essas mulheres sofreram?

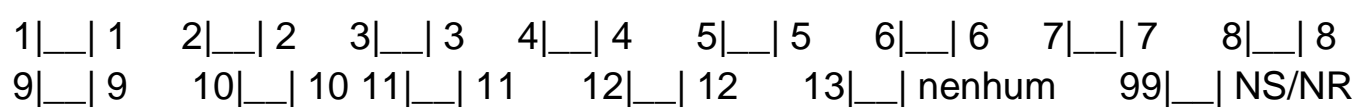

8. Essas mulheres tiveram quantos bebês prematuros (antes do tempo - 37 semanas)?

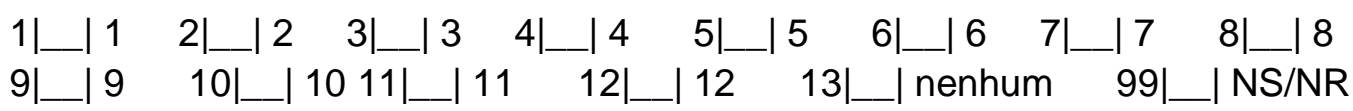

9. Essas mulheres tiveram quantos bebês com peso abaixo de $2500 \mathrm{~g}$ ?

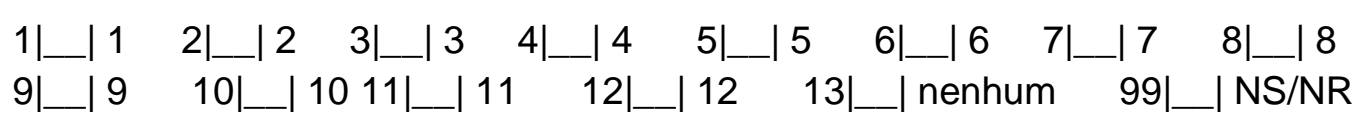

10. Quantos bebês (dessas mulheres) nasceram mortos? (após a 20ª semana de gestação/5ํำ mês)

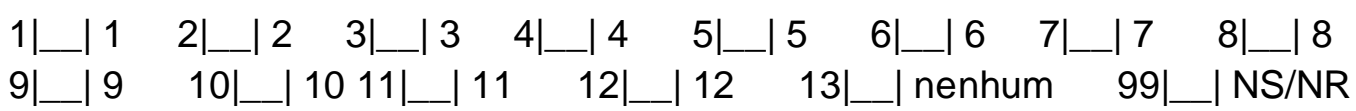

11. Essas mulheres tiveram quantos bebês com malformação? (preencha MALFORMAÇÃO caso sejam assinaladas alternativas de 1 a 12)

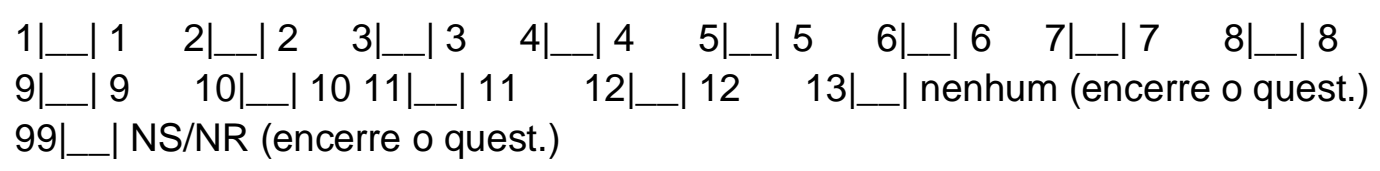


MÓDULO - MALFORMAÇÃO (referente ao módulo GRAVIDEZ).

(Para responder as próximas questões, veja o número de identificação dos moradores da residência na pg. 4, questão 26)

1. Quais pessoas que moram em sua casa apresentaram malformações ao nascer?

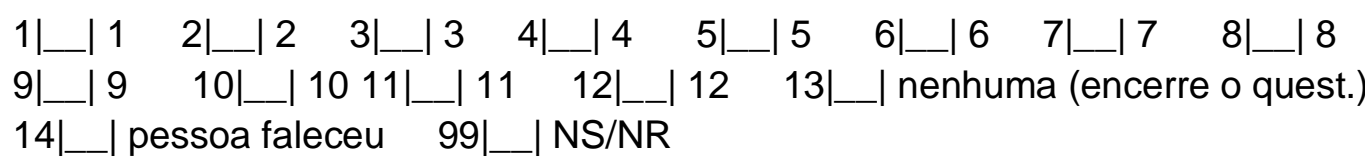

QUAIS PESSOAS APRESENTAM ESSES PROBLEMAS DE MALFORMAÇÃO?

2. Membros inferiores ou superiores

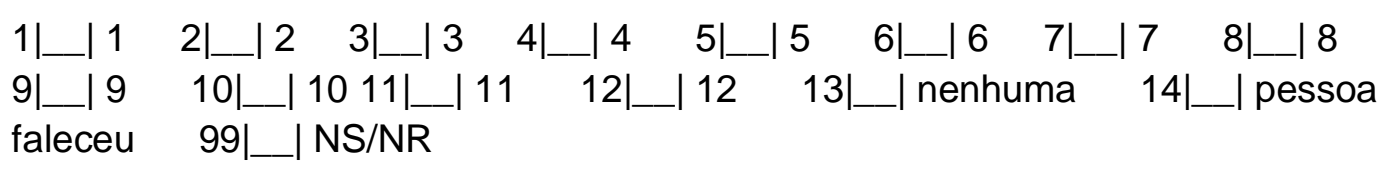

3. Coração

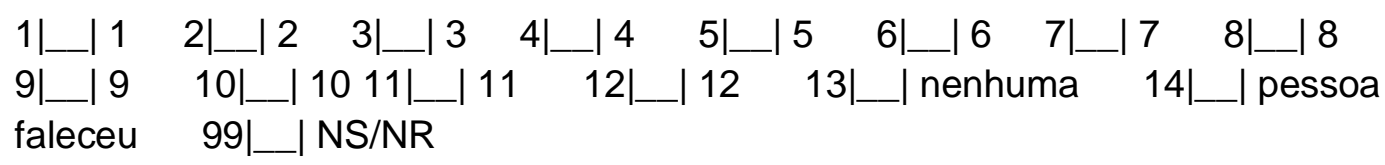

4. Lábio leporino (abertura no lábio/boca)

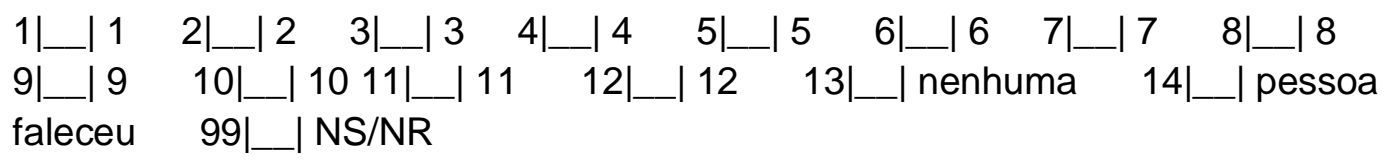

5. Espinha bífida (espinha partida)

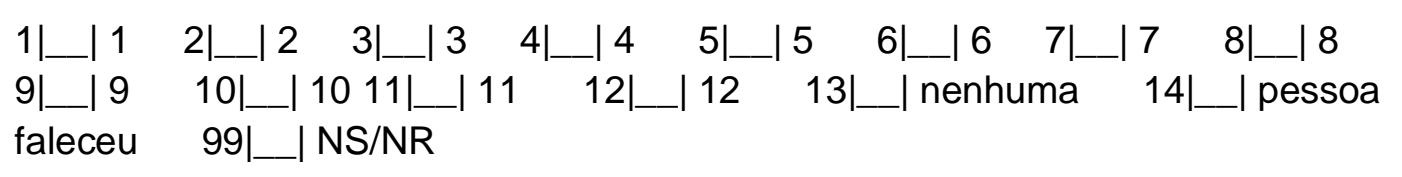


6. Hidrocefalia (cabeça grande)

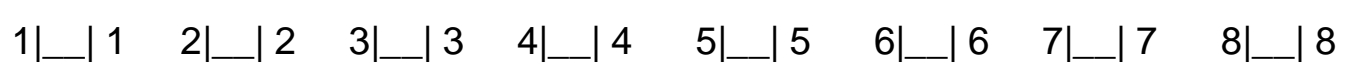

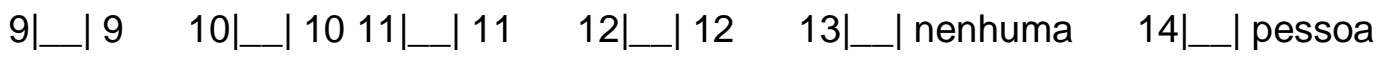
faleceu $99|\ldots|$ NS/NR

20. Outras

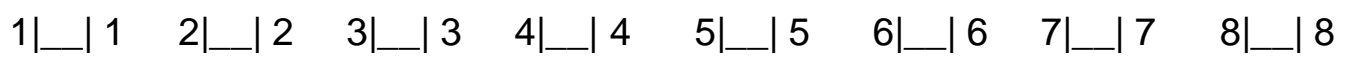

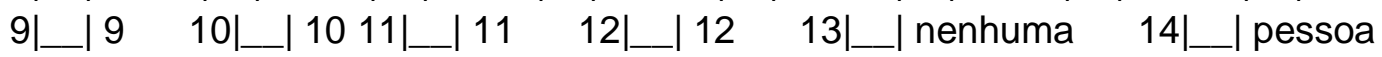
faleceu $99 \mid$ _ NS/NR

TÉRMINO DO MÓDULO - |___ : : |___ horas min 


\subsection{ANEXo C - APRovação NO COMITÊ de ÉticA dA CAPPESQ}

\section{APROVAÇÃO}

A Comissão de Ética para Análise de Projetos de Pesquisa CAPPesa da Diretoria Clínica do Hospital das Clínicas e da Faculdade de Medicina da Universidade de São Paulo, em sessão de 15/04/2009, APROVOU O Protocolo de Pesquisa n 0262/09, intitulado: "AVALIAÇĀO DE DESFECHOS RELACIONADOS À GESTAÇÃO EM ÁREAS CONTAMINADAS NA REGIÃO DO ESTUÁRIO DE SANTOS E SĀO VICENTE." apresentado pelo Departamento de PATOLOGIA, inclusive o Termo de Consentimento Livre e Esclarecido.

Cabe ao pesquisador elaborar e apresentar à CAPPesq, os relatórios parciais e final sobre a pesquisa (Resolução do Conselho Nacional de Saúde n 196, de 10/10/1996, inciso IX.2, letra "c").

Pesquisador (a) Responsável: Luiz Alberto Amador Pereira

Pesquisador (a) Executante: Mariana Tavares Guimarães

CAPpesq, 16 de Abril de 2009

Prof. Dr. Eduardo Massad Presidente da Comissão de Ética para Análise de Projetos de Pesquisa

Comissão de Ética para Análise de Projetos de Pesquisa do HCFMUSP e da FMUSP Diretoria Clínica do Hospital das Clínicas da Faculdade de Medicina da Universidade de Săo Paulo Rua Ovídio Pires de Campos 225, $5^{\circ}$ andar - CEP 05403010 - São Paulo - SP Fone: 01130696442 Fax: 01130696492 e-mail: cappesq@hcnet.usp.br/ secretariacappesq2@hcnet.usp.br 


\section{REFERÊNCIAS*}

1. Greenpeace. Crimes ambientais corporativos no Brasil. [internet]. 2002 [citado Jun 2009]; [32p]. Disponível em: http://www.greenpeace.org.br/toxicos/pdf/corporate_crimes_port.pdf.

2. Young AF, Fusco W. Espaços de vulnerabilidade sócio-ambiental para a população da Baixada Santista: identificação e análise das áreas críticas. [internet]. In: Anais do XV Encontro Nacional de Estudos Populacionais da Associação Brasileira de Estudos Populacionais; 2006; Caxambu, Brasil. [14p]. Disponível em: http://www.abep.org.br/usuario/GerenciaNavegacao.php?caderno_id=540\&ni vel=1.

3. Guimarães MT. Avaliação de desfechos relacionados à gestação na região do estuário de Santos e São Vicente - estudo preliminar [dissertação]. Santos: Universidade Católica de Santos; 2008.

4. Pereira LAAP. Introdução. laap@usp.br [mensagem pessoal] [citado mai 2012]. E-mail para Mariana Tavares Guimarães (marianatguimaraes@yahoo.com.br).

\footnotetext{
* De acordo com:

Adaptado de International Committee of Medical Journals Editors (Vancouver).

Universidade de São Paulo. Faculdade de Medicina. Serviço de Biblioteca e Documentação. Guia de apresentação de dissertações, teses e monografias da FMUSP. Elaborado por Anneliese Carneiro da Cunha, Maria Julia A.L. Freddi, Maria F. Crestana, Marinalva de S. Aragão, Suely C. Cardoso, Valéria Vilhena. 3a ed. São Paulo: Divisão de Biblioteca e Documentação; 2011.

Abreviaturas dos títulos dos periódicos de acordo com List of Journals Indexed in Index Medicus.
} 
5. Gonzalez JL, Thouvenin B, Dange C, Chiffoleau, JF, Boutier B. Role of Particle Sorption Properties in the Behavior and Speciation of Trace Metals inMacrotidal Estuaries: The Cadmium Example. The Handbook of Environmental Chemistry Series. 2006;5:265-301.

6. CETESB. Sistema Estuarino de Santos e São Vicente. São Paulo: CETESB; 2001. Relatório Técnico. 141p.

7. SEADE. Perfil Municipal. [internet]. [citado Jan 2012]; Disponível em: http://www.seade.gov.br/produtos/perfil/.

8. Nascimento LFC, Gotlieb SLD. Fatores de risco para o baixo peso ao nascer, com base em informações da declaração de nascido vivo em Guaratinguetá, SP, no ano de 1998. Informe Epidemiológico do SUS. 2001;10(3):113-20.

9. Braga ALF. Quantificação dos efeitos da poluição do ar sobre a saúde da população pediátrica da cidade de São Paulo e proposta de monitorização. [Tese]. São Paulo: Faculdade de Medicina da Universidade de São Paulo; 1998.

10. Pereira LAAP. Associação entre perdas fetais tardias e poluição atmosférica no município de São Paulo. [Tese]. São Paulo: Faculdade de Medicina da Universidade de São Paulo; 1999.

\footnotetext{
* De acordo com:

Adaptado de International Committee of Medical Journals Editors (Vancouver).

Universidade de São Paulo. Faculdade de Medicina. Serviço de Biblioteca e Documentação. Guia de apresentação de dissertações, teses e monografias da FMUSP. Elaborado por Anneliese Carneiro da Cunha, Maria Julia A.L. Freddi, Maria F. Crestana, Marinalva de S. Aragão, Suely C. Cardoso, Valéria Vilhena. 3a ed. São Paulo: Divisão de Biblioteca e Documentação; 2011.

Abreviaturas dos títulos dos periódicos de acordo com List of Journals Indexed in Index Medicus.
} 
11. Rezende J. A gravidez, conceito. Duração In: Rezende J (org.). Obstetrícia. Rio de Janeiro: Gyanabara-Koogan; 2005. 121-8.

12. Schüller-Faccini L, Leite JCL, Sanseverino MTV. Avaliação de teratógenos na população brasileira. Ciência \& Saúde Coletiva. 2002;7(1):65-71.

13. Webster WS. Teratogen update: congenital rubella. Teratology. 1998;58:13-23.

14. Mnif W, Hassine AlH, Bouaziz A, Bartegi A, Thomas O, Roig B. Effect of endocrine disruptor pesticides:a review. International Journal of Environmental Research and Public Health. 2011;8:2265-303.

15. Hossain N, Triche EW. Environmental factors implicated in the causation of adverse pregnancy outcome. Seminars in Perinatology. 2007;31(4): 240-2.

16. Perera FP, Jedrychowski W, Rauh V, Whyatt RM. Molecular epidemiologic research on the effects of environmental pollutants on the fetus. Environmental Health Perspectives. 1999; 107(3):451-60.

17. Guillette Jr LJ, Edwards TM. Environmental influences on fertility: can we learn lessons from studies of wildlife?. Fertility and Sterility. 2008;89(S1):e214.

\footnotetext{
* De acordo com:

Adaptado de International Committee of Medical Journals Editors (Vancouver).

Universidade de São Paulo. Faculdade de Medicina. Serviço de Biblioteca e Documentação. Guia de apresentação de dissertações, teses e monografias da FMUSP. Elaborado por Anneliese Carneiro da Cunha, Maria Julia A.L. Freddi, Maria F. Crestana, Marinalva de S. Aragão, Suely C. Cardoso, Valéria Vilhena. 3a ed. São Paulo: Divisão de Biblioteca e Documentação; 2011.

Abreviaturas dos títulos dos periódicos de acordo com List of Journals Indexed in Index Medicus.
} 
18. Whyatt RM, Perera FP. Application of biologic markers to studies of environmental risks in children and the developing fetus. Environmental Health Perspectives. 1995;103(S6):105-10.

19. Bosetti C, Nieuwenhuijsen MJ, Gallus S, Cipriani S, La Vecchia C, Parazzini F. Ambient particulate matter and preterm birth or birth weight: a rwview of the literature. Archives Toxicology. 2010;84:447-60.

20. Toft G, Hagmar L, Giwercman A, Bonde JP. Epidemiological evidence on reproductive effects of persistent organochlorines in humans. Reproductive Toxicology. 2004;19:5-26.

21. UNICEF, WHO. Low Birth Weight: Country, Regional and Global Estimates. New York:UNICEF; 2004. 31p.

22. Kramer MS. Determinants of low birth weight: methodological assessment and meta-analysis. Bulletin of the World Health Organization. 1987;65(5):663-737.

23. Medeiros A, Gouveia N. Relação entre baixo peso ao nascer e a poluição do ar no Município de São Paulo. Revista de Saúde Pública. 2005;39(6):96572.

24. Costa CE, Goetlieb. Estudo epidemiológico do peso ao nascer a partir da declaração de nascido vivo. Revista de Saúde Pública. 1998;32(4):328-34.

\footnotetext{
* De acordo com:

Adaptado de International Committee of Medical Journals Editors (Vancouver).

Universidade de São Paulo. Faculdade de Medicina. Serviço de Biblioteca e Documentação. Guia de apresentação de dissertações, teses e monografias da FMUSP. Elaborado por Anneliese Carneiro da Cunha, Maria Julia A.L. Freddi, Maria F. Crestana, Marinalva de S. Aragão, Suely C. Cardoso, Valéria Vilhena. 3a ed. São Paulo: Divisão de Biblioteca e Documentação; 2011.

Abreviaturas dos títulos dos periódicos de acordo com List of Journals Indexed in Index Medicus.
} 
25. Gouveia N, Bremner SA, Novaes HMD. Association between ambient air pollution and birth weight in São Paulo, Brazil. Journal of Epidemiology and Community Health. 2004;58(1):11-7.

26. Elliott P, Briggs D, Morris S, De Hoogh C, Hurt C, Jensen TK, Maitland I, Richardson S, Wakefield J, Jarup L. Risk of adverse birth outcomes in populations living near landfill sites. British Medical Journal. 2001;323(7309):363-8.

27. Oliveira LM, Stein N, Sanseverino MTV, Vargas VMF, Fachel JMG, Schüler L. Reproductive outcomes in a area adjacent to a petrochemical plant in southern Brazil. Revista de Saúde Pública. 2002;36(1):81-7.

28. OMS. Classificação Estatística Internacional de Doenças e Problemas Relacionados à Saúde. São Paulo: Centro Colaborador da OMS para Classificação de Doenças em Português. 1998; 10ed.

29. Corrêa MD, Corrêa Jr MD. Parto Pretermo. In: Rezende J (org.). Obstetrícia. Rio de Janeiro: Gyanabara-Koogan; 2005. 929-46.

30. Hansen C, Neller A, Williams G, Simpson R. Maternal exposure to low levels of ambient air pollution and preterm birth in Brisbane, Australia. BJOG. 2006;113(8):935-41.

\footnotetext{
* De acordo com:

Adaptado de International Committee of Medical Journals Editors (Vancouver).

Universidade de São Paulo. Faculdade de Medicina. Serviço de Biblioteca e Documentação. Guia de apresentação de dissertações, teses e monografias da FMUSP. Elaborado por Anneliese Carneiro da Cunha, Maria Julia A.L. Freddi, Maria F. Crestana, Marinalva de S. Aragão, Suely C. Cardoso, Valéria Vilhena. 3a ed. São Paulo: Divisão de Biblioteca e Documentação; 2011.

Abreviaturas dos títulos dos periódicos de acordo com List of Journals Indexed in Index Medicus.
} 
31. Maroziene L, Grazuleviciene R. Maternal exposure to low-level air pollution and pregnancy outcomes: a population-based study. Environmental Health Journal. 2002;1(6):paginação irregular.

32. Ritz B, Yu F, Chapa G, Fruin S. Effect of air pollution on preterm birth among children born in Southern California between 1989 and 1993.

Epidemiology. 2000;11(5):502-11.

33. Rezende J, Montenegro CAB. Abortamento. In: Rezende J (org.). Obstetrícia. Rio de Janeiro: Gyanabara-Koogan; 2005. 749-75.

34. Jorge ACG. Perdas fetais tardias, condição sócio-econômica e poluição atmosférica: uma abordagem temporo-espacial. [Dissertação]. São Paulo: Faculdade de Medicina da Universidade de São Paulo; 2004.

35. Korrick SA, Chen C, Damokosh Al, Ni J, Liu X, Cho SI, Altshul L, Ryan L, Xu X. Association of DDT with spontaneous abortion: a case-control study. Ann Epidemiol. 2001;11(7):491-6.

36. Smrcka V, Leznarova D. Environmental pollution and the occurrence of congenital defects in a 15-year period in a south Moravian district. Acta Chirurgiae Plasticae. 1998;40(4):112-4.

\footnotetext{
* De acordo com:

Adaptado de International Committee of Medical Journals Editors (Vancouver).

Universidade de São Paulo. Faculdade de Medicina. Serviço de Biblioteca e Documentação. Guia de apresentação de dissertações, teses e monografias da FMUSP. Elaborado por Anneliese Carneiro da Cunha, Maria Julia A.L. Freddi, Maria F. Crestana, Marinalva de S. Aragão, Suely C. Cardoso, Valéria Vilhena. 3a ed. São Paulo: Divisão de Biblioteca e Documentação; 2011.

Abreviaturas dos títulos dos periódicos de acordo com List of Journals Indexed in Index Medicus.
} 
37. Pereira LAAP, Loomis D, Conceição GMS, Braga ALF, Arcas RM, Kishi HS, Singer JM, Böhm GM, Sladiva PHN. Association between air pollution and intrauterine mortality inSão Paulo, Brazil. Environmental Health Perspectives. 1998;106(6):325-9.

38. Rezende J, Carakushansky G. Anomalias Congênitas: Etiologia e Prevenção. In: Rezende J (org.). Obstetrícia. Rio de Janeiro: GyanabaraKoogan; 2005. 1034-51.

39. Dolk $\mathrm{H}$, Vrijheid M. The impact of environmental pollution on congenital anomalies. British Medical Bulletin. 2003;68:25-45.

40. Ritz B, Yu F, Fruin S, Chapa G, Shaw GM, Harris JA. Ambient air pollution and risk of birth defects in Southern California. American Journal of Epidemiology. 2002;155(1):17-24.

41. Gilboa SM, Mendola P, Olshan AF, Langlois PH, Savitz DA, Loomis D, Herring $\mathrm{AH}$, Fixler DE. Relation between ambient air quality and selected birth defects, seven county study, Texas, 1997-2000. American Journal of Epidemiology. 2005;162(3):238-52.

42. Monteleone-Neto R, Brunoni D, Laurenti R. O Projeto Cubatão: uma proposta em aberto à comunidade científica. Revista Ciência Hoje. 1982;1:14-5.

\footnotetext{
* De acordo com:

Adaptado de International Committee of Medical Journals Editors (Vancouver).

Universidade de São Paulo. Faculdade de Medicina. Serviço de Biblioteca e Documentação. Guia de apresentação de dissertações, teses e monografias da FMUSP. Elaborado por Anneliese Carneiro da Cunha, Maria Julia A.L. Freddi, Maria F. Crestana, Marinalva de S. Aragão, Suely C. Cardoso, Valéria Vilhena. 3a ed. São Paulo: Divisão de Biblioteca e Documentação; 2011.

Abreviaturas dos títulos dos periódicos de acordo com List of Journals Indexed in Index Medicus.
} 
43. Elster N. Less is more: the risks of multiple births. The Institute for Science, Law, and Technology Working Group on Reproductive Technology. Fertility and Sterility. 2000;74(4):617-23.

44. Allsopp M. Costner P, Johnston P. Incineration and human health: State of knowledge of the impacts of waste incinerators on human health. Environmental Science and Pollution Research International. 2001;8(2):1415.

45. Obi-Osius N, Misselwitz B, Karmaus W, Witten J. Twin frequency and industrial pollution in different regions of Hesse, Germany. Occupational and Environmental Medicine. 2004;61(6):482-7.

46. RIPSA. Rede Intergerencial de Informações para a Saúde. Indicadores básicos de saúde no Brasil: conceitos e aplicações. Ministério da Saúde. OPAS. Brasília, 2001

47. Spigel S. Estatística não paramétrica. São Paulo:Editora McGraw-Hill do Brasil; 1981.

48. Kleinbaum DG, Kupper LL, Muller KE, Nizam A. Applied regression analysis and other multivariable methods. Belmont: Duxbury Press; 1998.

\footnotetext{
* De acordo com:

Adaptado de International Committee of Medical Journals Editors (Vancouver).

Universidade de São Paulo. Faculdade de Medicina. Serviço de Biblioteca e Documentação. Guia de apresentação de dissertações, teses e monografias da FMUSP. Elaborado por Anneliese Carneiro da Cunha, Maria Julia A.L. Freddi, Maria F. Crestana, Marinalva de S. Aragão, Suely C. Cardoso, Valéria Vilhena. 3a ed. São Paulo: Divisão de Biblioteca e Documentação; 2011.

Abreviaturas dos títulos dos periódicos de acordo com List of Journals Indexed in Index Medicus.
} 
49 Braga ALF (org) et al. [internet]. Estudo Epidemiológico na População Residente na Baixada Santista - Estuário de Santos: Avaliação de Indicadores de Efeito e de Exposição a Contaminantes Ambientais [citado jul 2011]; Disponível em: http://www.unisantos.br/upload/menu3niveis_1258486195098_relatorio_final _estuario_completo.pdf.

50. IBGE. [internet]. Censo 2000. [citado Fev 2006]; Disponível em: http://www.ibge.gov.br/censo/default.php.

51. INCA. [internet]. Inquérito Domiciliar sobre Comportamentos de Risco e Morbidade Referida de Doenças e Agravos não Transmissíveis. Brasil, 15 capitais e Distrito Federal 2002-2003. [citado Fev 2006]; Disponível em: http://www.inca.gov.br/inquerito.

52. IBGE. Coordenação de População e Indicadores Sociais. Indicadores Sociodemográficos e de Saúde no Brasil. 2009. 152p.

53. Paiva PTA, Wajnman, S. Das causas às conseqüências econômicas da transição demográfica no Brasil. Revista Brasileira de Estudos de População. 2005;22(2):303-22.

\footnotetext{
* De acordo com:

Adaptado de International Committee of Medical Journals Editors (Vancouver).

Universidade de São Paulo. Faculdade de Medicina. Serviço de Biblioteca e Documentação. Guia de apresentação de dissertações, teses e monografias da FMUSP. Elaborado por Anneliese Carneiro da Cunha, Maria Julia A.L. Freddi, Maria F. Crestana, Marinalva de S. Aragão, Suely C. Cardoso, Valéria Vilhena. 3a ed. São Paulo: Divisão de Biblioteca e Documentação; 2011.

Abreviaturas dos títulos dos periódicos de acordo com List of Journals Indexed in Index Medicus.
} 
54. Berquó E, Cavenaghi S. Mapeamento sócio-econômico e demográfico dos regimes de fecundidade no Brasil e sua variação entre 1991 e 2000. [internet] In: Anais do XIV Encontro Nacional de Estudos Populacionais da Associação Brasileira de Estudos Populacionais; 2006, Caxambu, Brasil. [18p] Disponível em: http://www.abep.org.br/usuario/GerenciaNavegacao.php?caderno_id=430\&ni vel $=1$.

55. Martins CM, Almeida MF. Fecundidade e diferenciais intra-urbanos de desenvolvimento humano, São Paulo, Brasil, 1997. Revista de Saúde Pública. 2001;35(5):421-427.

56. Kilsztajn S, Rossbach A, Carmo MSN, Sugahara GTL. Assistência prénatal, baixo peso e prematuridade no Estado de São Paulo, 2000. Revista de Saúde Pública. 2003;37(3):303-10.

57. UNICEF. Situação Mundial da Infência 2008. Caderno Brasil. Distrito Federal. 2008. 64p.

58. Gurgel RQ, Dias IMO, França VLA, Castañedaet DFN. Distribuição espacial do baixo peso ao nascer em Sergipe, Brasil, 1995/1998. Caderno de Saúde Pública. 2005;21(5):1329-37.

59. Sadeck LSR, Barros JCR, Ramos JLA. Variação secular do peso de recém-nascidos do hospital das clínicas de São Paulo em quatro períodos nos últimos 50 anos. Pediatria (São Paulo). 2000;22(1):14-20.

* De acordo com:

Adaptado de International Committee of Medical Journals Editors (Vancouver).

Universidade de São Paulo. Faculdade de Medicina. Serviço de Biblioteca e Documentação. Guia de apresentação de dissertações, teses e monografias da FMUSP. Elaborado por Anneliese Carneiro da Cunha, Maria Julia A.L. Freddi, Maria F. Crestana, Marinalva de S. Aragão, Suely C. Cardoso, Valéria Vilhena. 3a ed. São Paulo: Divisão de Biblioteca e Documentação; 2011.

Abreviaturas dos títulos dos periódicos de acordo com List of Journals Indexed in Index Medicus. 
60. Minagawa AT, Biagoline REM, Fujimori E, Oliveira IMV, Moreira APCA, Ortega LDS. Baixo peso ao nascer e condições maternas no pré-natal. Rev Esc Enferm USP. 2006;40(4):548-54.

61. Monteiro CA, Benicio MHD, Ortiz LP. Tendência secular do peso ao nascer na cidade de São Paulo (1976-1998). Revista de Saúde Pública. 2000;34(S6):26-40.

62. Silveira MF, Vistora CG, Barros AJD, Santos IS, Matijasevich A, Barros FC. Determinants of preterm birth: Pelotas, Rio Grande do Sul State, Brazil, 2004 birth cohort. Cadernos de Saúde Pública. 2010;26(1):185-194.

63. Lawn J, Shibuya K, Stein C. No cry at birth: global estimates of intrapartum stillbirths and intrapartum-related neonatal deaths. Bull World Health Organization. 2005;83(6):409-17.

64. Martin JA, Hamilton BE, Sutton PD, Ventura SJ, Menacker F. Births: Final Data for 2006. Public Health Resources. 2009;Paper 65.

65. Barros FC, Victora CG, Matijasevich A, Horta BL, Silveira MF, Barros AJD. Preterm births, low birth weight, and intrauterine growth restriction in three birth cohorts in Southern Brazil: 1982, 1993 and 2004. Cadernos de Saúde Pública. 2008;24(S3):S390-S8.

\footnotetext{
* De acordo com:

Adaptado de International Committee of Medical Journals Editors (Vancouver).

Universidade de São Paulo. Faculdade de Medicina. Serviço de Biblioteca e Documentação. Guia de apresentação de dissertações, teses e monografias da FMUSP. Elaborado por Anneliese Carneiro da Cunha, Maria Julia A.L. Freddi, Maria F. Crestana, Marinalva de S. Aragão, Suely C. Cardoso, Valéria Vilhena. 3a ed. São Paulo: Divisão de Biblioteca e Documentação; 2011.

Abreviaturas dos títulos dos periódicos de acordo com List of Journals Indexed in Index Medicus.
} 
66. Barros FC, Barros AJD, Villar J, Matijasevich A, Domingues MR, Victora CG. How many low birthweight babies in low- and middleincome countries are preterm?. Revista de Saúde Pública. 2011;45(3):607-16.

67. Gray R, Bonellie SR, Chalmers J, Greer I, Jarvis S, Williams C .Social inequalities in preterm birth in Scotland 1980-2003: findings from an areabased measure of deprivation. BJOG. 2008;115(1):82-90.

68. Cascaes AM, Gauche H, Baramarchi FM, Borges CM, Peres KG. Prematuridade e fatores associados no Estado de Santa Catarina, Brasil, no ano de 2005: análise dos dados do Sistema de Informações sobre Nascidos Vivos. Cadernos de Saúde Pública. 2008;24(5):1024-32.

69. Fernández RR, Larentis DZ, Fontana T, Jaeger GP, Moreira PB, Garcias GL, Roth MGM. Anencefalia: um estudo epidemiológico de treze anos na cidade de Pelotas. Ciência \& Saúde Coletiva. 2005;10(1):185-90.

70. Geraldo CF, Garcias GL, Roth MGM. Prevalência de nascimentos gemelares em Pelotas, Rio Grande do Sul, Brasil. Revista Brasileira de Saúde Materna-Infantil. 2008;8(4):411-7.

71. Giglio MRP, Lamounier JÁ, Morais Neto OL. Via de parto e risco para mortalidade neonatal em Goiânia no ano de 2000. Revista de Saúde Pública. $2005 ; 39(3): 350-7$.

\footnotetext{
* De acordo com:

Adaptado de International Committee of Medical Journals Editors (Vancouver).

Universidade de São Paulo. Faculdade de Medicina. Serviço de Biblioteca e Documentação. Guia de apresentação de dissertações, teses e monografias da FMUSP. Elaborado por Anneliese Carneiro da Cunha, Maria Julia A.L. Freddi, Maria F. Crestana, Marinalva de S. Aragão, Suely C. Cardoso, Valéria Vilhena. 3a ed. São Paulo: Divisão de Biblioteca e Documentação; 2011.

Abreviaturas dos títulos dos periódicos de acordo com List of Journals Indexed in Index Medicus.
} 
72. Almeida $S D$ de $M$, Barros $M B$ de $A$. Eqüidade e atenção à saúde da gestante em Campinas (SP), Brasil. Revista Panamericana de Salud Publica. 2005;17(1):15-25.

73. Institute of Medicine. Committee on Understanding Premature Birth and Assuring Healthy Outcomes. [internet] 2007. Preterm Birth: Causes, Consequences, and Prevention. [citado em Jul 2011]. Disponível em: http://www.nap.edu/catalog/11622.html.

74. IBGE [internet]. Registro Civil 2010: Número de divórcios é o maior desde 1984. [citado Fev 2012]; Disponível em: http://www.ibge.gov.br/home/presidencia/noticias/noticia_visualiza.php?id_no ticia=2031\&id_pagina $=1$

75. Silveira MF, Santos IS, Barros AJD, Matijasevich A, Barros FC, Victora CG. Aumento da prematuridade no Brasil: revisão de estudos de base populacional. Revista de Saúde Pública. 2008;42(5):957-64.

76. Vettore MV, Gama SGN, Lamarca GA, Schilithz AOC, Leal, MC. Housing conditions as a social determinant of low birthweight and preterm low birthweight. Revista de Saúde Pública. 2010;44(6):1021-31.

77. Younglai EV, Holloway AC, Foster WG. Environmental and occupational factors affecting fertility and IVF success. Human Reproduction Update. $2005 ; 11(1): 43-57$

\footnotetext{
* De acordo com:

Adaptado de International Committee of Medical Journals Editors (Vancouver).

Universidade de São Paulo. Faculdade de Medicina. Serviço de Biblioteca e Documentação. Guia de apresentação de dissertações, teses e monografias da FMUSP. Elaborado por Anneliese Carneiro da Cunha, Maria Julia A.L. Freddi, Maria F. Crestana, Marinalva de S. Aragão, Suely C. Cardoso, Valéria Vilhena. 3a ed. São Paulo: Divisão de Biblioteca e Documentação; 2011.

Abreviaturas dos títulos dos periódicos de acordo com List of Journals Indexed in Index Medicus.
} 
78. Leite JCL, Schüller-Faccini L. Defeitos congênitos em uma região de mineração de carvão. Revista de Saúde Pública. 2001;35(2):136-41.

79. Burdorf A, Brand t, Jaddoe VW, Hofman A, Mackenbach JP, Steegers EAP. The effects of work-related maternal risk factors on time to pregnancy, preterm birth and birth weight: the generation $\mathrm{R}$ study. Occupational Enviromental Medicine. 2011;68:197-204.

80. Leopércio W, Gigliotti A. Tabagismo e suas peculiaridades durante a gestação: uma revisão crítica. Jornal Brasileiro de Pneumologia. 2004;30(2):176-85.

81. Lambers DS, Clark KE. The maternal and fetal physiologic effects of nicotine. Seminars in Perinatology. 1996;20(2):115-26.

82. Grillo E, Freitas PF. Smoking and other pre-gestational risk factors for spontaneous preterm birth. Revista Brasileira de Saúde Materna-Infanti. 2011;11(4):397-403.

83. Windham G, Fenster G. Environmental contaminants and pregnancy outcomes. Fertility and Sterility. 2008;89(S1):e111-6.

84. Ribeiro VS, Figueiredo FP, Silva AAM, Batista RLF, Barbieri MA, Lamy Filho F, Alves MTSSB, Santos AM, Bettiol H. Do socioeconomic factors explain why maternal smoking during pregnancy is more frequent in a more

\footnotetext{
* De acordo com:

Adaptado de International Committee of Medical Journals Editors (Vancouver).

Universidade de São Paulo. Faculdade de Medicina. Serviço de Biblioteca e Documentação. Guia de apresentação de dissertações, teses e monografias da FMUSP. Elaborado por Anneliese Carneiro da Cunha, Maria Julia A.L. Freddi, Maria F. Crestana, Marinalva de S. Aragão, Suely C. Cardoso, Valéria Vilhena. 3a ed. São Paulo: Divisão de Biblioteca e Documentação; 2011.

Abreviaturas dos títulos dos periódicos de acordo com List of Journals Indexed in Index Medicus.
} 
developed city of Brazil?. Brazilian Journal of Medical and Biological Research. 2007;40:1203-10.

85. Silva I, Quevedo LA, Silva LA, Oliveira SS, Pinheiro RT. Associação entre abuso de álcool durante a gestação e o peso ao nascer. Revista de Saúde Pública. 2011;45(5):864-9.

86. Freire TM, Machado JC, Melo EV, Melo DG. Efeitos do consumo de bebida alcoólica sobre o feto. Revista Brasileira de Ginecologia e Obstetrícia. 2005;27(7):376-81.

87. Woodruff TK, Walker CL. Fetal and early postnatal environmental exposures and reproductive health effects in the female. Fertility and Sterility. 2008;89(S1):e47-51

88. Guimarães MT, Cunha MG, Carvalho DP, Sampaio T, Braga ALF, Pereira LAAP. Desfechos relacionados à gravidez em áreas contaminadas, SP, Brasil. Revista Brasileira de Epidemiologia. 2011;14(4):598-608.

89. Vardanega K, De Lorenzi DRS, Spiandorello WP, Zapparoli MF. Fatores de Risco para Natimortalidade em um Hospital Universitário da Região Sul do Brasil. Revista Brasileira de Ginecologia e Obstetrícia. 2002;24(9):617-22.

90. De Lorenzi DRS, Tanaka ACA, Bozzetti MC, Ribas FE, Weissheimer LA. A natimortalidade como indicador de saúde perinatal. Cadernos de Saúde Pública. 2001;17(1):141-6.

\footnotetext{
* De acordo com:

Adaptado de International Committee of Medical Journals Editors (Vancouver).

Universidade de São Paulo. Faculdade de Medicina. Serviço de Biblioteca e Documentação. Guia de apresentação de dissertações, teses e monografias da FMUSP. Elaborado por Anneliese Carneiro da Cunha, Maria Julia A.L. Freddi, Maria F. Crestana, Marinalva de S. Aragão, Suely C. Cardoso, Valéria Vilhena. 3a ed. São Paulo: Divisão de Biblioteca e Documentação; 2011.

Abreviaturas dos títulos dos periódicos de acordo com List of Journals Indexed in Index Medicus.
} 
91. Belfort P. Medicina Preventiva: Assistência Pré-natal. In: Rezende J (org.). Obstetrícia. Rio de Janeiro: Gyanabara-Koogan; 2005. 268-86.

92. Gilbreath S, Kass PH. Adverse Birth Outcomes Associated with Open Dumpsites in Alaska Native Villages. American Journal of Epidemiology. 2006;164(6): 518-528.

93. Torres-Arreola L, Berkowitz G, Torres-Sánchez, López-Cervantes M, Cebrián ME, Uribe M, López-Carrillo L. Preterm birth in relation to maternal organochlorine serum levels. Annals of Epidemiology. 2003;13(3):158-62.

94. Leem JH, Kaplan BM, Shiim YK, Pohl HR, Gotway CA, Bullard SM, Rogers JF, Smith MM, Tylenda CA. Exposures to air pollutants during pregnancy and preterm delivery. Environmental Health Perspectives. 2006;114(6):905-10.

95. Nazer J, Cifuentes L. Malformaciones congénitas en Chile y Latino América: Una visión epidemiológica del ECLAMC del período 1995-2008. Revista Médica de Chile. 2011;139:72-78.

96. Vrijheid M, Martinez D, Manzanares S, Dadvand P, Schembari A, Rankin J, Nieuwenhuijsen, M. Ambient Air Pollution and Risk of Congenital Anomalies: A Systematic Review and Meta-analysis. Environmental Health Perspectives. 2011;119(5):598-606.

\footnotetext{
* De acordo com:

Adaptado de International Committee of Medical Journals Editors (Vancouver).

Universidade de São Paulo. Faculdade de Medicina. Serviço de Biblioteca e Documentação. Guia de apresentação de dissertações, teses e monografias da FMUSP. Elaborado por Anneliese Carneiro da Cunha, Maria Julia A.L. Freddi, Maria F. Crestana, Marinalva de S. Aragão, Suely C. Cardoso, Valéria Vilhena. 3a ed. São Paulo: Divisão de Biblioteca e Documentação; 2011.

Abreviaturas dos títulos dos periódicos de acordo com List of Journals Indexed in Index Medicus.
} 
97. Thakur JS, Prinja S, Singh D, Rajwanshi A, Prasad R, Parwana HK, Kumar R. Adverse reproductive and child health outcomes among people living near highly toxic waste water drains in Punjab, India. Journal of Epidemiologic \& Community Health. 2010;64:148-54.

98. Noguez PT, Muccillo-Baisch AL, Vaz MRC, Soares MCF. Aborto espontâneo em mulheres residentes nas proximidades do Parque Industrial do município do Rio Grande - RS. Texto \& Contexto Enfermagem. $2008 ; 17(3): 435-46$.

99. Schoeps D, Almeida MF, Alencar GP, França Jr I, Novaes HMD, Siqueira AAF, Campbell O, Rodrigues LC. Fatores de risco para mortalidade neonatal precoce. Revista de Saúde Pública. 2007;41(6):1013-22.

100. Dolk H, Vrijheid M, Armstrong B, Abramsky L, Bianchi F, Garne E, Nelen V, Robert E, Scott JES, Stone D, Tenconi R. Risk of congenital anomalies near hazardous-waste landfill sites in Europe: the EUROHAZCON study. Lancet. 1998;352:423-7.

101. Gouveia N, Prado RR. Riscos à saúde em áreas próximas a aterrros de resíduos sólidos urbanos. Revista de Saúde Pública. 2010;44(5):859-66.

102. Dummer TJB, Dickinson HO, Parker L. Adverse Pregnancy Outcomes near Landfill Sites in Cumbria, Northwest England, 1950-1993. Archives of Environmental Health. 2003;58(11): 692-8.

\footnotetext{
* De acordo com:

Adaptado de International Committee of Medical Journals Editors (Vancouver).

Universidade de São Paulo. Faculdade de Medicina. Serviço de Biblioteca e Documentação. Guia de apresentação de dissertações, teses e monografias da FMUSP. Elaborado por Anneliese Carneiro da Cunha, Maria Julia A.L. Freddi, Maria F. Crestana, Marinalva de S. Aragão, Suely C. Cardoso, Valéria Vilhena. 3a ed. São Paulo: Divisão de Biblioteca e Documentação; 2011.

Abreviaturas dos títulos dos periódicos de acordo com List of Journals Indexed in Index Medicus.
} 
103. WHO - World Health Organization. Regional Office for Europe. European Centre for Environmental an Health Methods of Assessing Risk to Health from Exposure to Hazards released from Waste Landfills. [report]. Lodz, Polônia. $2000 . \quad$ [Disponível em: http://www.bvsde.paho.org/tutorial/fulltex/landfill.pdf].

104. CETESB. Relação de áreas contaminadas por município em 2010. [internet] 2010 [citado Jul 2011]. Disponível em: http://www.cetesb.sp.gov.br/userfiles/file/areascontaminadas/2011/municipios.pdf1.

105. MS (Ministério da Saúde). Secretaria de vigilância em saúde ambiental. [internet]. Resumo Executivo do estudo de avaliação de Risco à Saúde Humana nos sites da Baixada Santista, municípios de Itanhaém e São Vicente. [citado Mar 2012]; Disponível em: http://portal.saude.gov.br/portal/arquivos/pdf/resumo_executivo_baixada_san tista.pdf.

\footnotetext{
* De acordo com:

Adaptado de International Committee of Medical Journals Editors (Vancouver).

Universidade de São Paulo. Faculdade de Medicina. Serviço de Biblioteca e Documentação. Guia de apresentação de dissertações, teses e monografias da FMUSP. Elaborado por Anneliese Carneiro da Cunha Maria Julia A.L. Freddi, Maria F. Crestana, Marinalva de S. Aragão, Suely C. Cardoso, Valéria Vilhena. 3a ed. São Paulo: Divisão de Biblioteca e Documentação; 2011.

Abreviaturas dos títulos dos periódicos de acordo com List of Journals Indexed in Index Medicus.
} 